\title{
Quantitative Field Constraints on the Dynamics of Silicic Magma Chamber Rejuvenation and Overturn
}

\author{
by \\ Amelia Anne Bain \\ B.Sc. (Hons.), The University of Glasgow, 2006 \\ A THESIS SUBMITTED IN PARTIAL FULFILLMENT OF \\ THE REQUIREMENTS FOR THE DEGREE OF \\ MASTER OF SCIENCE \\ in \\ The Faculty of Graduate Studies \\ (Geological Sciences) \\ THE UNIVERSITY OF BRITISH COLUMBIA \\ (Vancouver) \\ August 2010 \\ (c) Amelia Anne Bain 2010
}




\section{Abstract}

A number of recent papers by Bachmann and co-authors investigate a hypothesis that the catastrophic eruption of large-volume, crystal-rich silicic magmas is a consequence of reheating (so-called rejuvenation) and overturn of partially molten, buoyant silicic material by repeated injection of dense, hot mafic magma. In support of this model, we analyse an extensive suite of kinematic indicators for the buoyant overturn of silicic crystal mush layers of the Coastal Maine Magmatic Province, apparently in response to the injection and cooling of hot, dense mafic magmas. We use spectral analysis, microtextural analysis and scaling theory to identify, characterise and understand the length-scales of deformation along sharp interfaces separating mafic and silicic intrusive layers, from the scale of individual crystals $(\sim 1 \mathrm{~cm})$ to in excess of the mafic layer thickness $(>100 \mathrm{~m})$. Deformations at the largest scale lengths are comparable to the silicic layer thickness, consistent with Rayleigh-Taylor theory, and support a conjecture that mafic recharge can cause large-scale overturning of silicic magma chambers. By contrast, deformations at the scale of crystals probably record buoyancy effects related to melt percolation and intermediate scales are explained by compaction. The evolution of rejuvenation is investigated and a condition for large-scale overturn of the chamber is proposed. This work provides the first 
field-based confirmation of the rejuvenation-overturn hypothesis. Additional laboratory experiments addressing the overturn of a particle-rich buoyant fluid layer overlain by a denser fluid layer are outlined in Appendix C. 


\section{Preface}

A. M. Jellinek identified and designed the research program. The research and data analyses were performed by A. A. Bain in consultation with A. M. Jellinek. This manuscript was prepared by A. A. Bain with edits from A. M. Jellinek.

A version of Chapter 2 of this thesis will be submitted for publication under the same title as this thesis. A. A. Bain will be first author, A. M. Jellinek will be second author. 


\section{Table of Contents}

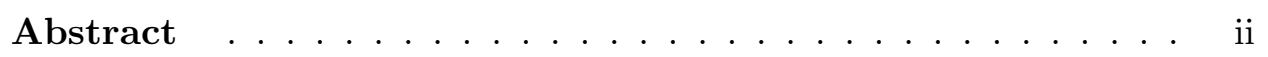

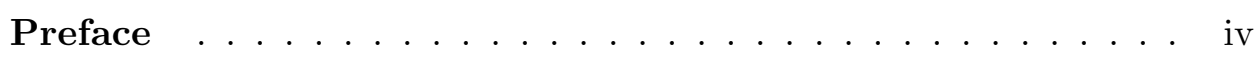

Table of Contents . . . . . . . . . . . . .

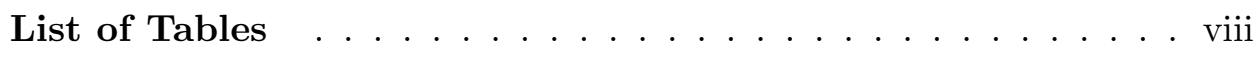

List of Figures $\ldots \ldots \ldots \ldots \ldots \ldots$ ix

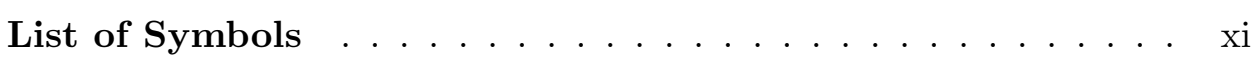

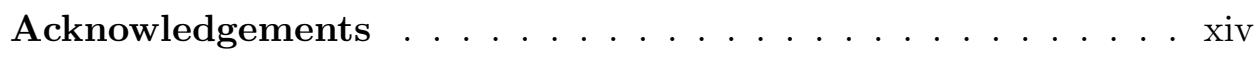

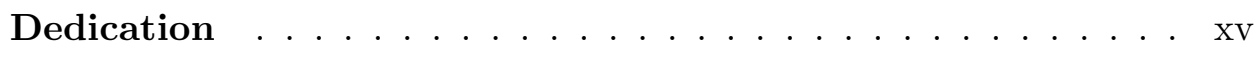

1 Introduction . . . . . . . . . . . . . . 1

1.1 Large Silicic Volcanic Systems and the Rejuvenation Hypoth-

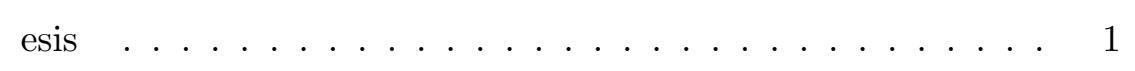

1.2 Testing the Rejuvenation Hypothesis . . . . . . . . . . 3

2 Quantitative Field Constraints on the Dynamics of Silicic Magma Chamber Rejuvenation and Overturn . . . . . . 5 
2.1 Context and Motivation ............... 5

2.2 Theory ............................. 13

2.2 .1 Overview . . . . . . . . . . . . 13

2.2.2 Buoyancy-driven overturn of a silicic layer . . . . 17

2.2.3 Buoyancy effects driven by melting . . . . . . . 18

2.2.4 Buoyancy effects driven by compaction . . . . . . 23

2.2.5 Summary of model predictions: three processes, three distinct wavelengths . . . . . . . . . . . 25

2.3 Field Observations . . . . . . . . . . . . . . . . . . . . . . . . 28

2.3.1 Deformed mafic-silicic interfaces . . . . . . . 28

2.3.2 Silicic mush structures _. . . . . . . . . . . 29

2.3.3 Deformation within the silicic layer . . . . . . . 33

2.3.4 Microtexture of irregular granodiorite upwellings . . . 37

2.4 Spectral Analysis . . . . . . . . . . . . . . . . . . 39

2.5 Comparison With Theory . . . . . . . . . . . . . . . . 42

2.5.1 Long-wavelength data: large-scale buoyant overturn . 42

2.5.2 Short-wavelength data: melting . . . . . . . . 43

2.5.3 Intermediate wavelengths: compaction . . . . . . . 44

2.6 Discussion . . . . . . . . . . . . . . . . 45

2.6.1 Links between deformation style and petrologic characterisation .................. 45

2.6.2 Evolution of rejuvenation . . . . . . . . . . . 45

2.6.3 Condition for complete overturning: a critical condition for eruption? . . . . . . . . . . . . 52

2.7 Conclusions . . . . . . . . . . . . . . . . 55 
Table of Contents

3 Concluding Remarks . . . . . . . . . . . . . 56

Bibliography . . . . . . . . . . . . . . . . . 58

\section{Appendices}

A Field Data . . . . . . . . . . . . . . . 67

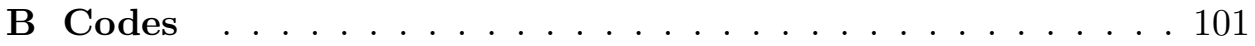

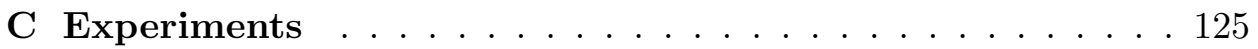

C.1 Motivation and set-up . . . . . . . . . . . . 125

C.2 Results . . . . . . . . . . . . . . 126

C.3 Discussion . . . . . . . . . . . . . . 127 


\section{List of Tables}

2.1 Values of parameters . . . . . . . . . . . . 28 


\section{List of Figures}

2.1 Location and maps of the field area . . . . . . . . . . 9

2.2 Summary of field observations . . . . . . . . . . . . . . 12

2.3 Schematic representation of the parameters and geometries associated with each deformation process . . . . . . . 15

2.4 Wavelengths predicted for each deformation process . . . . . 20

2.5 Mode of heat transfer from the mafic sheet to the silicic mush 23

2.6 Timescales predicted for each deformation process . . . . . 27

2.7 Field data collection and spectral analysis . . . . . . . . . 31

2.8 Classes of upwelling silicic structures . . . . . . . . . . . . 32

2.9 Deformation within the silicic layer . . . . . . . . 36

2.10 Microstructure of irregular granodiorite upwellings . . . . . . 38

2.11 Examples of interfaces where resolution of the longest wavelengths is limited by the scale of the exposure . . . . . . . 40

2.12 Comparison of two methods for calculating the longest wavelength in each interface . . . . . . . . . . . . . . . 41

2.13 Comparison of the longest wavelengths with predictions from equation $(2.2) \ldots \ldots \ldots \ldots \ldots \ldots$ 
2.14 Comparison of the shortest wavelengths with predictions from equation $(2.4) \ldots \ldots \ldots \ldots \ldots \ldots$

2.15 Comparison of intermediate wavelengths with predictions from equation $(2.14) \ldots \ldots \ldots \ldots \ldots$. . . . . . . . . . . . . .

2.16 Comparison of the petrologic characterisation of upwellings with long, short and intermediate wavelength data . . . . 47

2.17 Field guide . . . . . . . . . . . . . . 51

2.18 Comparison of the timescale for buoyant overturn of the silicic layer and the timescale for cooling of the mafic sheet . . . . 54

C.1 Experimental apparatus and set-up . . . . . . . . . . . 126

C.2 Diapir and pipe experimental régimes . . . . . . . . . . 128 


\section{List of Symbols}

\begin{tabular}{lll} 
Symbol & Variable & Units \\
\hline$b$ & & \\
$d_{x l}$ & average size of crystals in the mush & $\mathrm{m}$ \\
$g$ & acceleration due to gravity & $\mathrm{m} \cdot \mathrm{s}^{-2}$ \\
$h$ & layer thickness & $\mathrm{m}$ \\
$k$ & initial permeability of the solid matrix in the mush & $\mathrm{m}^{2}$ \\
$q_{b}$ & heat flux supplied from the basalt & $\mathrm{W} \cdot \mathrm{m}^{-2}$ \\
$q_{\text {out }}$ & heat flux out of the magma chamber & $\mathrm{W} \cdot \mathrm{m}^{-2}$ \\
$C_{b}$ & specific heat capacity of the basalt & $\mathrm{J} \cdot \mathrm{kg}^{-1} \cdot \mathrm{K}^{-1}$ \\
$C_{1}$ & scaling constant & - \\
$C_{2}$ & scaling constant & - \\
$K$ & thermal conductivity of the mush & $\mathrm{W} \cdot \mathrm{K}^{-1} \cdot \mathrm{m}^{-1}$ \\
$L$ & latent heat of melting of solid matrix in the mush & $\mathrm{kJ} . \mathrm{kg}^{-1}$ \\
$P$ & geometric constant & - \\
$Q$ & geometric constant & - \\
\hline Ra & Rayleigh number & - \\
\hline
\end{tabular}




\begin{tabular}{|c|c|c|}
\hline$T$ & temperature & ${ }^{\circ} \mathrm{K}$ \\
\hline$V$ & effective viscosity ratio & - \\
\hline$V_{\text {com }}$ & compaction rate & $\mathrm{m} \cdot \mathrm{s}^{-1}$ \\
\hline$V_{m}$ & melting velocity & $\mathrm{m} . \mathrm{s}^{-1}$ \\
\hline$\alpha$ & thermal expansion coefficient & $\mathrm{K}^{-1}$ \\
\hline$\beta$ & constant & - \\
\hline$\delta_{\text {com }}$ & characteristic compaction length for the mush & $\mathrm{m}$ \\
\hline$\kappa$ & thermal diffusivity & $\mathrm{m}^{2} \cdot \mathrm{s}^{-1}$ \\
\hline$\lambda$ & wavelength & $\mathrm{m}$ \\
\hline$\mu$ & effective viscosity & Pa.s \\
\hline$\mu_{\text {mat }}$ & $\begin{array}{l}\text { initial effective viscosity of the solid } \\
\text { matrix in the mush }\end{array}$ & Pa.s \\
\hline$\phi$ & porosity of the mush & - \\
\hline$\rho$ & density & $\mathrm{kg} \cdot \mathrm{m}^{-3}$ \\
\hline$\tau$ & characteristic timescale & $\mathrm{s}$ \\
\hline$\Delta \rho$ & $\rho_{b}-\rho_{s}$ & $\mathrm{~kg} \cdot \mathrm{m}^{-3}$ \\
\hline$\Delta \rho_{\text {com }}$ & $\rho_{b}-\rho_{i}$ & $\mathrm{~kg} \cdot \mathrm{m}^{-3}$ \\
\hline$\Delta \rho_{m, 1}$ & $\rho_{b}-\rho_{m}$ & $\mathrm{~kg} \cdot \mathrm{m}^{-3}$ \\
\hline$\Delta \rho_{m, 2}$ & $\rho_{s o l}-\rho_{m}$ & $\mathrm{~kg} \cdot \mathrm{m}^{-3}$ \\
\hline
\end{tabular}


List of Symbols

\section{Subscripts}

quantities relating to the basaltic layer

$c$

quantities relating to conduction

com

quantities relating to compaction

$i$

quantities relating to the interstitial melt of the mush

$m$

quantities relating to the melt layer

$s$

quantities relating to the silicic (mush) layer

sol quantities relating to the solid matrix of the mush

RT quantities relating to the buoyant overturn of a silicic or

a mafic layer 


\section{Acknowledgements}

This work was funded in part by the Natural Science and Engineering Research Council, the Canadian Institute for Advanced Research and the National Science Foundation.

I gratefully acknowledge the help of my supervisor, Mark Jellinek, for his continuing support and mentorship. I thank my committee members Lori Kennedy and Kelly Russell for their interest and guidance, and use of the Volcanology and Petrology Lab. equipment. I am indebted to members of my lab group, Kirsten Hodge, Ben Kennedy and Heather Wilson, for support, distractions and helpful discussions. Guillaume Carazzo provided invaluable laboratory assistance in designing and conducting experiments, as well as formatting this thesis. Not least, I thank Bob Wiebe for guidance in the field and infectious enthusiasm. 


\section{Dedication}

This thesis is dedicated to my parents, Helen and Andrew. 


\section{Chapter 1}

\section{Introduction}

\subsection{Large Silicic Volcanic Systems and the Rejuvenation Hypothesis}

Catastrophic explosive volcanic eruptions with the potential to significantly impact the global population and climate are events that regularly punctuate the geological record. These events are characterised by the eruption over a very short timescale of several days to a week of very large volumes ( $>1000 \mathrm{~km}^{3}, \sim 10^{3}$ times that of the 1980 eruption of Mount St Helens) of highly viscous silicic magma containing large proportions of crystals (40$45 \%$ ). However, gravity and seismic investigations of the structure beneath recently-active calderas such as Yellowstone suggest the presence of extensive partially molten "mush" zones and have failed to detect large molten magma bodies (e.g. [1,2]). This has lead to the suggestion that large batches of mobile magma exist only ephemerally in the crust and that silicic magma reservoirs spend most of their supra-solidus lifespan as extensive, uneruptible partially-molten mushes. This suggestion is consistent with varied petrologic observations in small and large silicic systems inferring a transient heating episode shortly preceding eruption (e.g. $[3,4])$. 


\subsection{Large Silicic Volcanic Systems and the Rejuvenation Hypothesis}

In this picture, triggering an explosive silicic eruption of catastrophic proportions requires the rapid mobilisation of a large volume of molten magma from a silicic mush, as well as the generation of sufficient overpressure to rupture the chamber. A popular hypothesis is that the injection of hot, dense mafic magma into cool, upper crustal partially-molten silicic mushes could melt and weaken the silicic crystal framework and produce a large volume of eruptible magma where convection could occur. Exsolution of volatiles in the mafic sheet and/or in the overturning silicic magma could be responsible for generating overpressure.

This conceptual model, in which long periods of crystallisation are interrupted by episodes of mafic replenishment and partial re-melting of the silicic mush, was originally proposed by Mahood [5] in order to account for the difficulties in maintaining a large volume of molten silicic magma over the observed lifespan of volcanic systems. This model has been applied to diverse volcanic settings such as the Kos Ignimbrite [6], Long Valley [5], the Valles caldera [7], Soufrière Hills [8, 9] and the Fish Canyon Tuff [10]. These represent systems varying in composition (dacitic to rhyolitic) and volume $\left(0.1 \mathrm{~km}^{3}\right.$ to $\left.>5000 \mathrm{~km}^{3}\right)$, suggesting that the rejuvenation of upper crustal silicic mushes shortly before an eruption is a fairly common process [10].

The thermal rejuvenation hypothesis is strongly supported by field observations such as the widespread occurrence of mafic enclaves in silicic volcanic and plutonic rocks, as well as the existence of mafic-silicic layered intrusions where hundreds of mafic sheets are interlayered with and quenched against crystal mush layers. The injection of basaltic magma also offers an explanation for the increased seismicity that is often observed on a timescale of 


\subsection{Testing the Rejuvenation Hypothesis}

weeks to months before a major explosive eruption (e.g. [11, 12]).

\subsection{Testing the Rejuvenation Hypothesis}

Despite the many lines of evidence that are consistent with a rejuvenation hypothesis for generating large quantities of mobile silicic magma, key quantitative observational constraints on how rejuvenation proceeds (i.e. over what lengthscales and timescales) are still missing from the discussion. In particular, field observations that reliably record the overturning of silicic material in response to a mafic injection have not been made.

However, the buoyant rise of silicic crystal mush in response to the injection of dense mafic magma has been inferred in mafic-silicic layered intrusions around the globe. These intrusions typically consist of a basal unit made up of hundreds of mafic sheets interleaved with highly-crystalline silicic cumulate rock layers, overlain by a thick granitic unit. They are thought to record the sequential injection of basaltic mafic sheets onto the crystalrich floor of a growing silicic magma chamber. Complex deformation of the mafic-silicic interface parallel to the inferred direction of palaeo-gravity is observed at the contact between fine-grained basaltic layers and silicic cumulate layers. As such, this deformation represents a suite of kinematic indicators recording the thermal rejuvenation and buoyant overturn of silicic mush layers composing the chamber floor, following the injection of a hotter, denser mafic sheet. We propose that these kinematic indicators provide key observational constraints on the lengthscales over which act processes related to the rejuvenation of a crystal mush. 


\subsection{Testing the Rejuvenation Hypothesis}

In this work, we identify and characterise the wavelengths of deformation observed in 33 mafic-silicic interfaces from two plutons from the Coastal Maine Magmatic Province, the Pleasant Bay and Mount Desert Island layered intrusions. We establish scaling relationships for the characteristic wavelengths and timescales produced by three physical processes that may arise following a mafic injection: buoyancy effects driven by melting of the silicic layer; buoyancy effects driven by compaction of the silicic mush layer; and the buoyant overturn of the silicic layer. We compare the wavelengths that we expect these processes to produce with the wavelengths that we measure in the field using photomosaics and spectral analysis. For the range of parameters that may arise in the natural case, we compare the characteristic timescales for the development of these processes in order to build understanding of the sequence of events following a mafic replenishment, from injection to overturn. We then establish a conservative estimate for the thickness of silicic layer necessary to produce a complete overturning event.

In Appendix $\mathrm{C}$ we report a series of laboratory experiments developed to investigate the lengthscales and timescales of convection for the range of parameters warranted by the natural case. In these experiments, we place a dense layer of fluid over a lighter layer of fluid and record the form and rate of the ensuing convection. We build on previous investigations of this problem by including particles in one of the fluid layers to assess the importance of non-Newtonian effects. 


\section{Chapter 2}

\section{Quantitative Field}

\section{Constraints on the Dynamics}

\section{of Silicic Magma Chamber}

\section{Rejuvenation and Overturn}

\subsection{Context and Motivation}

The occurrences of large-volume, crystal-rich ignimbrites (e.g. Bishop [13] and Fish Canyon [14] tuffs) document the scale and severity of events that are among the most arresting volcanological phenomena. In such explosive caldera-forming eruptions, more than $10^{3} \mathrm{~km}^{3}$ of crystal-rich magma are erupted over a time scale of several days to one week [15] and thus they constitute a threat to the global climate and human civilisation to rival the potential impacts of global warming.

Over the last two decades, there has been growing recognition that homogeneity in silicic magma composition at the chamber-wide scale is in contrast with striking textural and chemical complexities at the scale of crystals 


\subsection{Context and Motivation}

[10]. In addition, widespread petrologic observations from silicic volcanic rocks are indicative of repeated interaction between mafic and silicic magmas [9] and/or an episode of transient heating shortly before eruption [3, 4]. These observations include quenched mafic enclaves $[9,16]$, resorbed and reverse or oscillatory-zoned phenocrysts indicative of chemical disequilibrium $[4,7,9,10]$ and scattered silicic holocrystalline xenoliths [10].

Together with the interpretation that many mafic-silicic layered intrusions are incrementally constructed by repeated mafic and silicic injections [17-21], these petrologic, chemical and numerical studies have led to the development of the so-called rejuvenation model $[5,8,22,23]$. In this model, silicic magma bodies composed of a touching framework of crystals and interstitial melt (i.e. silicic mushes) are remobilized in response to the injection and spreading of hotter mafic magma. Heat $[22,24]$ and potentially volatile transfer [25] from a crystallizing layer of injected basalt ponded at the floor of a silicic magma chamber can melt, weaken and destroy the crystalline framework of the underlying, less dense, silicic mush [26]. This could potentially lead to partial or large-scale convective overturn of the chamber [27], stirring and magma mixing [26] and eruption [10]. In this scenario, overturn and mixing may be driven by heating of the resident silicic magma by underplating mafic magma [8] or by destabilizing buoyancy effects arising due to density contrasts between the resident and replenishing magmas [26, 28].

The viability of the mafic-silicic rejuvenation model is a topic of vigorous discussion. Key data currently missing from the debate, however, are field observations that reliably record the overturning of silicic material in response to a mafic injection. To address this problem, we analyze in de- 


\subsection{Context and Motivation}

tail apparently well-established kinematic indicators for such rejuvenation events in mafic-silicic layered intrusions forming the Coastal Maine Magmatic Province [29-31].

More generally, mafic-silicic layered plutons are widely-recognized features of continental magmatism that commonly preserve varied magma mingling features indicative of buoyancy effects arising between mafic and silicic magmatic layers [18, 19]. Examples include, but are not limited to, Cape Breton Island [33], Aztec Wash [21, 34], Searchlight pluton [35], Pyramid Peak [36], Burnett Inlet [37], the Tarçouate Laccolith [38] and Kameruka Suite plutons, Australia [39]. The Coastal Maine Magmatic Province, USA, comprises a suite of exhumed silicic plutons consisting in large part of interlayered crystal-rich silicic units and laterally-extensive mafic sheets [17] (Figure 2.1). Within the Pleasant Bay and Mount Desert Island mafic-silicic layered intrusions numerous laterally extensive mafic layers of basaltic composition and varying thickness (from $10 \mathrm{~cm}$ to upwards of $100-200 \mathrm{~m}$ ) overlie layers of silicic cumulate rocks in the range 0.005-5 m thickness. Sharp interfaces separating the mafic and silicic layers are extensively deformed in a quasi-periodic way in the direction parallel to palaeogravity over length scales ranging from the size of a crystal to the basalt or silicic layer depth (Figure 2.2). More specifically, various classes of upwelling silicic structures are observed: sinusoidal deformation at the scale of crystals (Figure 2.2b), sinusoidal deformation at the scale of centimetres-metres (Figure 2.2a and 2.2c) and axisymmetric pipes of crystal mush (Figure 2.2d). Together, these features form a complexly deformed interface over many scales (Figure 2.2e) with the $3-\mathrm{D}$ aspect shown schematically in Figure 2.2f. As the mafic sheets 


\subsection{Context and Motivation}
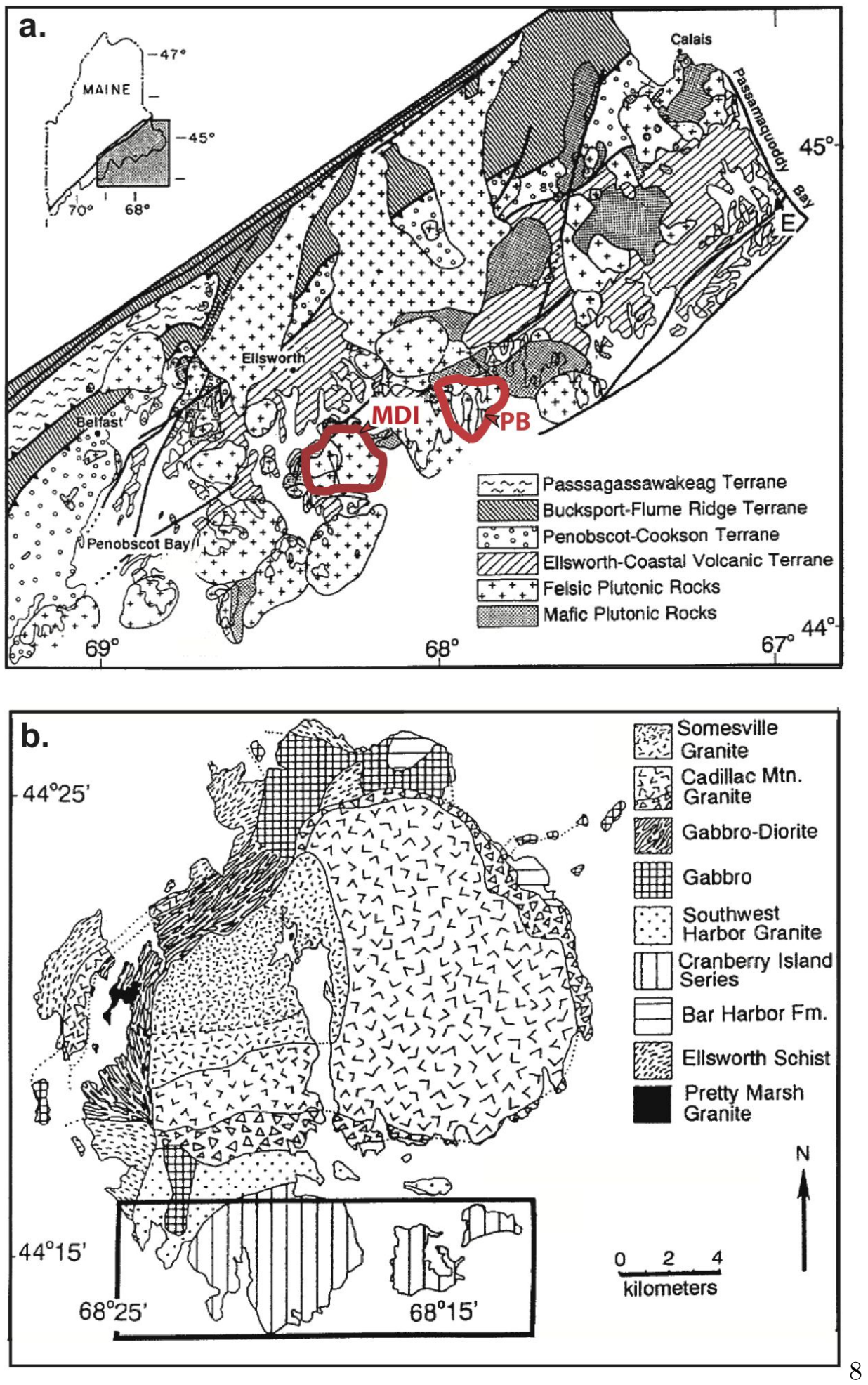

Figure 2.1 


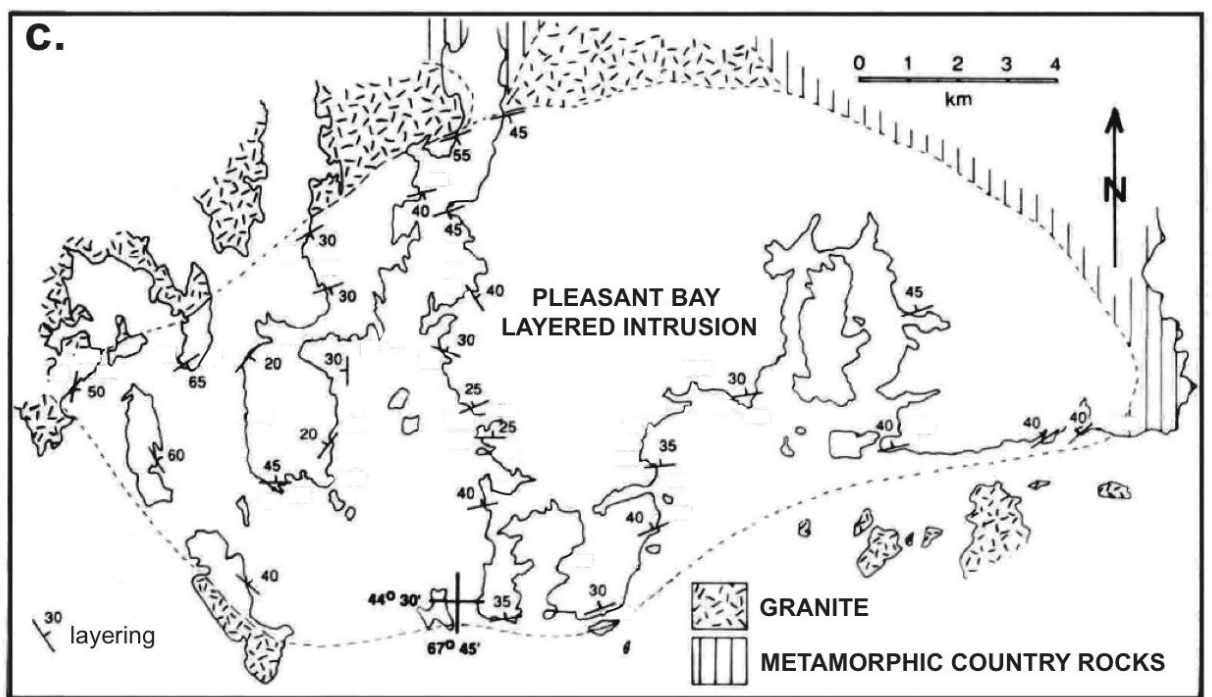

Figure 2.1: Location and maps of the field area. a. The Coastal Maine Magmatic Province is located on the northeast coast of the U.S.A. and comprises a suite of Silurian to Early Carboniferous plutons and associated volcanics. The Pleasant Bay (PB) and Mount Desert Island (MDI) maficsilicic layered plutons are outlined in red. b. Geological map of MDI. The mafic-silicic layered unit (Gabbro-Diorite) is located at the base of the tilted pluton, on the western shore of the island. The Cranberry Island Series (boxed) are contemporaneous deposits of explosive volcanism. c. Geological map of PB. $90 \%$ of exposed rocks are layered mafic rocks with intercalated silicic cumulate layers in rapid succession. (a. and b. modified from [32], c. modified from [17]) 


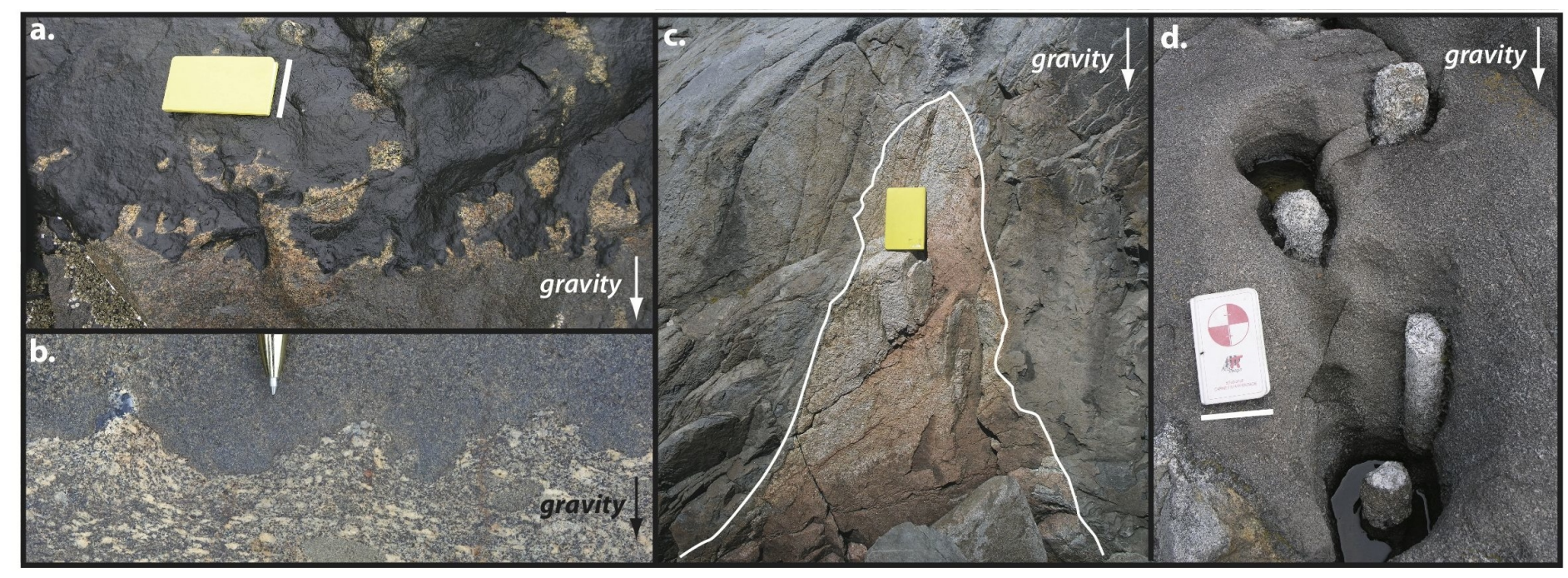

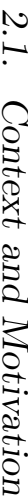

Figure 2.2 


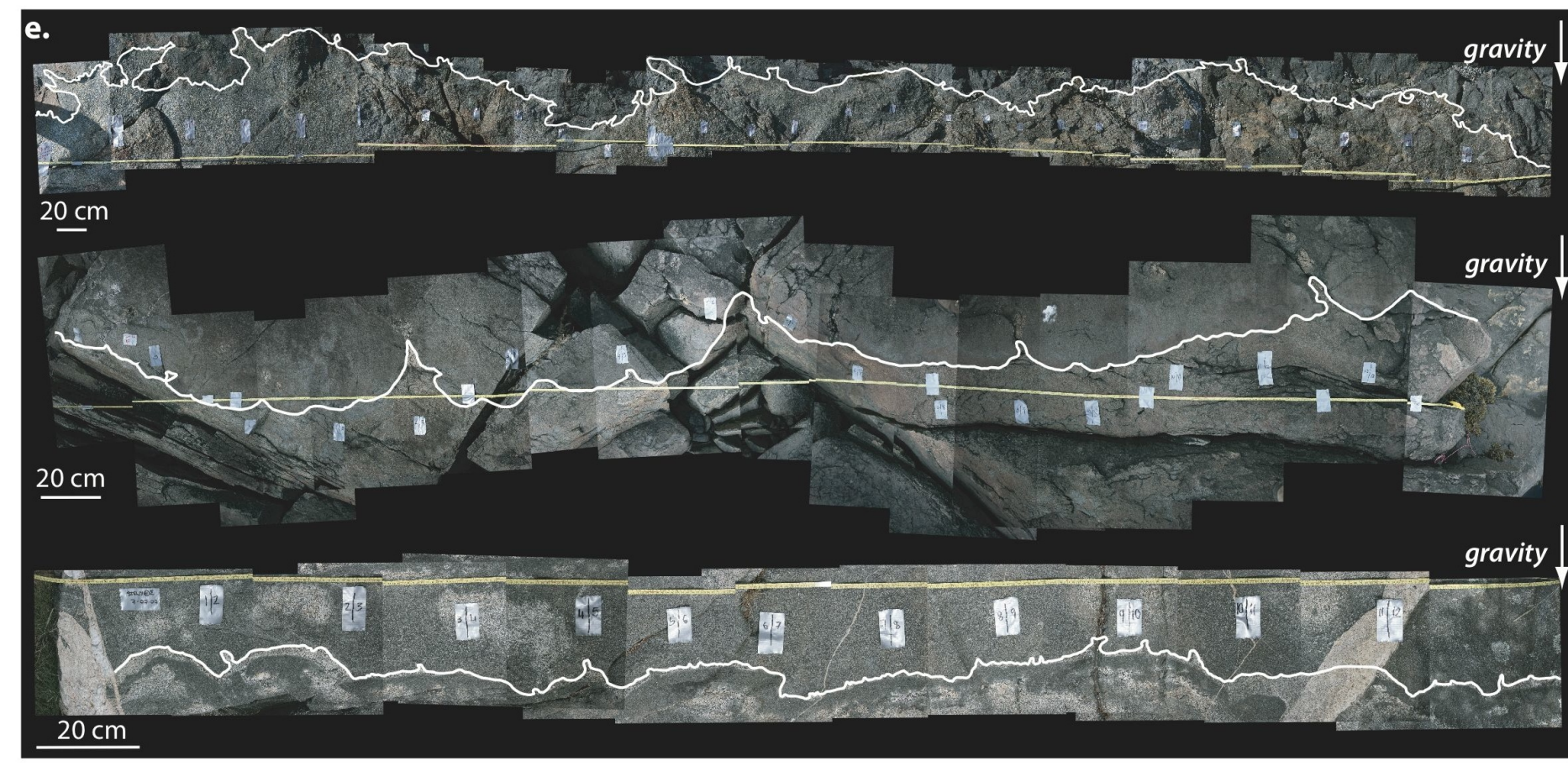

Figure 2.2 


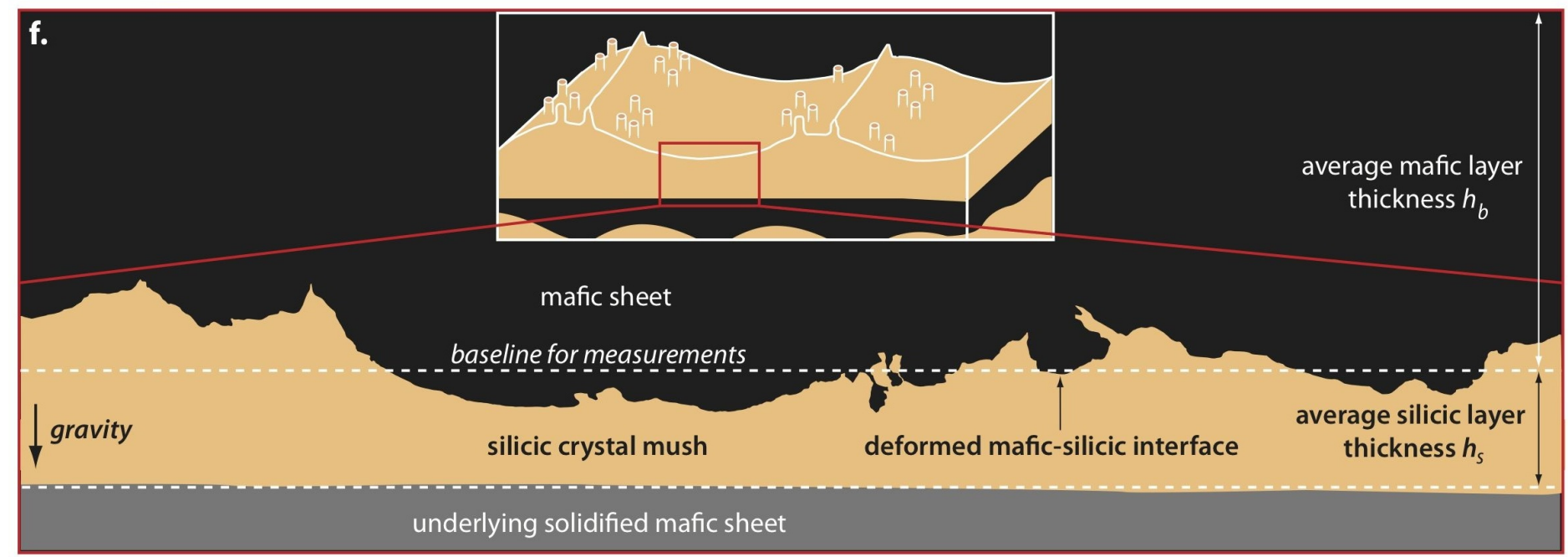

Figure 2.2: Summary of field observations. a. Sharply-defined mafic-silicic interfaces showing deformation parallel to palaeo-gravity at a range of scales. b. Sinusoidal $\mathrm{cm}$-scale deformation on the scale of crystal aggregates (pencil for scale). c. Metre-scale deformation of the interface on the scale of the silicic mush layer thickness. $\mathbf{d}$. Axisymmetric pipes of silicic crystal mush piercing the upper mafic sheet. Scale bar in a, $\mathbf{c}$ and $\mathbf{d}$ represents $15 \mathrm{~cm}$. e. Examples of mafic-silicic interfaces with deformation at scales ranging from centimetres-metres (interfaces traced in white). f. Schematic representation of a typical exposure of a mafic-silicic interface, with the inferred direction of palaeo-gravity, the average silicic and average mafic layer thickness we measured and the baseline chosen to create our digital maps and spatial series. Inset shows the inferred large-scale geometry based on our field study, including linear silicic breakouts (metre-scale) and clusters of axisymmetric silicic pipes $(\sim 10 \mathrm{~cm}$ diametre $)$ often displaying aligned crystal fabrics. 
are expected to have been denser than the underlying silicic layers, in accord with previous work (e.g. [18, 29]), we hypothesise that such features constitute kinematic indicators recording a protracted history of mafic replenishment and subsequent convective overturn, consistent with expectations from the rejuvenation model.

In this thesis we compare the observed quasi-periodic deformation of mafic-silicic interfaces at various scales with expectations based on classical Rayleigh-Taylor theory for three distinct physical processes: (i) the buoyant and large-scale overturn of a silicic igneous layer; (ii) the melting of a silicic mush layer due to heat transfer from an overlying mafic layer; and (iii) the compaction of a silicic mush layer by an overlying denser mafic layer. In section 2.2, we present a scaling theory for each of these processes, in turn. We summarise our field observations in section 2.3 and analyze these data quantitatively using spectral analysis in section 2.4. These results are compared with theory in section 2.5 and discussed in section 2.6. Our concluding remarks and future directions are presented in section 2.7.

\subsection{Theory}

\subsubsection{Overview}

Our hypothesis that buoyancy effects will arise in response to mafic injections can be tested by comparing the deformation we observe at various scale lengths to expectations based on classical Rayleigh-Taylor theory. The problem is defined in Figure 2.3. Hot basalt is envisioned to enter a cold, silicic magma chamber through a dike and spread out as a laminar grav- 

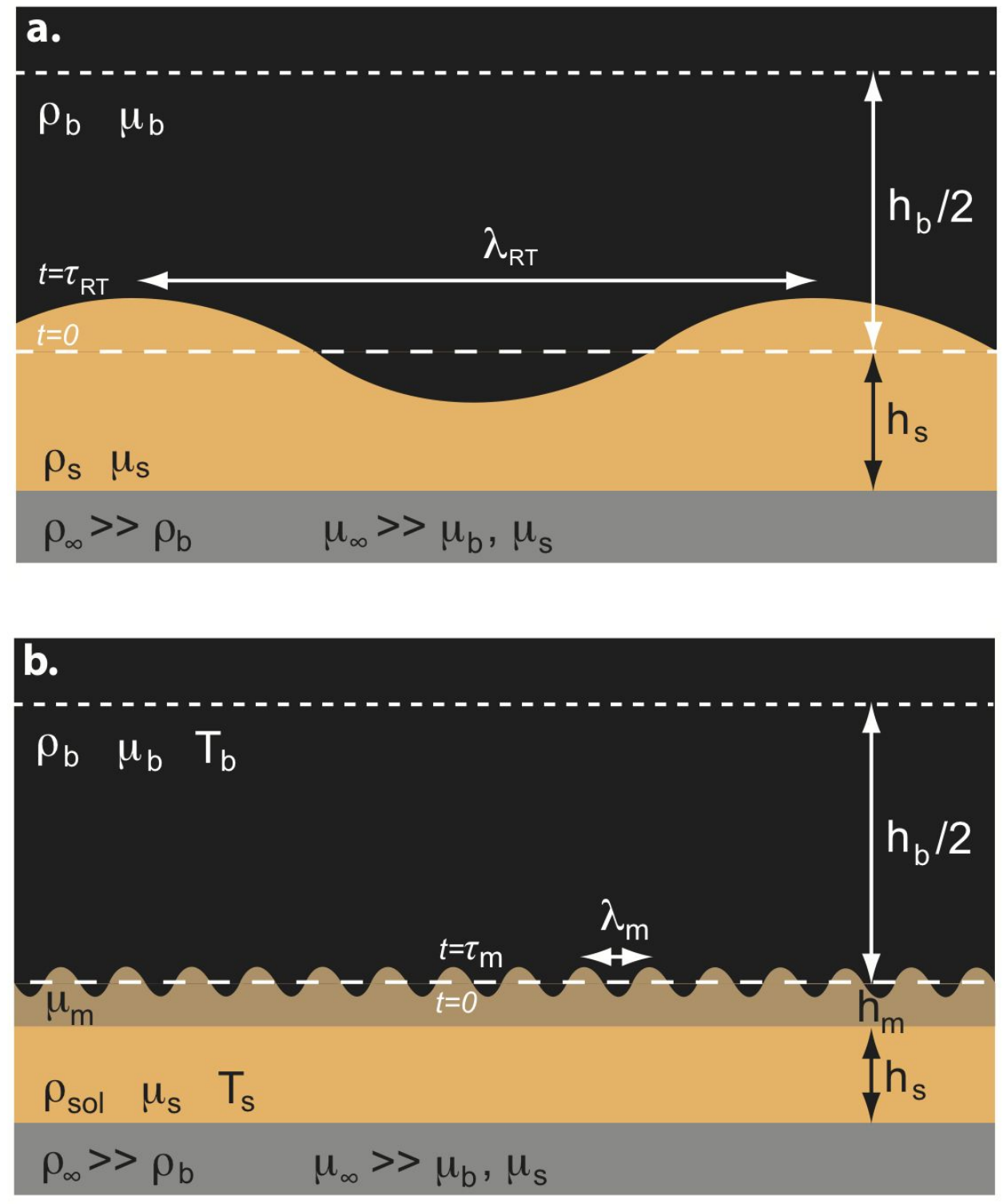

Figure 2.3 

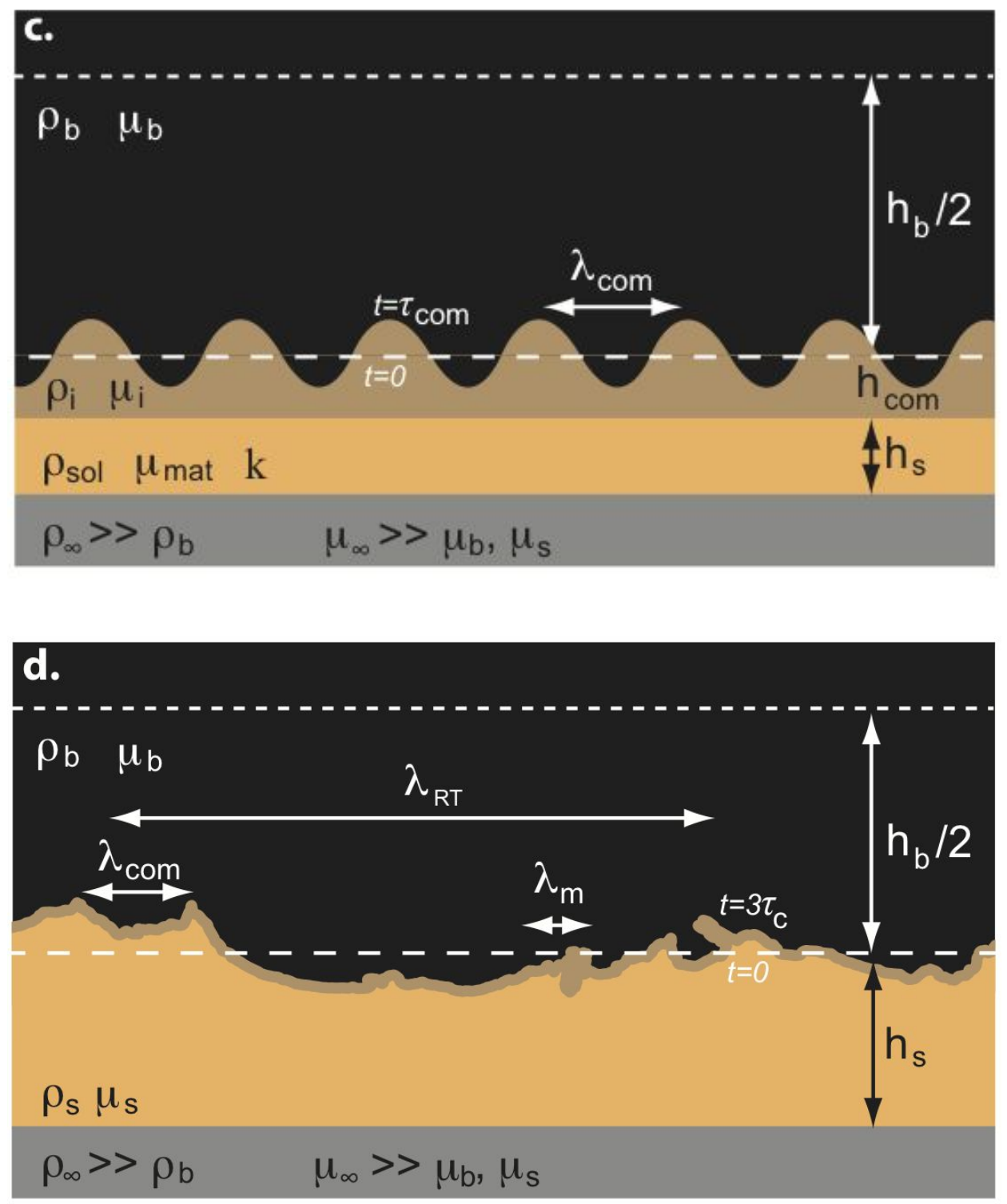

Figure 2.3: Schematic representation of the parameters and geometries associated with each deformation process: a. Buoyant overturn of the silicic layer; b. Buoyancy effects driven by melting; c. Buoyancy effects driven by compaction. d. Sum of the three characteristic wavelengths that may give rise to the complex deformation observed in the field. 
ity current over a floor. Beneath this current is a floor composed of a less dense cumulate "mush" in which silica-rich liquid occupies the interstices of a touching framework or matrix of feldspar, quartz and biotite crystals.

Over the short time scales of basalt injection and spreading we assume that this mush is sufficiently strong to resist deformation and overturning, consistent with the observed large aspect ratio of the basaltic layers. At longer time scales, however, heat transfer from the basalt will weaken the underlying mush by reducing the effective viscosities of the liquid phase and the solid matrix and by potentially melting back the solid framework. The basalt will progressively "sink", depending on the extent of melting, compaction and large-scale upwelling of the mush (Figure 2.3) as time approaches and exceeds the characteristic time for conduction across the mush layer thickness $h_{s}$ or the basalt layer thickness $h_{b}$ (whichever is smaller)

$$
\tau_{c}=\frac{h^{2}}{4 \kappa}
$$

where $\kappa$ is the thermal diffusivity, $h=h_{s}$ if $h_{s} \leq h_{b}$ and $h=h_{b}$ if $h_{b} \leq h_{s}$ (all symbols used in the text are defined in Table B.1, Appendix B). We assume that this evolution ends once the basalt layer becomes too cold to deform in an effectively viscous way, consistent with field observations of preserved silicic upwellings and tensile fractures at their cusps. Calculations show that such a condition is met after approximately $3 \tau_{c}$. We consider these processes, in turn. 


\subsubsection{Buoyancy-driven overturn of a silicic layer (Figure}

\section{3a)}

The gravitational stability of a layer of dense basalt overlying a buoyant layer of silicic mush can, in principle, be understood with well-established Rayleigh-Taylor theory for viscous fluids (e.g., [40] and references therein). Following [40] the key result is that the most unstable wavelength

$$
\lambda_{R T}=Q\left(\frac{\mu_{b}}{\mu_{s}}\right) \pi h_{s}
$$

grows on a time scale for the Stokes rise of a volume of silicic mush through its own thickness

$$
\tau_{R T}=P\left(\frac{\mu_{b}}{\mu_{s}}\right)\left(\frac{\mu_{s}}{g h_{s} \Delta \rho}\right)
$$

where $\mu_{b}$ is the effective viscosity of the mafic layer, $\mu_{s}$ is the effective viscosity of the silicic layer, $g$ is the acceleration due to gravity and $\Delta \rho$ is the density difference between the layers. In this problem, the geometric constants $P$ and $Q$ depend primarily on the viscosity ratio [40]. For $\mu_{b}=\mu_{s}$ the asymptotic values are $P=10.298$ and $Q=1.182$. Where $\mu_{b} \ll \mu_{s}, P \rightarrow 6.22$ and $Q \rightarrow 0.94$. For $\mu_{b} \gg \mu_{s}, P=(324)^{1 / 3}\left(\mu_{b} / \mu_{s}\right)^{1 / 3}$ and $Q=(2 / 3)^{1 / 3}\left(\mu_{b} / \mu_{s}\right)^{1 / 3}$.

Some care must be applied when considering the average effective viscosity of each layer: Over time the basalt is solidifying and becoming more viscous and the silicic mush is melting and becoming less viscous. However, the analysis of field data in section 2.4 below shows that the basalt-mush interface is periodically deformed at and above the scale of the layer depth, 
consistent with equation 2.2. Thus, it is reasonable to assume that $\tau_{R T} \ll \tau_{c}$, which implies that the growth rate of the instability that produced these features was sufficiently high at the time they were formed to not be significantly influenced by the time-dependent evolution of the temperature field in both layers. An additional complication is that the long-term preservation of these features probably reflects, in large part, a stress-dependence in the rheology of one or both layers (slow solidification will have a minor role because $\left.\tau_{R T} \ll \tau_{c}\right)$. Thus, any effective viscosity ratio applied is appropriate only under the conditions at the time of deformation.

In Figure 2.4a we plot the wavelength predicted for buoyant overturn of the silicic layer, as a function of silicic layer thickness.

\subsubsection{Buoyancy effects driven by melting (Figure $2.3 \mathrm{~b}$ )}

The heat flux delivered from the cooling basalt layer can melt the underlying mush, leading to the production of a buoyant melt layer. Where this layer grows sufficiently thick it can become gravitationally unstable and rise into the overlying basalt. The scaling analysis of this class of Rayleigh-Taylor problem is similar in form to the last section. One important difference is, however, that the unstable layer is not imposed as a discrete layer but is produced monotonically in time as a result of a buoyancy flux (i.e., a weight deficiency per unit time) arising as a result of melting at the top of the mush.

Following the approach of Kerr [41], the most unstable wavelength

$$
\lambda_{m}=Q\left(\frac{\mu_{b}}{\mu_{m}}\right) \pi h_{m}
$$




\subsection{Theory}
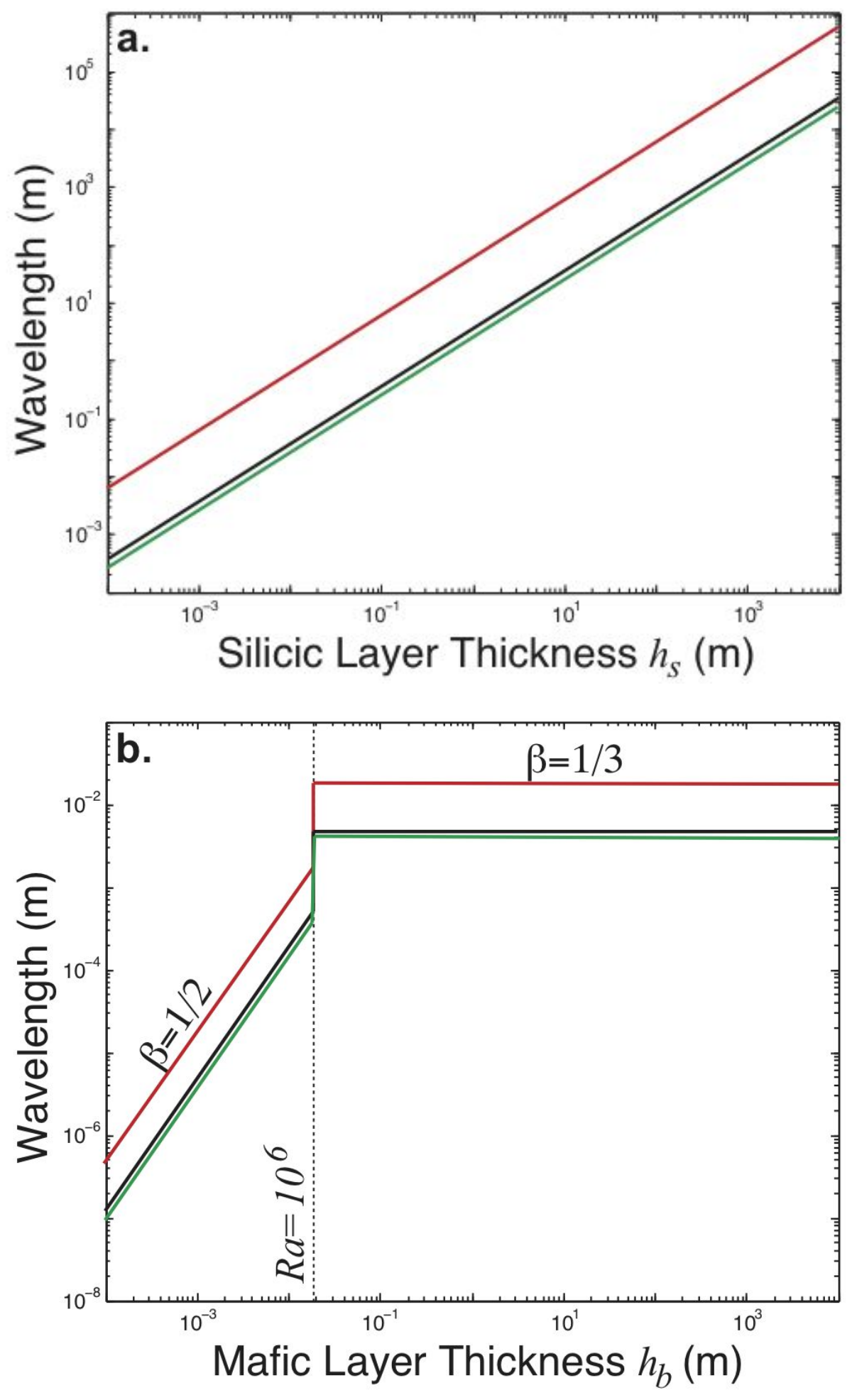

Figure 2.4 


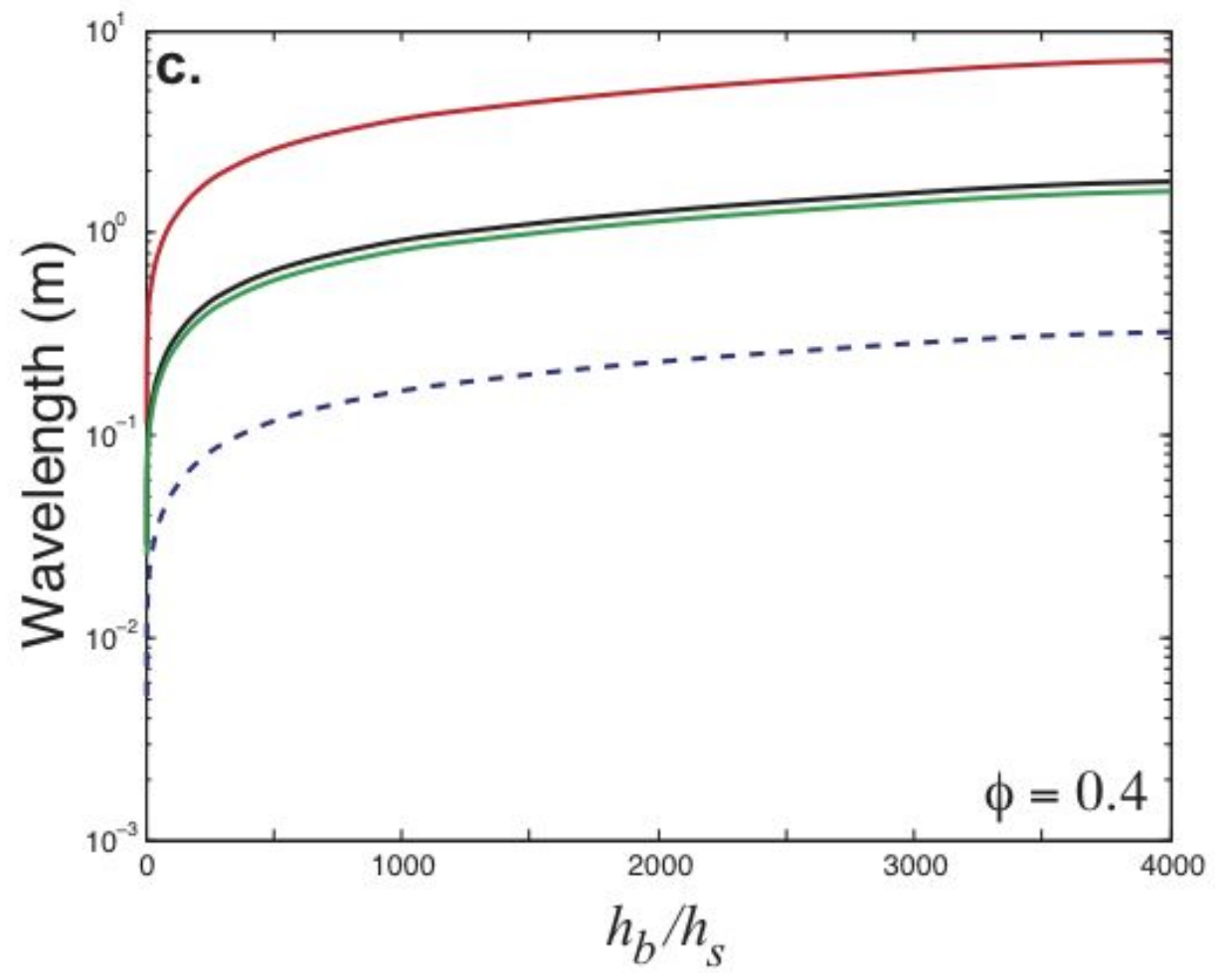

Figure 2.4: Wavelengths predicted for each deformation process: a. Buoyant overturn of the silicic layer; b. Buoyancy effects driven by melting of the silicic layer; c. Buoyancy effects driven by compaction of a silicic mush layer of porosity $\phi$. In each panel wavelengths are plotted for three values of the relevant effective viscosity ratio $\left(\mu_{b} / \mu_{s}, \mu_{b} / \mu_{m}\right.$ or $\left.\mu_{b} / \mu_{i}\right): 10^{-1}$ (green), $10^{0}$ (black) and $10^{4}$ (red). The dashed line in panel $\mathbf{c}$ is the characteristic compaction length-scale $\delta_{\text {com }}$ plotted against the ratio of mafic to silicic layer thickness. 
will grow on a Stokes rise time scale

$$
\tau_{m}=\left(\frac{P\left(\mu_{b} / \mu_{m}\right) \mu_{m}}{g V_{m} \Delta \rho_{m, 1}}\right)^{1 / 2}
$$

where $h_{m}$ is the critical thickness of the melt layer, $\mu_{m}$ is the effective viscosity of the melt layer, $V_{m}$ is a melting velocity and $\Delta \rho_{m, 1}$ is the density difference between the melt layer and the basaltic layer.

Here, we take the melting rate of a mush with porosity $\phi$, to be governed primarily by a balance between the heat flux supplied from the basalt $q_{b}$ and the latent heat $L$ of melting for the solid fraction $(1-\phi)$ of the mush (e.g. $[42,43])$ and, thus,

$$
V_{m} \sim \frac{q_{b}}{\rho_{\text {sol }} L(1-\phi)}
$$

where $\rho_{\text {sol }}$ is the density of the solid matrix in the mush and the symbol $\sim$ means "scales as" or "is the same order of magnitude as". The buoyant melt layer thickness is then

$$
h_{m} \sim V_{m} \tau_{m}=C_{1} V_{m} \tau_{m}
$$

where the geometric constant $C_{1}$ is an unknown function of the porosity that can be estimated from our data analysis below. It is instructive to note that from comparison of equations 2.5 and 2.7 and defining $\Delta \rho_{m, 2}$ as the density difference between the melt and the solid matrix in the mush, that the melt layer thickness

$$
h_{m} \propto\left(\frac{g V_{m} \Delta \rho_{m, 2}}{\rho_{s o l}}\right)^{1 / 2}
$$


which is the square root of the buoyancy flux.

To establish the melting rate we require an appropriate scaling for the heat flux delivered into the mush, which depends on the presence and vigour of convection in the overlying basalt. A general form for this heat flux is

$$
q_{b}=\left(\frac{K\left(T_{b}-T_{s}\right)}{\left(h_{b} / 2\right)}\right) R a^{\beta}
$$

where $K$ is the thermal conductivity of the mush, $T_{b}$ is the temperature of the basalt, $T_{s}$ is the temperature of the mush and $\beta$ is a constant. The Rayleigh number measuring the strength of this convection is

$$
R a=\frac{\rho_{b} g \alpha\left(T_{b}-T_{s}\right) h_{b}^{3}}{\mu_{b} \kappa}
$$

where $\alpha$ is the thermal expansion coefficient. For $R a<R a_{c r} \approx 10^{3}, \beta=0$ and the heat flux into the top of the mush is by conduction across the basalt layer. At very high $R a$ (i.e., $R a>10^{6}$ ) experimental and numerical studies [44-47] show the flows are thermally well-mixed and that heat transfer is independent of the layer depth and, thus, $\beta \approx 1 / 3$ for both laminar and turbulent convection. For intermediate values of $R a$ the flows can be complicated but are usually characterised by a heat flux that has a stronger dependence on $R a$. A reasonable value for $\beta$ is around 1/5 [48]. In Figure 2.5 we show schematically the heat flux into the basalt $q_{b}$ as a function of the basalt layer thickness $h_{b}$ to indicate these regimes.

In Figure 2.4b we plot the wavelength predicted for melting of the silicic layer, as a function of mafic layer thickness. 


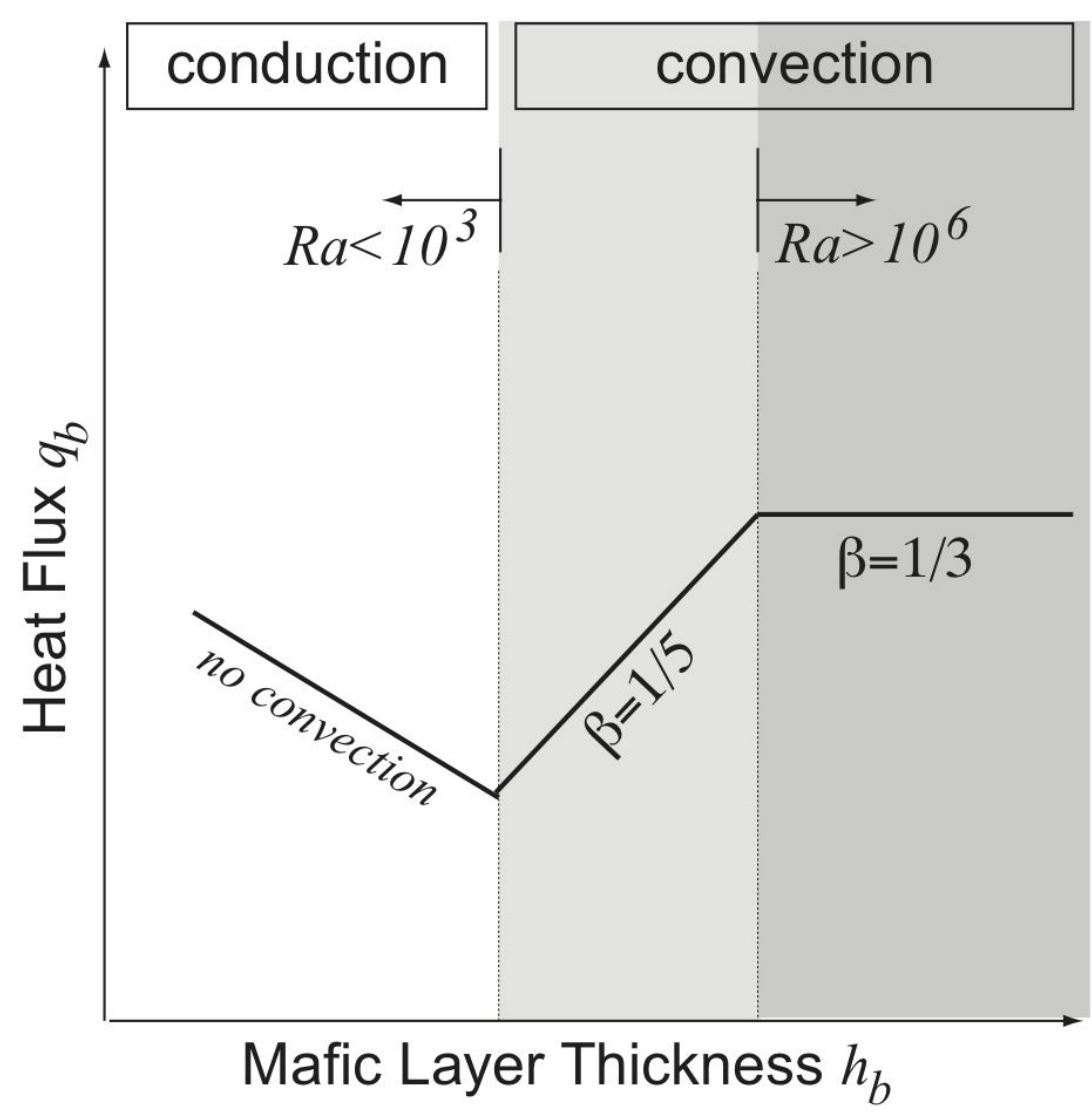

Figure 2.5: Mode of heat transfer from the mafic sheet to the silicic mush, as function of the heat flux $q_{b}$ and mafic layer thickness $h_{b}$.

\subsubsection{Buoyancy effects driven by compaction (Figure 2.3c)}

A mush underlying a dense layer of basalt can compact through the forced vertical expulsion of buoyant pore fluid to the basalt-mush interface. This buoyancy flux depends on the rate of compaction, which depends strongly on the permeability and effective viscosity of the solid matrix. The condition determining whether compaction will be important is that the silicic layer thickness be greater than the characteristic compaction length for the mush 
$\delta_{\text {com }}$ (e.g., [49]). Assuming that the densities of the pore fluid $\rho_{i}$ and solid matrix in the mush are similar (i.e., that there is negligible convection or compaction within the mush prior to the basalt injection and, thus, $\rho_{i}=$ $\left.\rho_{\text {sol }}<\rho_{b}\right)$, this critical condition is:

$$
\frac{h_{s}}{\delta_{c o m}}=\frac{h_{s}}{\left[\left(k \mu_{m a t} / \mu_{i}\right)\left(h_{b} / h_{s}\right)\right]^{1 / 2}}>1
$$

where $k=\left(d_{x l}^{2} / 5.6\right) \phi^{5.5}[50]$ and $\left.\mu_{m a t}=\mu_{i} e^{b \phi}\right)$ [51] are the initial permeability and effective viscosity of the solid matrix in the mush of porosity $\phi$ composed of crystals with average size $d_{x l}$ (see Table 2.1). The viscosity $\mu_{\text {sol }}$ is the effective viscosity of the fully-crystallized silicic layer. Thus, for a given set of physical properties for the mush, the role of compaction will be enhanced for thicker basalt layers. Clearly both the effective viscosity and permeability of the mush can evolve in a complicated way as a result of progressive heating and melting and so this condition is conservative. Nevertheless, provided this critical condition is met, assuming that $\mu_{m a t} \gg \mu_{i}$ compaction will occur at a rate that depends on the upward flow of interstitial fluid. Taking the rise rate of pore fluid to be given by Darcy's law, this compaction rate is

$$
V_{\text {com }} \approx\left(\frac{h_{b}}{h_{s}}\right) \frac{k}{\mu_{i}} \Delta \rho_{c o m} g
$$

where $\Delta \rho_{\text {com }}=\left(\rho_{b}-\rho_{i}\right)$ and $\mu_{i}$ is the effective viscosity of the interstitial fluid. Compaction will progress over a time scale

$$
\tau_{\text {com }} \sim \delta_{\text {com }} / V_{\text {com }}(1-\phi)
$$


If $\tau_{c o m} \ll \tau_{c}$ then in a way similar to above

$$
\lambda_{c o m}=Q\left(\frac{\mu_{b}}{\mu_{i}}\right) \pi h_{c o m}
$$

where the buoyant layer thickness is now

$$
h_{\text {com }}=C_{2} V_{\text {com }} \tau_{c o m}=C_{2} \delta_{c o m} /(1-\phi),
$$

and $C_{2}$ is a geometric constant of order 1 we obtain from our data.

In Figure 2.4c we plot the wavelength for compaction of the silicic mush layer, as a function of the ratio of mafic to silicic layer thickness.

\subsubsection{Summary of model predictions: three processes, three distinct wavelengths}

In Figure 2.3 we compare the three classes of proposed buoyancy effects using the parameters listed in Table 2.1. From comparison of equations 2.3, 2.5 and 2.13 in Figure 2.6, melting is expected to commence immediately on basalt spreading and will produce wavelengths at the scale of crystals (i.e. order centimetres). Provided the condition in equation 2.10 is met, subsequent compaction will cause deformation over scales comparable to a small or modest fraction of the silicic layer depth (i.e. order tens of centimetres). Large-scale overturning can occur simultaneously, producing deformation at the scale of the silicic layer depth. Figure 2.3d shows how the sum of these three harmonics might give rise to the deformation observed in the field. 
2.2. Theory
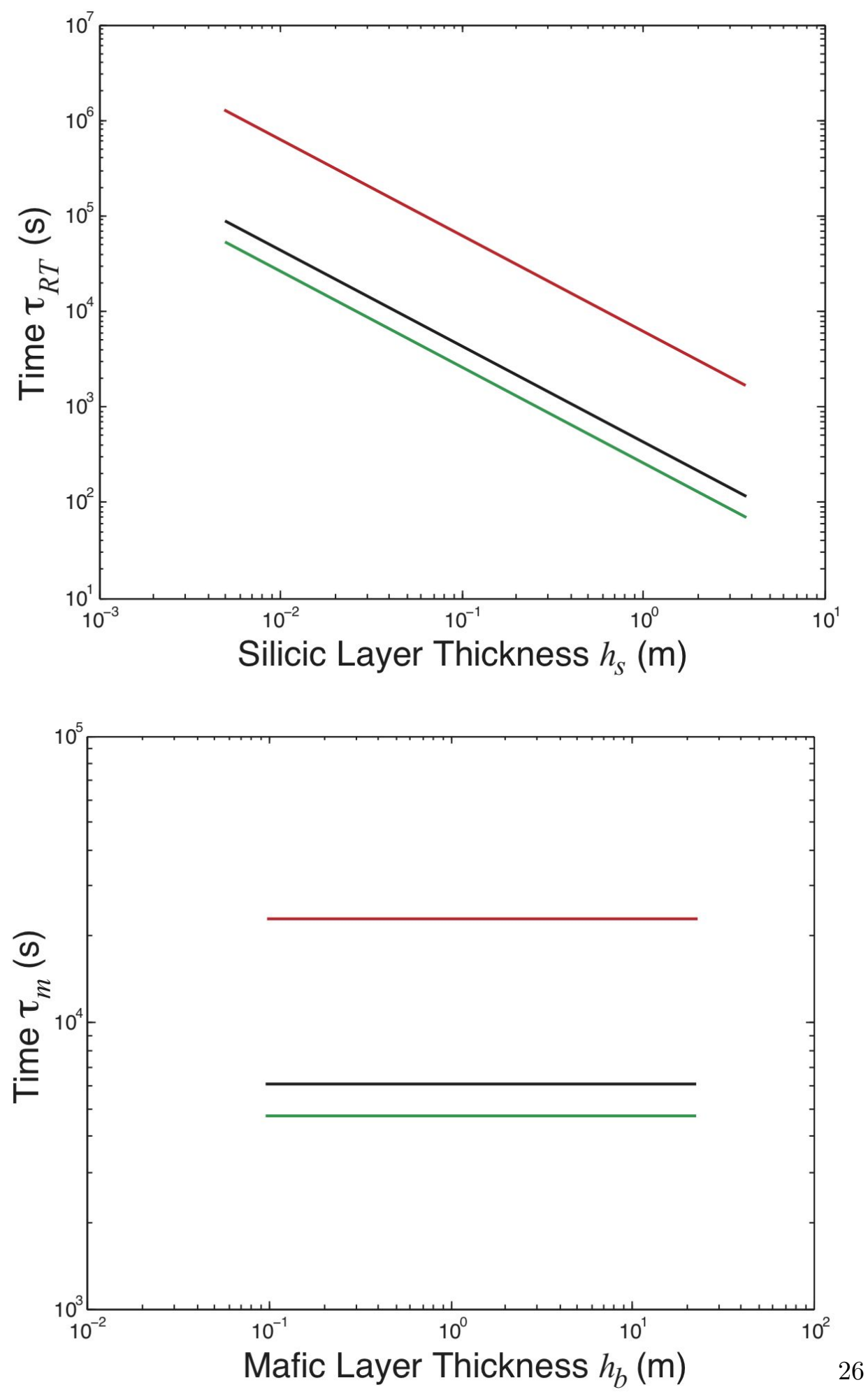

Figure 2.6 


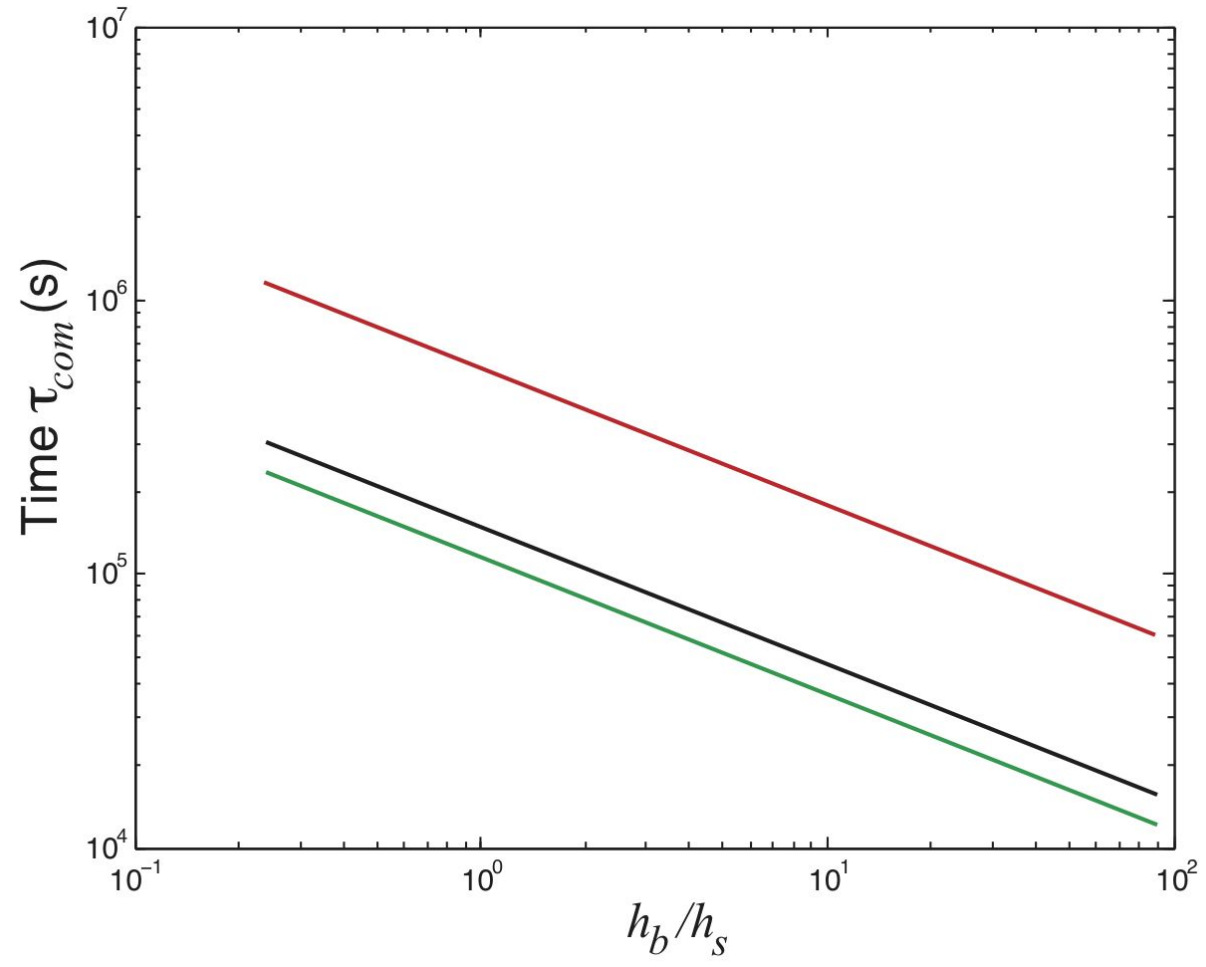

Figure 2.6: Timescales predicted for each deformation process: a. Buoyant overturn of the silicic layer; b. Buoyancy effects driven by melting of the silicic layer; c. Buoyancy effects driven by compaction of the silicic mush layer. Each timescale is plotted according to the observed range of $h_{s}$ and $h_{b}$ and three values of the relevant effective viscosity ratio $\left(\mu_{b} / \mu_{s}, \mu_{b} / \mu_{m}\right.$ or $\left.\mu_{b} / \mu_{i}\right): 10^{-1}$ (green), $10^{0}$ (black) and $10^{4}$ (red). All other parameters are listed in Table 2.1. 


\subsection{Field Observations}

\begin{tabular}{|c|c|c|c|}
\hline Symbol & Units & Value & Reference \\
\hline$b$ & - & 10 & \\
\hline$d_{x l}$ & $\mathrm{~m}$ & 0.02 & \\
\hline$g$ & $\mathrm{~m} \cdot \mathrm{s}^{-2}$ & 9.8 & \\
\hline$k$ & $\mathrm{~m}^{2}$ & $\left(d_{x l}^{2} / 5.6\right) \phi^{5.5}$ & {$[50]$} \\
\hline$q_{\text {out }}$ & $\mathrm{W} \cdot \mathrm{m}^{-2}$ & $0.1-1$ & {$[43]$} \\
\hline$q_{b}$ & $\mathrm{~W} \cdot \mathrm{m}^{-2}$ & $0.1\left(2 K_{b}\left(T_{b}-T_{s}\right) / h_{b}\right) R a^{\beta}$ & \\
\hline$C_{b}$ & $\mathrm{~J}^{\mathrm{kg}} \mathrm{g}^{-1} \cdot \mathrm{K}^{-1}$ & 1484 & {$[25]$} \\
\hline$K_{b}$ & $\mathrm{~W} \cdot \mathrm{K}^{-1} \cdot \mathrm{m}^{-1}$ & 0.3 & {$[52]$} \\
\hline$L$ & $\mathrm{~kJ} . \mathrm{kg}^{-1}$ & $2.7 \times 10^{5}$ & {$[25]$} \\
\hline$T_{b}$ & ${ }^{\circ} \mathrm{C}$ & 1100 & \\
\hline$T_{s}$ & ${ }^{\circ} \mathrm{C}$ & 900 & \\
\hline$\alpha$ & $K^{-1}$ & $5 \times 10^{-5}$ & {$[53]$} \\
\hline$\beta$ & - & 0.333 & \\
\hline$\kappa$ & $\mathrm{m}^{2} \cdot \mathrm{s}^{-1}$ & $K_{b} /\left(\rho_{b} C_{b}\right)$ & \\
\hline$\mu_{b}$ & Pa.s & 500 & \\
\hline$\mu_{i}$ & Pa.s & $10^{4}$ & \\
\hline$\mu_{m}$ & Pa.s & $10^{4}$ & \\
\hline$\mu_{s}$ & Pa.s & $\mu_{i}(1-1.35 \phi)^{-2.5}$ & {$[54]$} \\
\hline$\phi$ & - & $0.4-0.5$ & \\
\hline$\rho_{b}$ & $\mathrm{~kg} \cdot \mathrm{m}^{-3}$ & 2700 & \\
\hline$\rho_{i}$ & $\mathrm{~kg} \cdot \mathrm{m}^{-3}$ & 2300 & \\
\hline$\rho_{m}$ & $\mathrm{~kg} \cdot \mathrm{m}^{-3}$ & 2300 & \\
\hline$\rho_{s}$ & $\mathrm{~kg} \cdot \mathrm{m}^{-3}$ & 2300 & \\
\hline$\rho_{\text {sol }}$ & $\mathrm{kg} \cdot \mathrm{m}^{-3}$ & 2300 & \\
\hline
\end{tabular}

Table 2.1: Values of parameters used.

\section{$2.3 \quad$ Field Observations}

\subsubsection{Deformed mafic-silicic interfaces}

We selected 33 mafic-silicic interfaces from the Pleasant Bay and Mount

Desert Island plutons with a range of silicic/mafic layer thickness ratios (0.2- 


\subsection{Field Observations}

88). The average thickness of the mafic and silicic layers was determined in the plane normal to igneous layering and parallel with palaeogravity. We produced digital maps of each deformed interface by stitching highresolution digital photographs taken along strike (Figure 2.7a and b). The 33 digital maps are compiled in Appendix A.

Discrete spatial series of the deformation along strike were obtained by manually tracing the reconstructed interfaces from the digital maps and sampling the tracing at regular intervals. The periodic sinusoidal components constituting the interface (i.e., the wavelengths of deformation) are

then determined from spectral analysis as is discussed in section 2.4. All codes used to calculate spectra and analyse data are listed in Appendix B.

\subsubsection{Silicic mush structures}

Within our dataset we identify two petrologic classes of upwelling mush structures (Figure 2.8): granodiorite and pegmatite upwellings.

\section{Granodiorite upwellings}

The most common structure consists of equigranular granodiorite or porphyritic granodiorite with feldspar phenocrysts and occasionally mafic enclaves. Crystals $(0.5-1 \mathrm{~cm})$ in the granodiorite are aligned with the maficsilicic interface. The upwellings are irregular in shape (Figure 2.8a). 


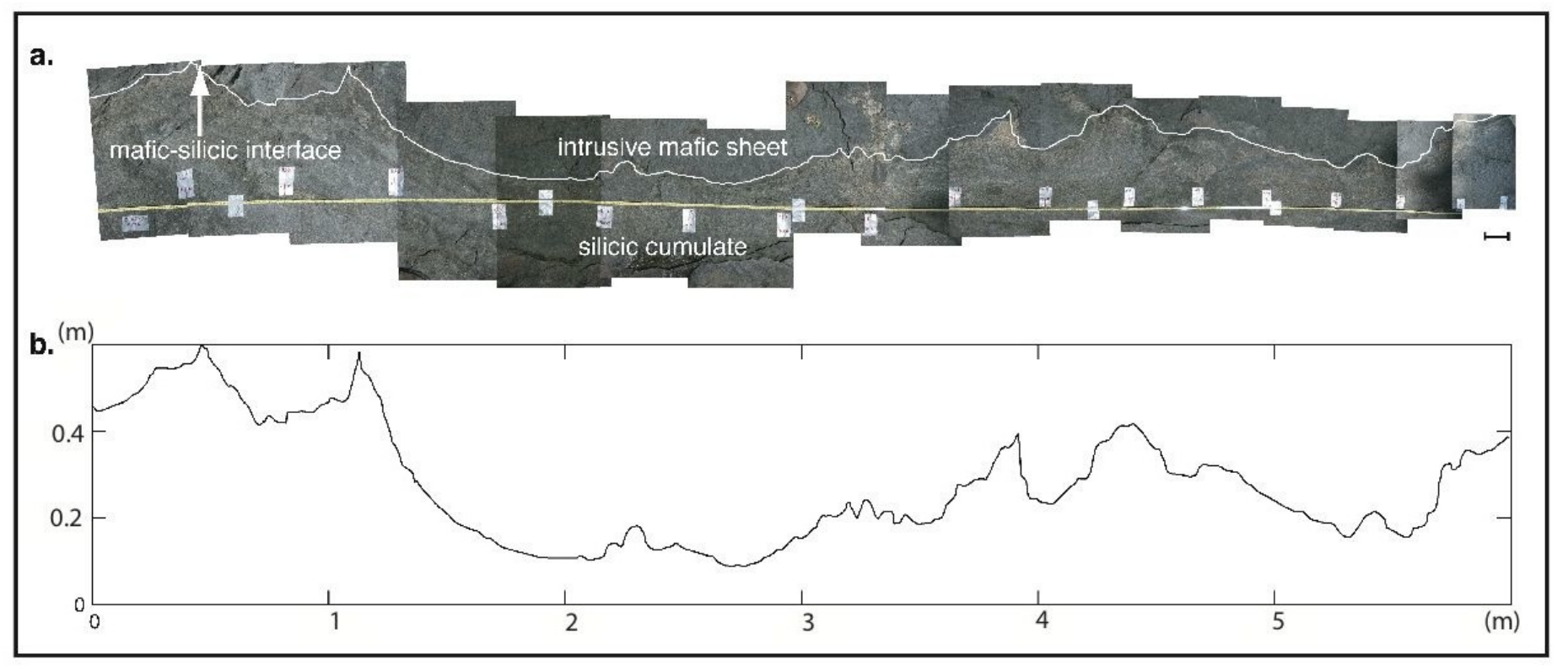

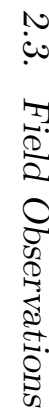

Figure 2.7 


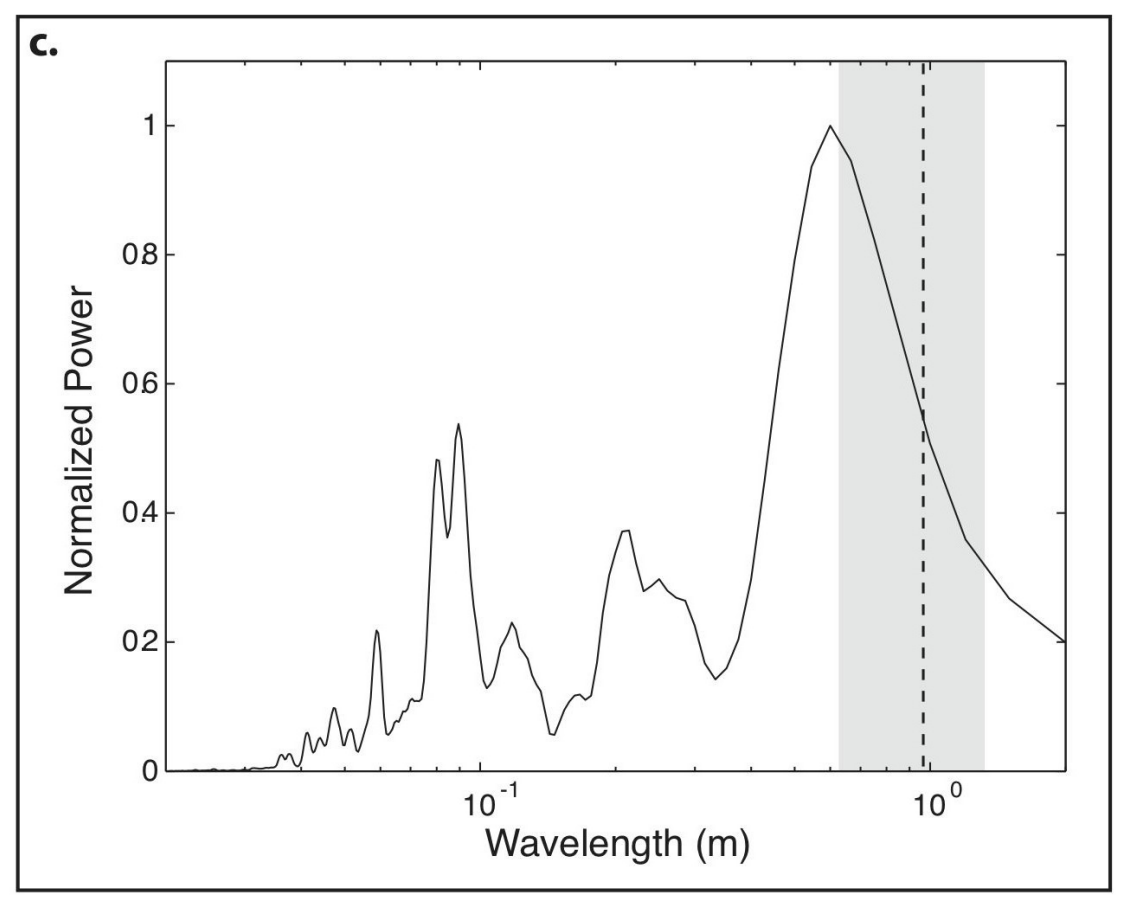

Figure 2.7: Field data collection and spectral analysis. a. Example of a deformed interface between a mafic sheet and the underlying silicic cumulate layer from the Pleasant Bay layered intrusion (length of the section is $6 \mathrm{~m}$; scale bar is $0.1 \mathrm{~m}$ ). b. The spatial series obtained from this interface and used for spectral analysis. c. Power spectrum calculated from the interface shown in a. The black dashed line represents the average longest wavelength $(0.95 \mathrm{~m})$ calculated from 10 iterations of spectral analysis of this interface; the horizontal extent of the shaded area represents the standard deviation $(0.33 \mathrm{~m})$ from the average. The average silicic layer thickness $h_{s}$ is $0.97 \mathrm{~m}$ at this location and is indistinguishable from the black dashed line in the plot. 


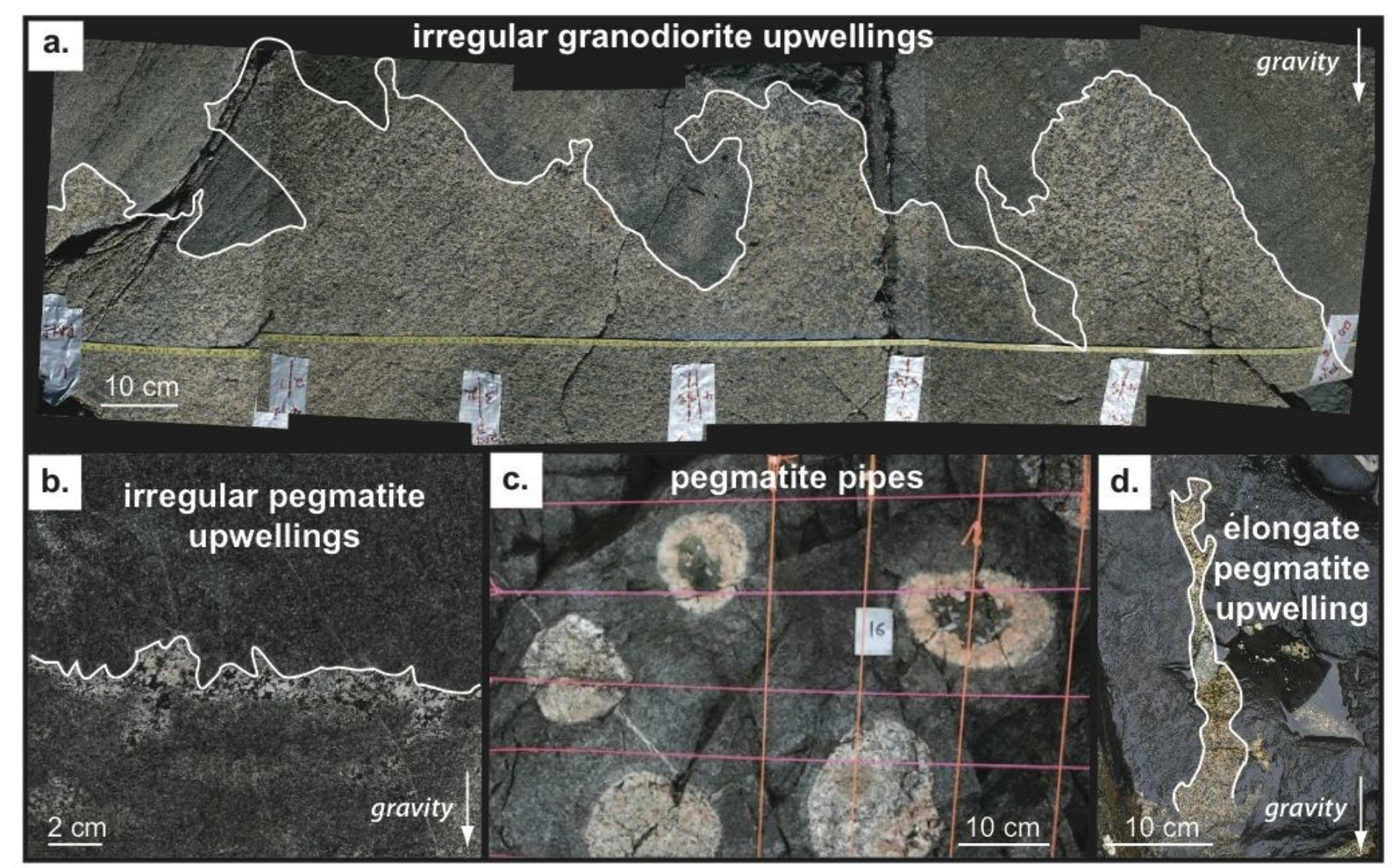

Figure 2.8: Classes of upwelling silicic structures: a. Irregular granodiorite upwellings; b. Irregular pegmatite upwellings; c. Pegmatite pipes (gravity directed into the page); d. Elongate pegmatite upwelling with no 3-D exposure. Where shown, the dashed white line follows the mafic-silicic interface. 


\subsection{Field Observations}

\section{Pegmatite upwellings}

All other upwellings consist of pegmatite, where the average crystal size is $3-5 \mathrm{~cm}$ and there is a notable decrease in the proportion of mafic minerals compared to the granodiorite. These upwellings tend to be elongate in shape and axisymmetric where 3-D exposure is available. We subdivide the pegmatite upwelling class depending on the morphology of the structures:

1. Some pegmatite upwellings are irregular in shape (Figure 2.8b);

2. Pegmatite pipes are axisymmetric in shape (Figure 2.8c);

3. Some pegmatite upwellings are elongate in shape but there is insufficient 3-D exposure to determine whether they are pipes (Figure 2.8d).

\subsubsection{Deformation within the silicic layer}

Figure 2.9 shows the deformation within the silicic layer associated with each class of upwelling defined above.

Irregular granodiorite upwellings (Figure 2.9a) typically display aligned mineral fabrics sub-parallel or at a low-angle to the interface. This fabric is also defined by elongate mafic enclaves when present and is usually stronger within a few cms of the interface and in areas of porphyritic texture. Within the limits of exposure, we estimate that in most cases strong to weak crystal alignment is present below the interface up to a distance of 0.01-0.3 times the greatest wavelength observed in the deformed interface.

The mineral alignment in pegmatite upwellings is difficult to assess due to the coarse nature of crystals (Figure $2.9 \mathrm{~b}$ and $2.9 \mathrm{c}$ ). Where detectable, 


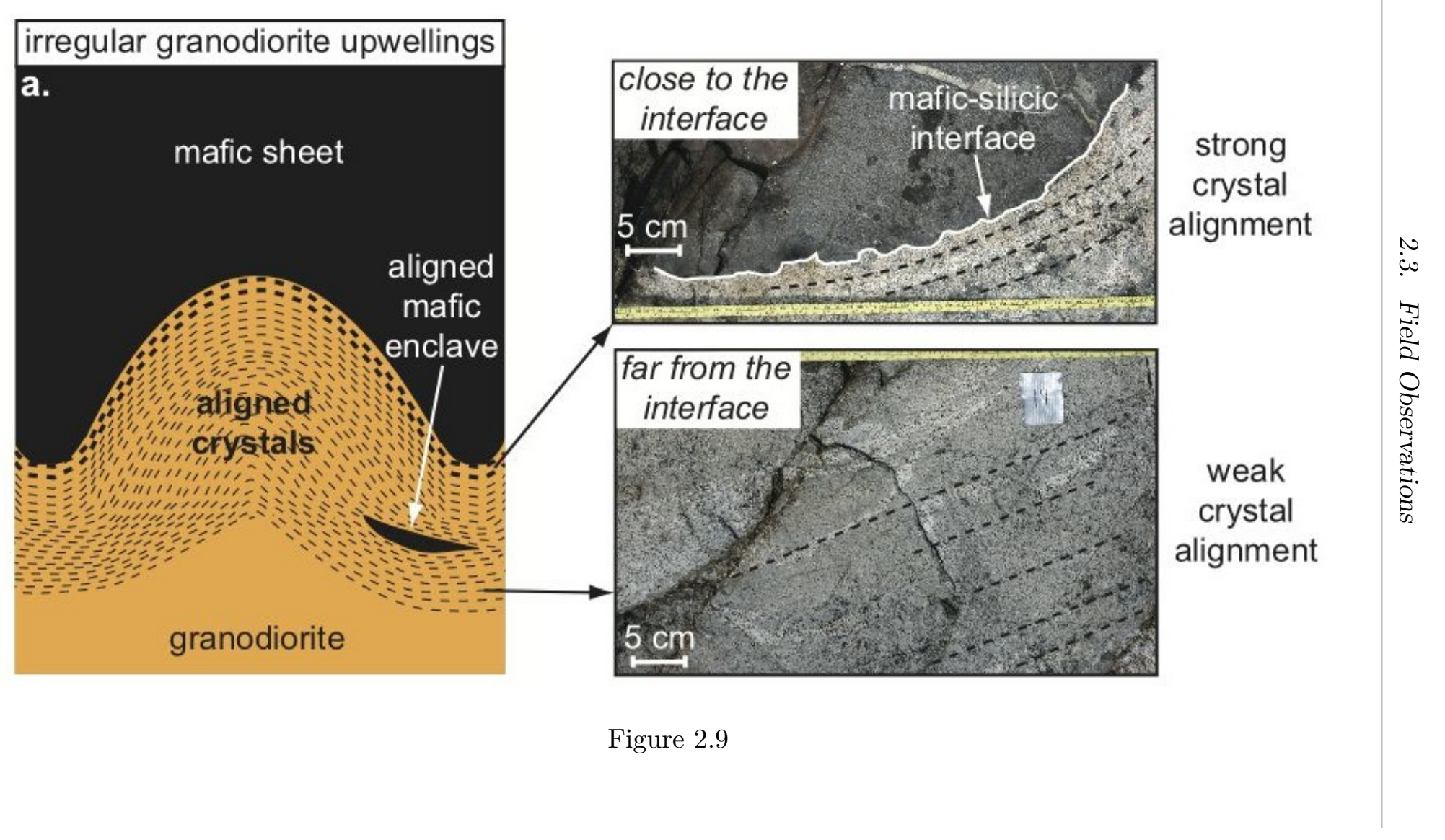




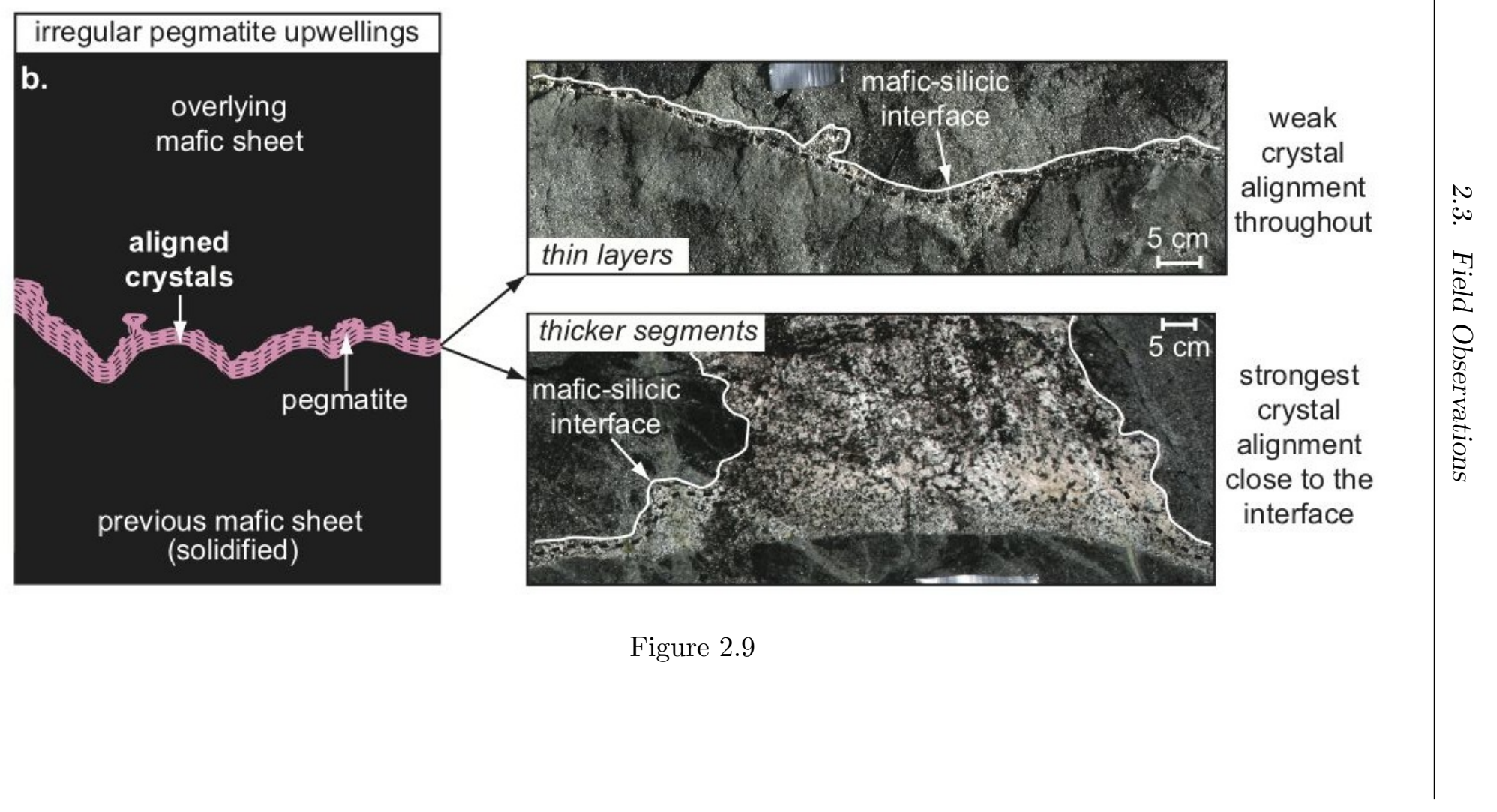



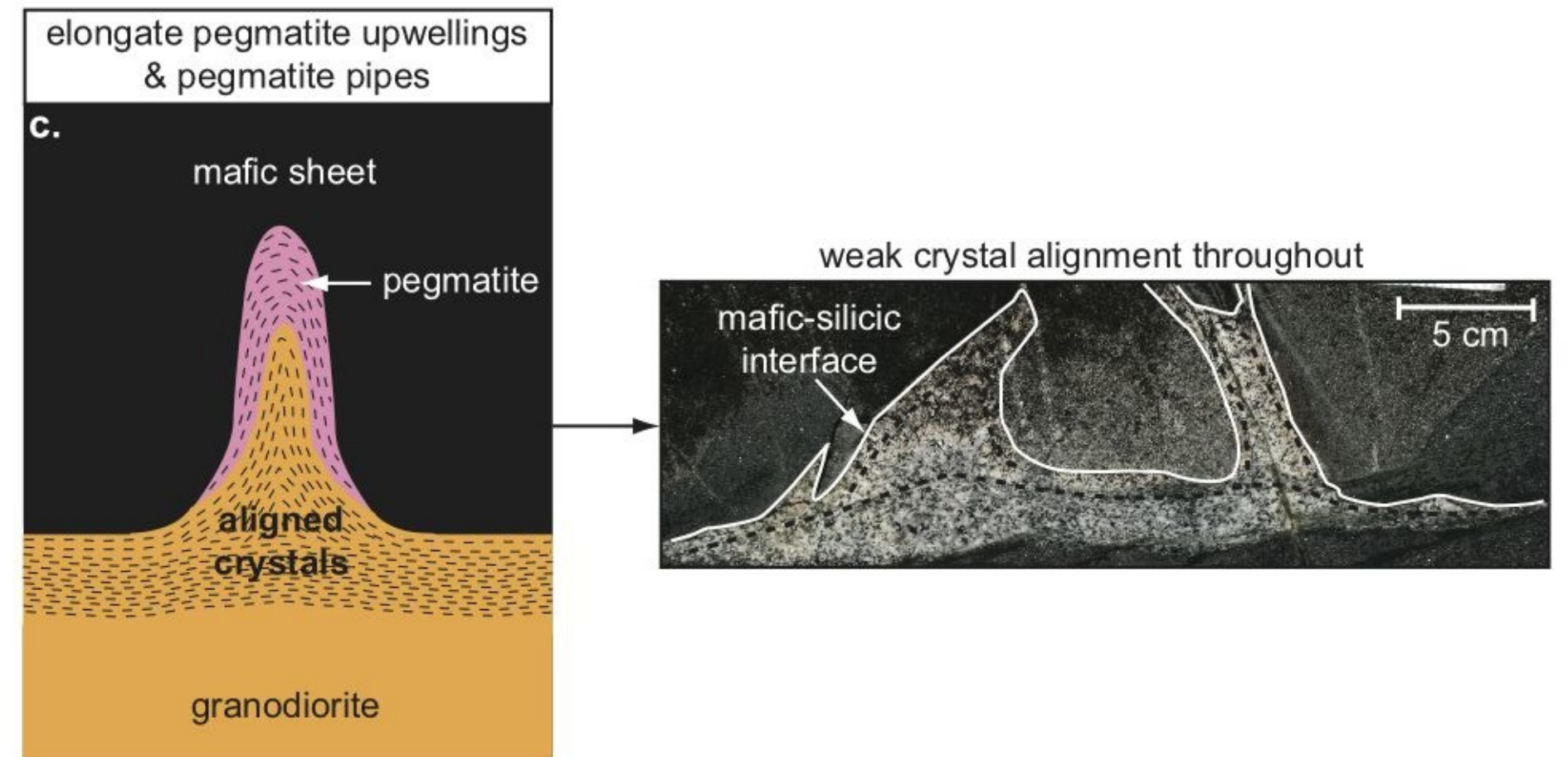

Figure 2.9: Diagrams and field photos illustrating the deformation within the silicic layer associated with a. irregular granodiorite upwellings, b. irregular pegmatite upwellings and c. elongate pegmatite upwellings and pegmatite pipes. 


\subsection{Field Observations}

irregular pegmatite upwellings display a weak mineral alignment through the thickness of the pegmatite (up to $10 \mathrm{~cm}$ in our interfaces). Pegmatite pipes and elongate pegmatite upwelllings (Figure 2.9c) typically display a weak and occasionally strong mineral alignment throughout the thickness of the pegmatite where silicic layers are very thin (up to a few $\mathrm{cm}$ ). Where silicic layers are thicker, crystal alignment tends to be stronger within a few $\mathrm{cm}$ of the interface and weaker further from the interface.

\subsubsection{Microtexture of irregular granodiorite upwellings}

To more completely characterise the deformation in granodiorite upwellings we perform a complementary microtextural study of magmatic crystal alignments and fabrics (e.g. [29]) on a representative suite of thin sections (crystals in the pegmatite class of upwellings are at the scale of the thin section, at which crystal alignments are not visible).

Away from the interface, the granodiorite shows a marked dichotomy in grain size between large 3-4 $\mathrm{mm}$ alkali feldspar and hornblende crystals and adjacent zones of a similar mineralogy with the addition of quartz and biotite, where the average grain size is only $0.5-2 \mathrm{~mm}$ (Figure 2.10a). Both these coarse-grained and fine-grained areas of the thin section show crystal alignments with similar orientations (Figure 2.10b). This alignment is typically oriented parallel to the mafic-silicic interface or at a low angle to the interface (up to $30^{\circ}$ ).

Close to the interface, we observe a coarser-grained band $2 \mathrm{~cm}$ thick immediately below mafic-silicic interface where crystal sizes average $5 \mathrm{~mm}$ (Figure 2.10c). The average crystal size is $2-3 \mathrm{~mm}$ outside this band. 


\subsection{Field Observations}

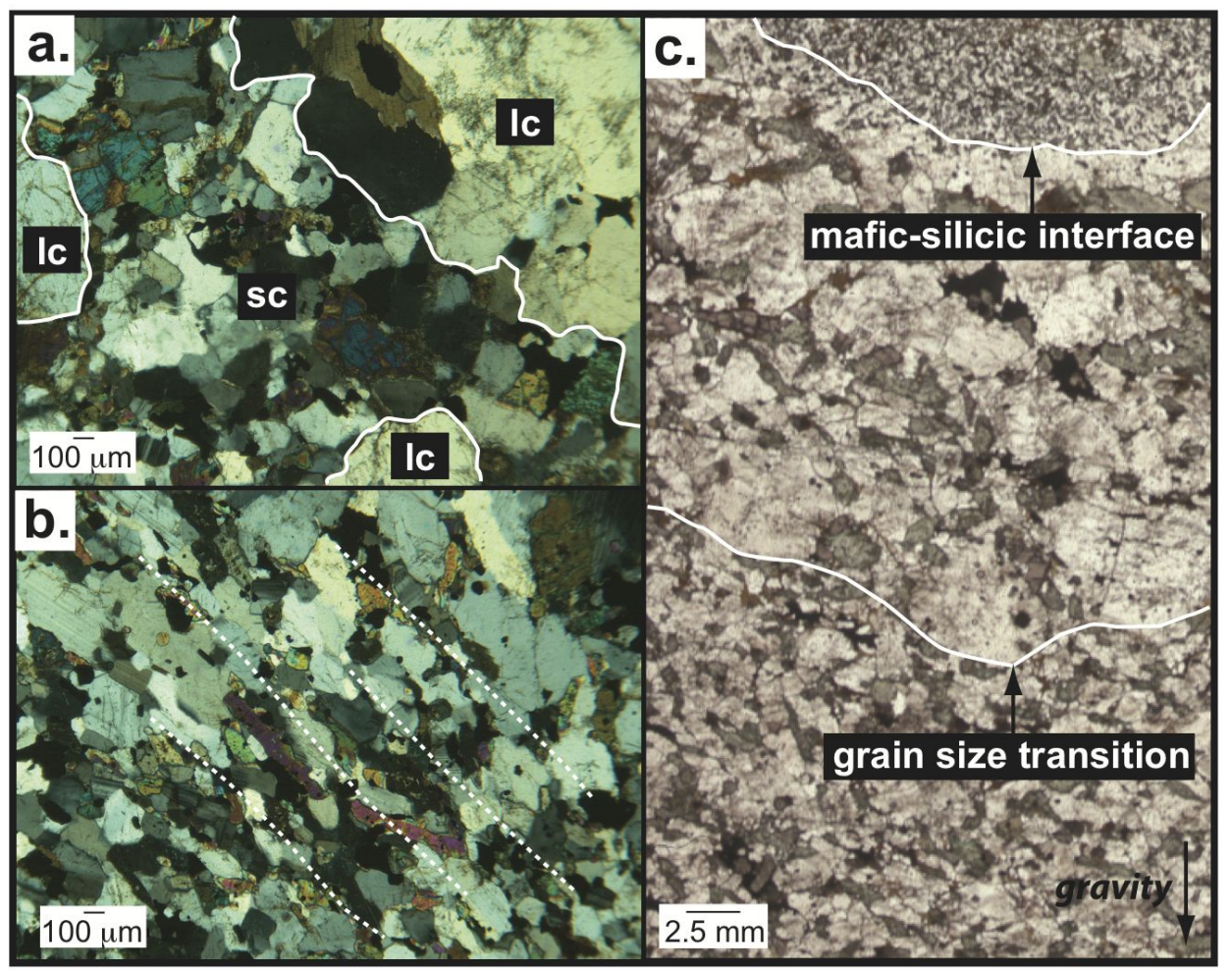

Figure 2.10: Microstructure of irregular granodiorite upwellings. a. Dichotomy in grain size away from the mafic-silicic interface, viewed under crossed polarisers (lc denotes zones with large average crystal sizes, sc denotes zones with smaller average crystal sizes). b. Crystal alignment in the granodiorite, viewed under plane polarised light. The orientation of crystal alignment is shown in white dotted lines. c. Coarser band of crystals immediately below the mafic-silicic interface. The interface is indicated at the top of the view, the coarse band of crystals is delimited by the two white lines. 


\subsection{Spectral Analysis}

\subsection{Spectral Analysis}

In many cases sinusoidal deformations occur with peak to peak wavelengths $\lambda$ comparable to or longer than the length of the exposure $L_{e}$ (Figure 2.11). In addition to limiting resolution at long wavelengths, these large-scale trends can impede resolution at short wavelengths. In light of this, we use separate algorithms to analyse long $\left(\lambda \geq L_{e}\right)$ and short $\left(\lambda<L_{e}\right)$ wavelengths.

For long wavelengths, we first identify those interfaces where the length of the exposure is less than the wavelength expected from equation (2) (i.e. $\lambda \leq$ $\left.h_{s}\right)$. For the interfaces that do not meet this condition, we then identify by eye large-scale trends at and beyond the scale of the exposure and establish an appropriate upper bound for the longest wavelength (i.e. the fundamental mode), which is limited to be either $\lambda_{\max } \approx L_{e}$ or $\lambda_{\max } \approx 2 L_{e}$ (Figure 2.11). For cases where $\lambda_{\max }>2 L_{e}$ we take $2 L_{e}$ as the fundamental mode and recognise that this value may strongly underestimate $\lambda_{\max }$.

To resolve short wavelengths $\left(\lambda<<h_{s}\right)$ as well as $\lambda \rightarrow h_{s}$, we difference the data to increase resolution at small length-scales. We calculate the power spectrum using Welch's method [55], which averages the periodograms of overlapping cosine-tapered sections of the data. Our maximum spectral analysis resolution, limited by the Nyquist frequency of our photomosaic sampling, is $0.002 \mathrm{~m}$ on average (about $10 \%$ of a typical crystal size). We take $0.003 \mathrm{~m}$ as a conservative bound for the resolved scales at all interfaces. Non-differenced and differenced spectra corresponding to each interface are shown in Appendix A. 

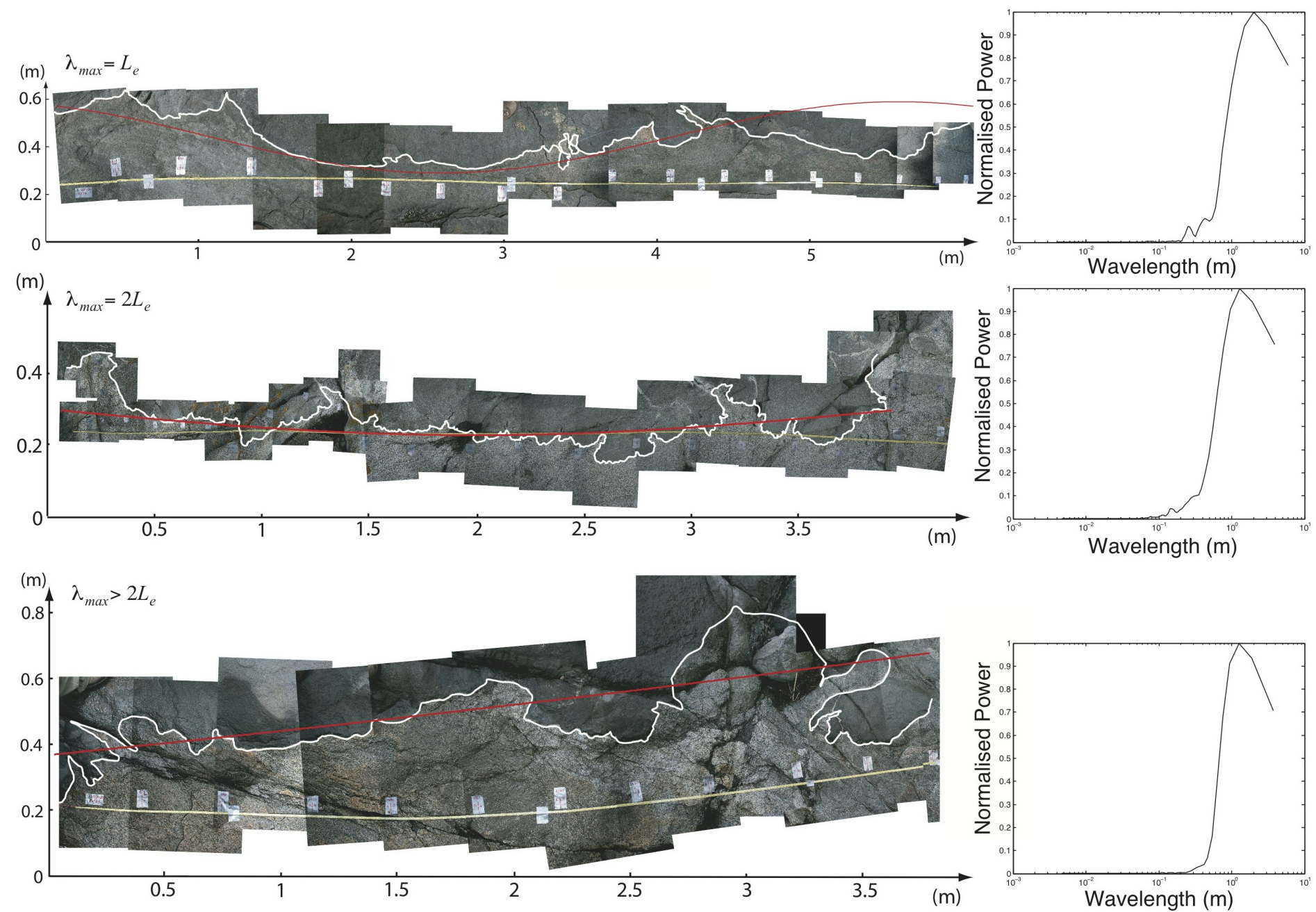

Figure 2.11: Examples of interfaces where resolution of the longest wavelengths is limited by the scale of the exposure, with the corresponding power spectra. a. Interface where a wavelength at the scale of the exposure is observed (shown in red). b. Interface where a wavelength twice the scale of the exposure is observed. c. Interface where a trend is observed. 


\subsection{Comparison With Theory}

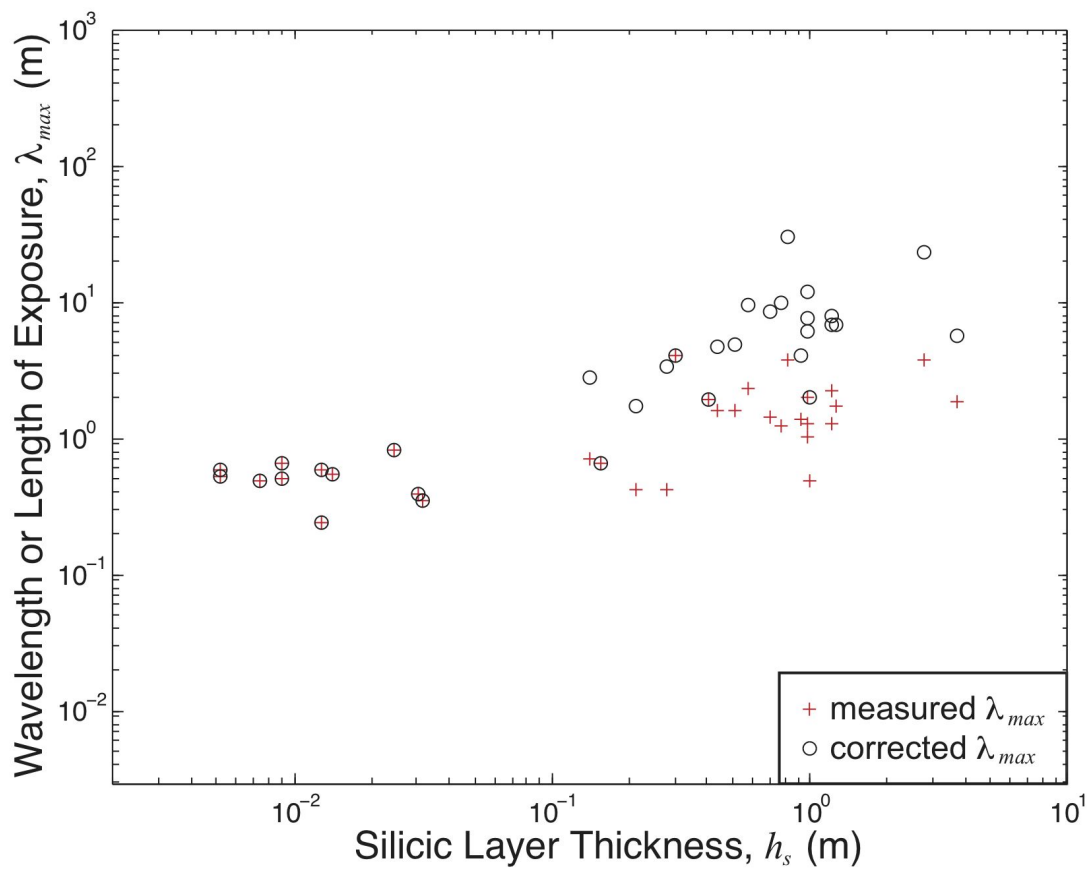

Figure 2.12: Comparison of two methods for calculating the longest wavelength in each interface: crosses are calculated using spectral analysis, circles are plotted depending on whether we observe a wavelength at a scale greater than the exposure.

To justify these two techniques, in Figure 2.12 we show the longest wavelengths estimated using both methods. It is apparent that where $\lambda>L_{e}$ results from spectral analysis give no dependence of $\lambda$ on $h_{s}$ when $\lambda>0.1 \mathrm{~m}$. However, assuming $\lambda_{\max }=L_{e}$ or $2 L_{e}$ we recover a monotonic dependence of $\lambda$ on $h_{s}$, the nature of which we explore in the following section. 


\subsection{Comparison With Theory}

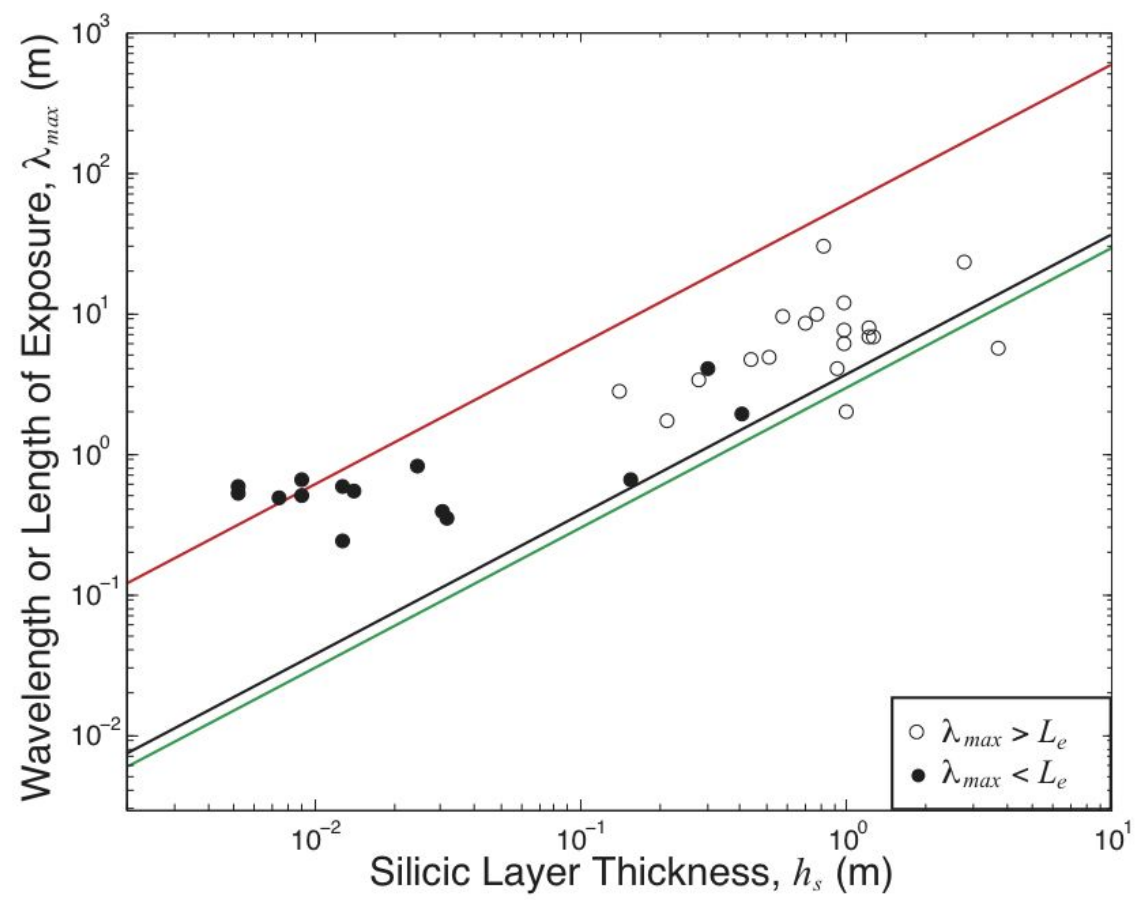

Figure 2.13: Comparison of the longest wavelengths with predictions from equation (2.2) for three values of the effective viscosity ratio $\mu_{b} / \mu_{s}: 10^{-1}$ (green), $10^{0}$ (black) and $10^{4}$ (red).

\subsection{Comparison With Theory}

\subsubsection{Long-wavelength data: large-scale buoyant overturn}

In Figure 2.13 we compare predictions from equation (2.2) with our compilated long-wavelength data (ranging 0.113-29.901 m). For the range of viscosity ratios shown in the figure the data are well-explained by the theory. The inferred viscosity ratios are further justified in section 2.6.2. 


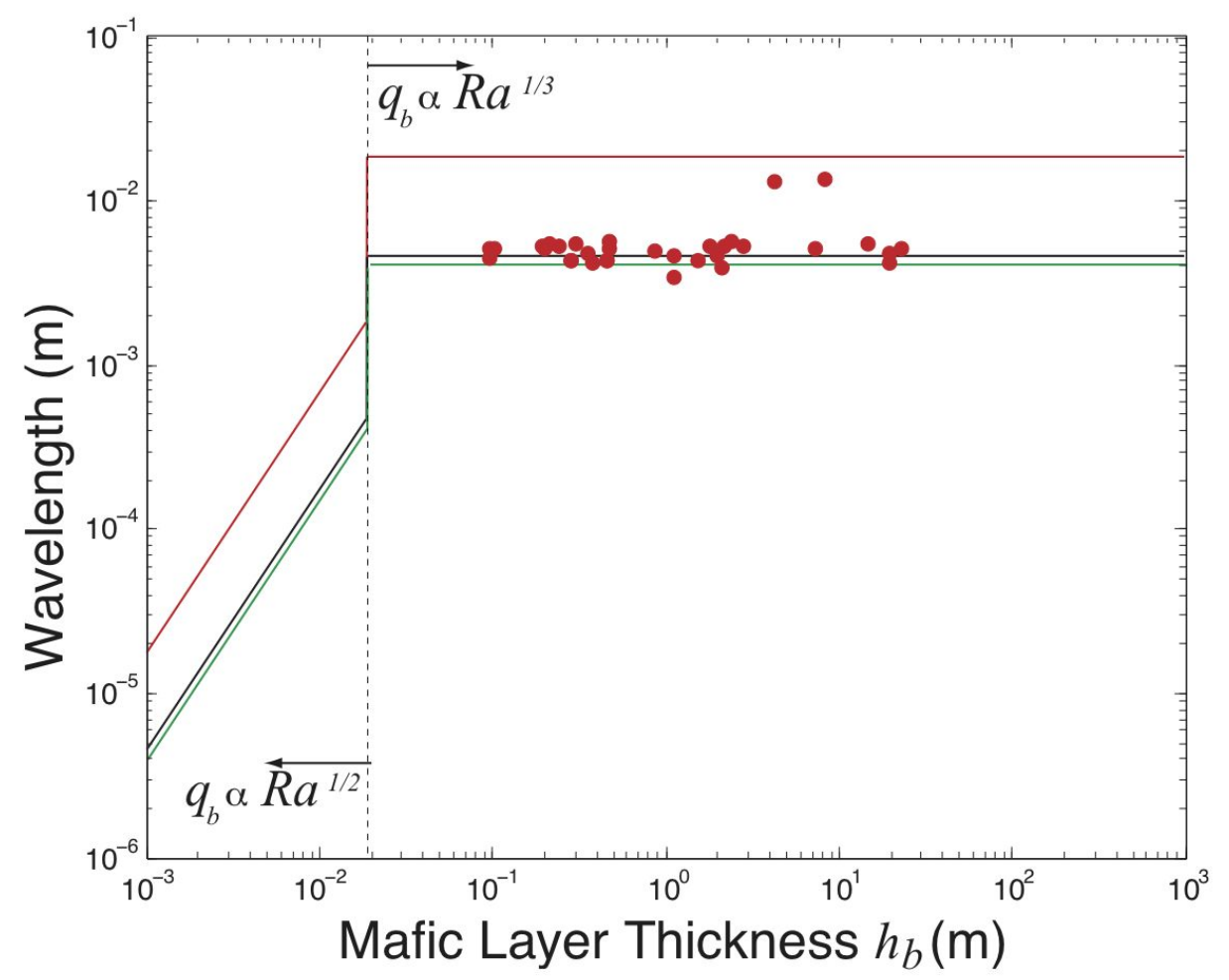

Figure 2.14: Comparison of the shortest wavelengths calculated from spectral analysis with predictions from equation (2.4) for three values of the effective viscosity ratio $\mu_{b} / \mu_{m}: 10^{-1}$ (green), $10^{0}$ (black) and $10^{4}$ (red). A fit to the data gives a scaling constant $\mathrm{C} 1=5 \times 10^{-4}$.

\subsubsection{Short-wavelength data: melting}

In Figure 2.14 we compare predictions from equation (2.4) with the shortest wavelengths in our differenced datasets for the same range of viscosity ratios. These wavelengths are comparable to the size of crystals and range from $0.003 \mathrm{~m}$ to $0.013 \mathrm{~cm}$. These data are well explained by equation $(2.4)$, consistent with vigourous convection in the mafic layer and heat transfer that is independent of the layer depth [44]. 


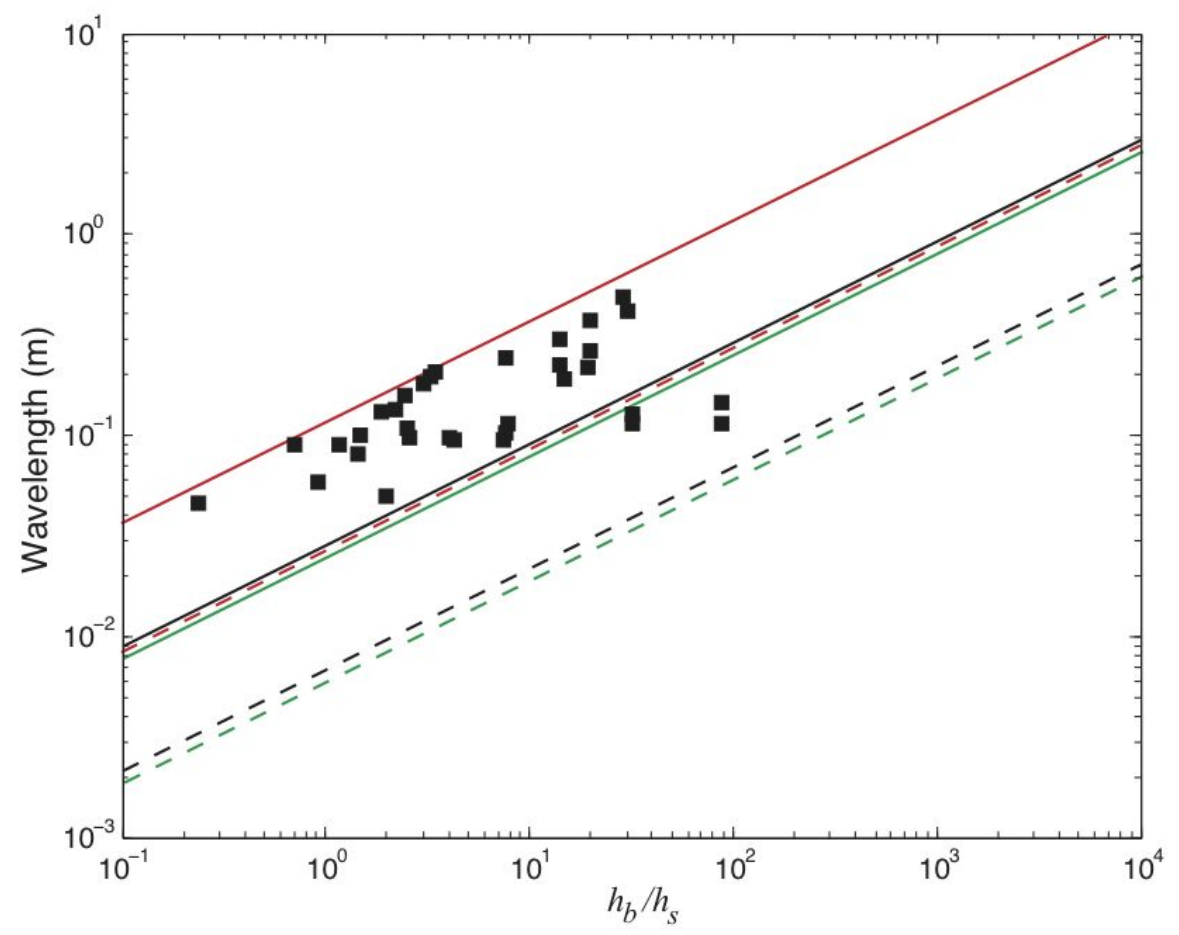

Figure 2.15: Comparison of intermediate wavelengths calculated from spectral analysis with predictions from equation (2.14) for three values of the effective viscosity ratio $\mu_{b} / \mu_{i}: 10^{-1}$ (green), $10^{0}$ (black) and $10^{4}$ (red). Solid lines correspond to a mush porosity $\phi$ of 0.4 , dashed lines correspond to a mush porosity $\phi$ of 0.5 ).

\subsubsection{Intermediate wavelengths: compaction}

In Figure 2.15 we compare predictions from equation (2.14) with intermediate wavelength data $(0.04-0.49 \mathrm{~m})$ from our differenced dataset for the same range of viscosity ratios. We assume a porosity of $40-50 \%$, i.e, two values of the porosity of the mush $(\phi=0.4$ and $\phi=0.5)$. The majority of the data are consistent with predictions assuming $\phi=0.4$. For the largest $h_{b} / h_{s}$, 
data are explained for $\phi=0.5$.

\subsection{Discussion}

\subsubsection{Links between deformation style and petrologic characterisation}

Given the observed classes of upwelling silicic structures, is the petrologic character of these upwellings diagnostic of the underlying process? In Figure 2.16 we combine the petrologic characterisation outlined in section 2.3.2 with our long, intermediate and short wavelength data in turn. Figure 2.16a shows that, except for very thin silicic layers $(\sim \mathrm{cm})$, deformation at the scale of the layer depth generally corresponds to upwellings of irregular granodiorite, consistent with a picture of large-scale overturning of the silicic mush layer. At smaller scales, complicated deformations predicted to arise in response to melting and compaction of the silicic layer involve all classes of upwellings, possibly consistent with the effects of melting back the solid matrix and expulsion of pore fluid during compaction that may have occurred simultaneously (Figure 2.16b and c). Melting and compaction are both processes that disaggregate crystal mush into variably sized packets ranging from crystal-poor fluid to crystal-rich mush. Thus, the appearance of all four classes of upwellings at intermediate and small scales is not surprising.

\subsubsection{Evolution of rejuvenation}

We show that the deformed mafic-silicic interfaces of the Coastal Maine plutons preserve three classes of deformation feature explained by three dis- 


\subsection{Discussion}
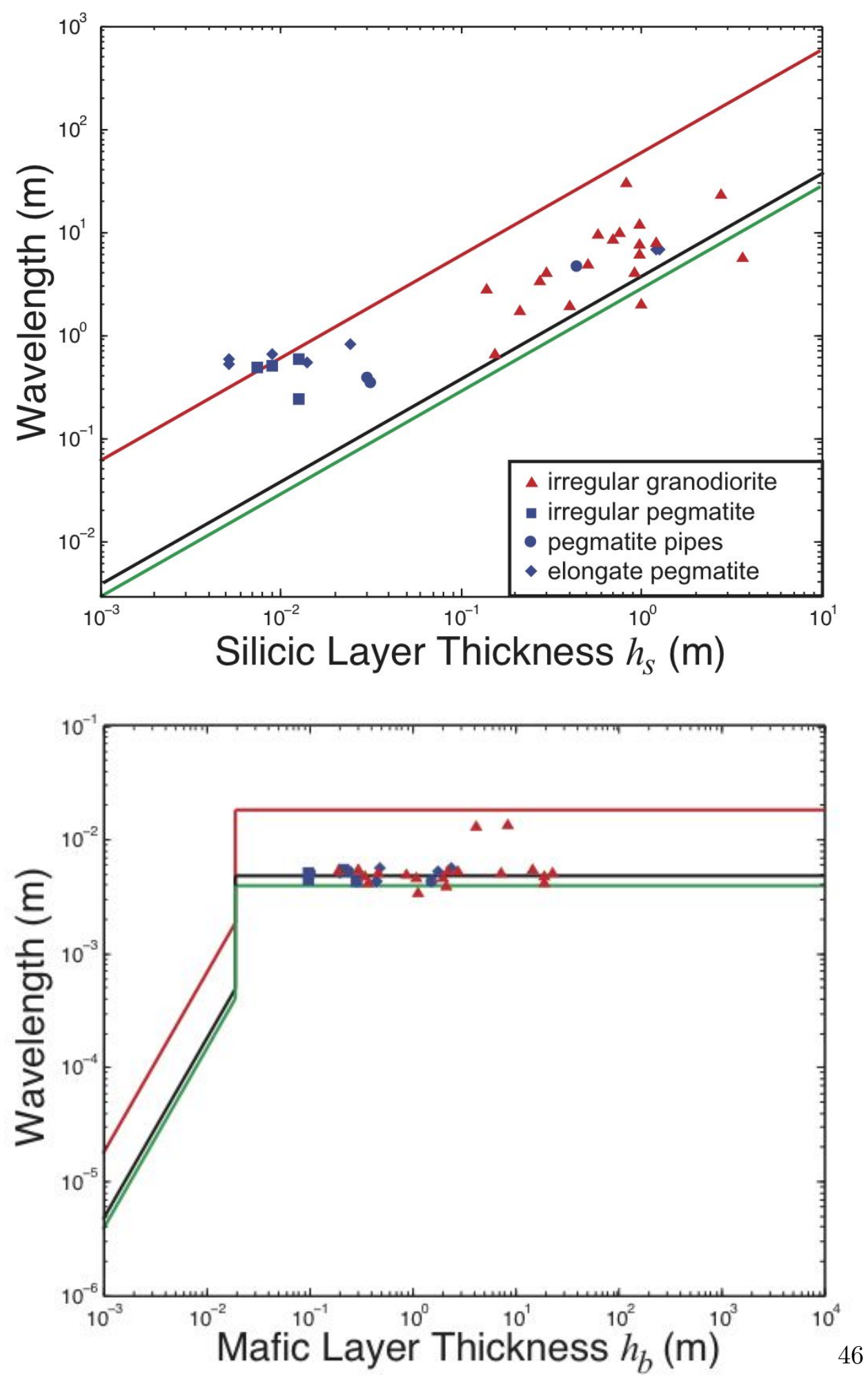

Figure 2.16 


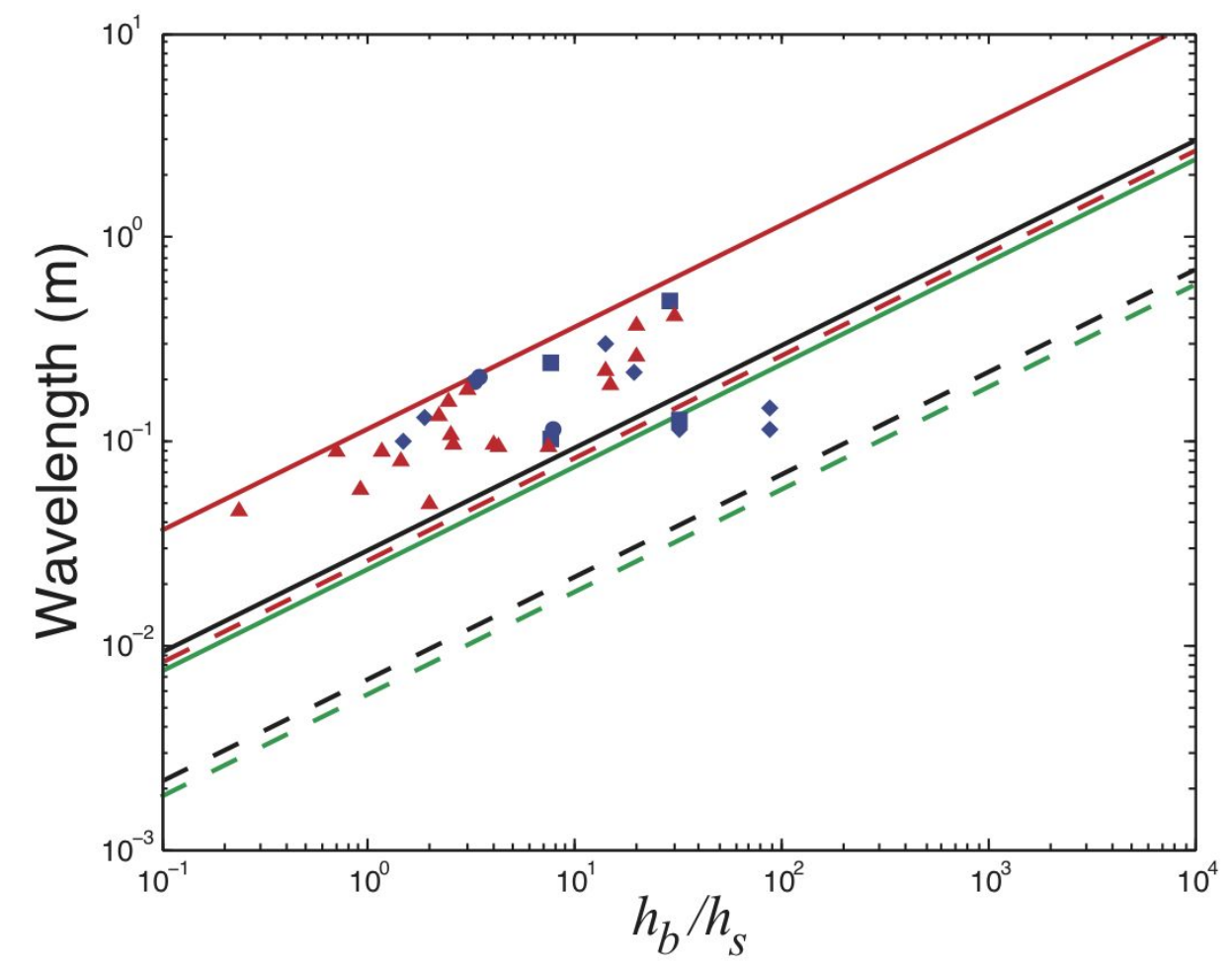

Figure 2.16: Comparison of the petrologic characterisation of upwellings with long (a), intermediate (b) and short (c) wavelength data. Symbols correspond to the dominant class of upwelling identified in each interface. The key to the symbols used throughout is shown in panel (a). Predicted wavelengths are plotted for three values of the relevant effective viscosity ratio $\left(\mu_{b} / \mu_{s}, \mu_{b} / \mu_{m}\right.$ or $\left.\mu_{b} / \mu_{i}\right): 10^{-1}$ (green), $10^{0}$ (black) and $10^{4}$ (red) in each panel. 


\subsection{Discussion}

tinct physical processes: short wavelength upwellings at the scale of crystals (0.003-0.013 m), consistent with buoyancy effects driven by melting of the silicic layer; intermediate wavelength deformation (0.04-0.49 m), consistent with buoyancy effects driven by compaction of the silicic mush layer; and upwellings of granodiorite at the scale of the full thickness of the silicic layer (0.24-29.901 m) driven by large-scale buoyant overturn of the mush. Each interface is, however, a time-integrated snapshot of the supra-solidus deformation processes that created it. Thus, an obvious question is the nature of the evolution of such a system to the preserved state observed in the field.

The evolution during rejuvenation depends on the relative timescales over which each deformation process acts (Figure 2.6). We expect long wavelengths related to the large-scale overturn of the silicic layer to develop almost immediately for the thickest silicic layers $\left(h_{s} \sim 3 \mathrm{~m}\right)$ if initially $\mu_{b} / \mu_{s}<1$, and up to several weeks after the basaltic injection for the thinnest silicic layers $\left(h_{s} \sim 10^{-2} \mathrm{~m}\right)$ if $\mu_{b} / \mu_{s}>1$ (Figure 2.6a). By contrast, we expect short wavelengths related to melting of the underlying silicic mush to develop within an hour (if $\mu_{b} / \mu_{m}<1$ ) to several hours (if $\mu_{b} / \mu_{m}>1$ ) of the injection of the basaltic layer (Figure 2.6b). Finally, for the observed range of $h_{b} / h_{s}$, we expect compaction of the silicic layer to develop after $\sim 11$ days if this ratio is low $\left(h_{b} / h_{s} \sim 10^{-1}\right)$ and $\mu_{b} / \mu_{i}>1$. If the ratio of mafic to silicic layer thickness is high $\left(h_{b} / h_{s} \sim 10^{2}\right)$ and $\mu_{b} / \mu_{i}<1$, we expect these wavelengths to develop only a few hours after the injection of the basaltic layer.

Assuming $\phi=0.4-0.5, \mu_{s}$ ranges from $6.9 \mu_{i}$ to $16.6 \mu_{i}$ (Table 2.1). Thus, as a first order simplification we assume that $\mu_{m}=\mu_{i} \sim O\left(\mu_{s}\right)$ and focus on 


\subsection{Discussion}

the effective viscosity ratio $\mu_{b} / \mu_{s}$. The evolution of the deforming interface is dependent on $\mu_{b} / \mu_{s}$ at the time of deformation. Figures 2.13 to 2.15 suggest that a plausible range in this parameter is order $10^{0}-10^{4}$. However, field constraints on the morphology of the upwelling mush structures can aid in constraining these values. The results of Olson and Singer [56] show that upwelling mush will take the form of diapirs if $\mu_{b} / \mu_{s} \leq O(1)$. In contrast, if $\mu_{b} / \mu_{s}>O\left(10^{2}\right)$ upwellings are expected to have large, spherical heads and narrow trailing tails (e.g. [56-59]). From careful examination of the varied classes of upwelling in our data set (e.g., Figure 2.8 and section 2.3.2), plausible viscosity ratios vary from $\mu_{b} / \mu_{s} \sim O(1)$ to $\mu_{b} / \mu_{s}>O\left(10^{2}\right)$, possibly indicative of distinct and widely disparate thermal conditions.

From these considerations, we envisage several ways in which the deformation of the interface may evolve (Figure 2.17). In the case where the silicic layer is thin relative to the basaltic layer $\left(h_{b} / h_{s} \sim 10^{2}\right)$ and $\mu_{b} / \mu_{s}<1$, melting of the silicic layer will lead to the formation of deformation at the scale of crystals in a matter of hours. Large-scale overturn of the silicic layer will follow in turn, after a few hours. Deformation resulting from the instability of a layer of interstitial melt produced by compaction of the silicic layer will occur after several hours. In this case, the timescales for the development of wavelengths related to each process are comparable and we expect the deformation of the mafic-silicic interface to be governed by all three processes and to develop deformations at short, intermediate and large-scale wavelengths. In the equivalent case where $\mu_{b} / \mu_{s}>1$, short wavelengths will develop in 7 hours, intermediate wavelengths after 11 days and long wavelengths after 23 days. In this case we expect the deformation of the 


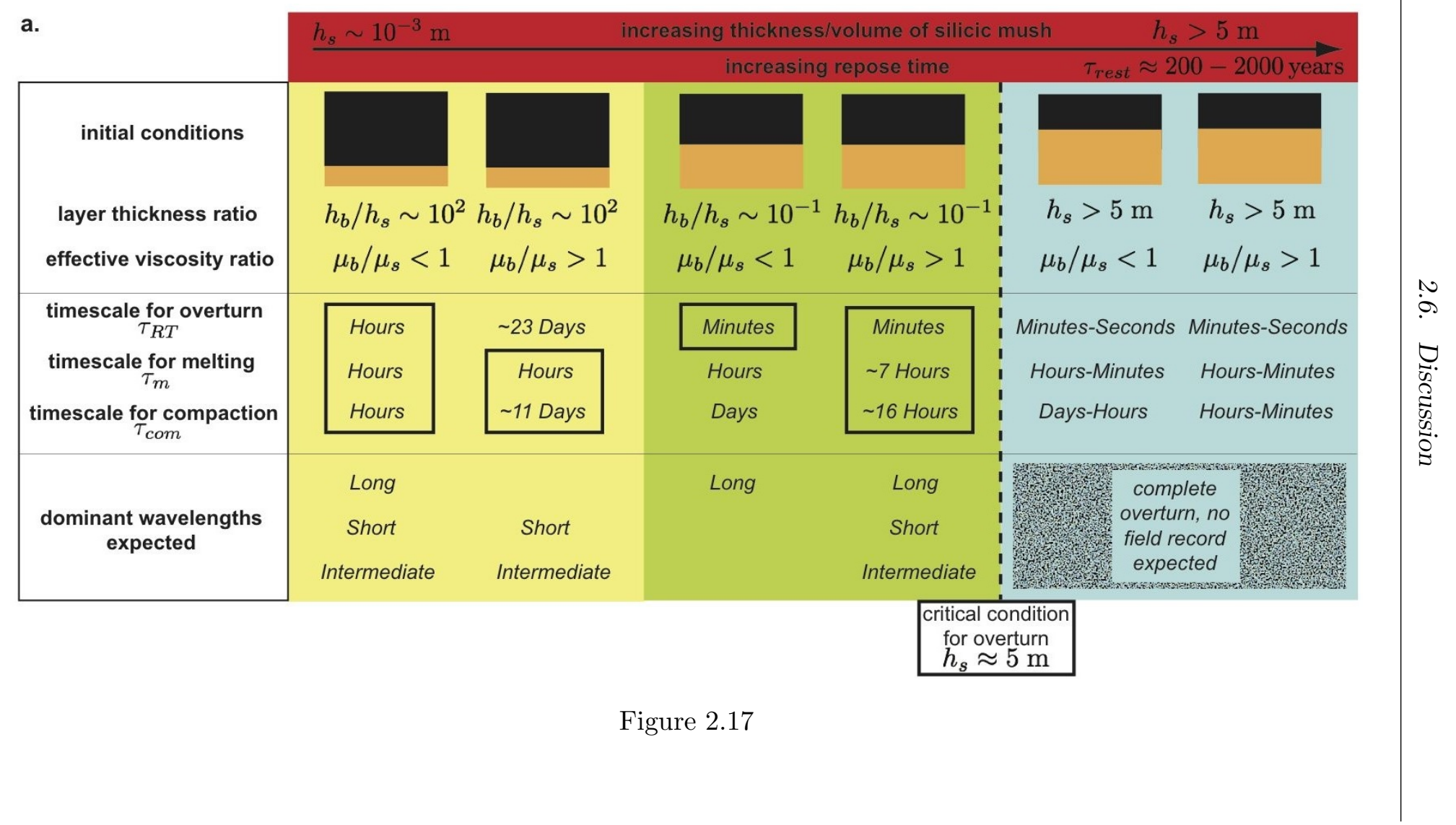




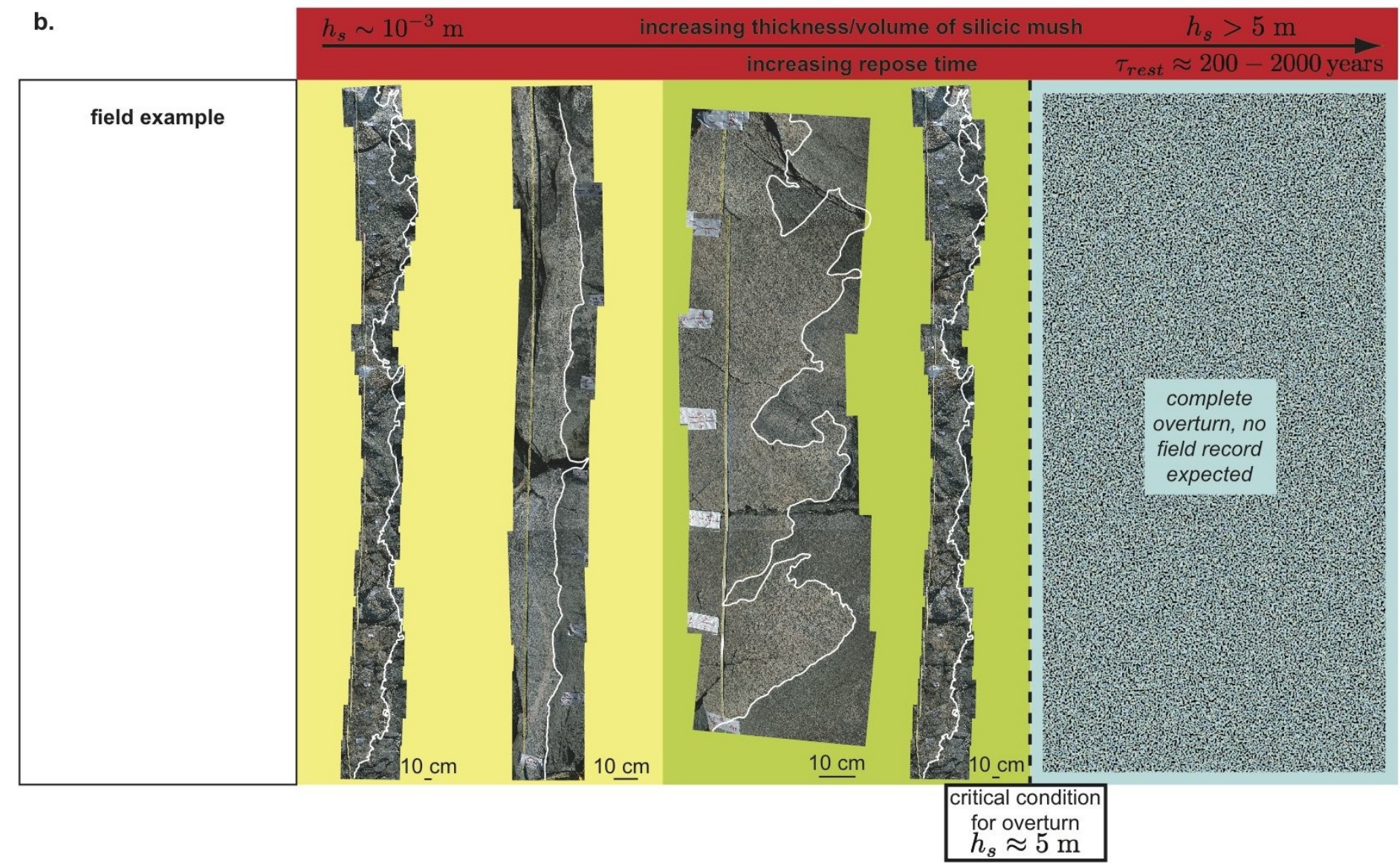

Figure 2.17: Field guide illustrating the timescales for melting, compaction and overturn, the dominant wavelengths expected (a) and the overall appearance (b) of a deformed mafic-silicic interface for a given set of initial conditions. This chart may be used to determine an appropriate viscosity ratio for a mafic-silicic interface based on the dominant wavelengths and layer thickness ratio observed in the field. 
interface to be dominated by wavelengths at small and intermediate scales. In the case where the silicic layer is thick relative to the basaltic layer $\left(h_{b} / h_{s} \sim 10^{-1}\right)$ and $\mu_{b} / \mu_{s}<1$, large-scale wavelengths related to the buoyant overturn of the silicic layer may develop immediately or within minutes of the injection of the mafic layer. The development of wavelengths related to the melting of the silicic layer will follow after $\sim 1$ hour, and those related to compaction will develop after several days. We expect the deformation of the interface to the dominated by the long-wavelength component of deformation in this case. In the case where $\mu_{b} / \mu_{s}>1$, the long wavelengths related to buoyant overturn of the silicic layer will develop first after $\sim 25$ mins, followed by short wavelengths related to melting $\sim 7$ hours and finally, intermediate wavelengths related to compaction $\sim 16$ hours. In this case again we expect the deformation of the mafic-silicic interface to develop at short, intermediate and large-scale wavelengths.

\subsubsection{Condition for complete overturning: a critical condition for eruption?}

To trigger a large eruption, mafic injection and thermal rejuvenation must induce a large-scale overturning event. However, the observed mafic-silicic interfaces represent events where the large-scale overturn of the buoyant silicic layer did not proceed to completion. In these instances, although the timescale for the onset of overturn was necessarily short relative to the time for cooling of the basaltic layer, upwelling probably ceased when the basalt became too cold to deform in an effectively viscous way and the upwelling silicic structures were consequently preserved. For the mafic layer to remain 


\subsection{Discussion}

hot enough to deform viscously so that an overturning event may proceed to completion, removing all the buoyant silicic material and destroying any evidence of the event, the timescale for overturn must therefore be much smaller than the timescale for cooling of the mafic layer. How thick must a silicic layer be in order to overturn completely? More generally, what is the critical condition for large-scale overturning that could lead to eruption?

Figure 2.18 shows the timescale for cooling of the mafic sheet and the timescale for overturn of the silicic layer for the range of observed silicic layer thicknesses and the inferred viscosity ratios. An absence of data for silicic layer thicknesses greater than $\sim 5$ m suggests a weakly-determined lower bound for the critical silicic layer thickness for (complete) overturn. This result suggests a dynamical criterion for overturn given by the intersection of solutions for $10^{-6} \tau_{c}$ and $\tau_{R T}$ at $h_{s_{c r i t}} \approx 5 \mathrm{~m}$, i.e. a critical Rayleigh number for overturn, which we define to be $R a_{o t} \equiv \tau_{c} / \tau_{R T}>10^{6}$. Thus, our results suggest that the silicic layer thickness $h_{s}$ must be at least $\mathrm{O}\left(10^{1}\right) \mathrm{m}$ in order for complete overturning to take place. If this condition is met, we expect no field record to be preserved (Figure 2.17).

Given that the Pleasant Bay layered intrusion, for example, is oval in plan view, measuring $12 \mathrm{~km}$ by $20 \mathrm{~km}$ across, we calculate what volume of silicic magma might be involved in such a complete overturning event. If we consider the maximum arial extent of a silicic layer to be $\mathrm{O}\left(10^{8}\right) \mathrm{m}^{2}$ based on the dimensions of this intrusion, the volume of overturning silicic magma during these events could be $\mathrm{O}(1) \mathrm{km}^{3}$ if $h_{s_{\text {crit }}} \approx 5 \mathrm{~m}$.

To grow a critical thickness of mush $h_{s_{c r i t}}$ that might overturn completely, a certain repose time between basaltic replenishments is presumably 


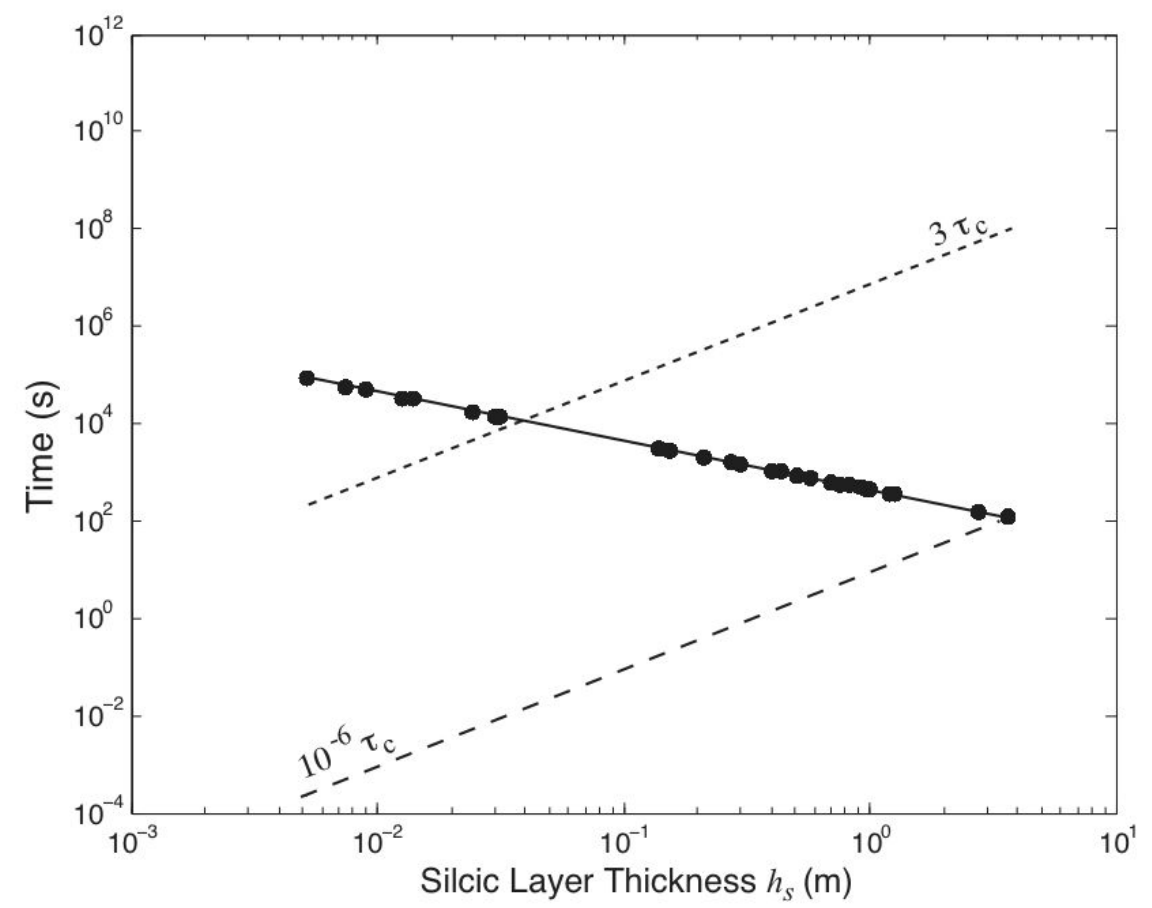

Figure 2.18: Comparison of the timescale for buoyant overturn of the silicic layer and the timescale for cooling of the mafic sheet for the observed range of $h_{s}$. The timescale for buoyant overturn is plotted for an effective viscosity ratio $\mu_{b} / \mu_{s}=10^{0}$ (solid line). Black circles are the predicted timescales for buoyant overturn of the 33 silicic layers we measured, arbitrarily plotted for the chosen effective viscosity ratio of $10^{0}$. The timescale $3 \tau_{c}$ corresponds to the limit in which the basalt stops deforming effectively viscously. The timescale $10^{-6} \tau_{c}$ is the critical timescale for complete overturning of the silicic layer, weakly determined by the absence of data above $h_{s} \approx 5 \mathrm{~m}$. 
necessary. If $h_{s_{\text {crit }}} \sim \mathrm{O}\left(10^{1}\right) \mathrm{m}$, then $d h_{s} / d t \sim q_{\text {out }} / \rho_{s} L(1-\phi)$ and the repose time is $\tau_{\text {rest }} \sim h_{s} \rho_{s} L(1-\phi) / q_{\text {out }}$, where $q_{\text {out }} \approx 10^{-1}-10^{0} \mathrm{~W} \cdot \mathrm{m}^{-2}$ is the heat flux out of the chamber. Thus, depending on the magnitude of the heat flux out of the chamber, the repose time $\tau_{\text {rest }}$ may vary between 200 and 2000 years.

\subsection{Conclusions}

Our work represents the first quantitative field constraints on the occurrence and evolution of rejuvenation events. Our results support a hypothesis that rejuvenation proceeds through melting of the silicic layer, compaction accompanied by explusion of interstitial liquid and overturning of the mafic-silicic layer before the basaltic layer becomes too cold to deform effectively viscously. The mafic-silicic interfaces we observe in the Pleasant Bay and Mount Desert island plutons represent instances where overturning did not proceed to completion. We propose a critical silicic layer thickness of $h_{s_{\text {crit }}} \approx 5 \mathrm{~m}$ for such an overturning event to proceed to completion. This condition may be a key precursor of large-scale eruptions. 


\section{Chapter 3}

\section{Concluding Remarks}

In this work, we have used detailed field observations from mafic-silicic layered intrusions, characterised with spectral analysis and compared with scaling theory to identify the role of three distinct physical processes active during the thermal rejuvenation of silicic crystal mushes by hotter, denser mafic magma. We have established that the thermal rejuvenation of mush layers is recorded by the development of (1) deformations at the scale of crystals related to the melting of the silicic layer; (2) deformations at the scale of the full thickness of the silicic layer due to buoyant overturn of the silicic layer and (3) deformations at intermediate scales due to the compaction of the silicic layer. For the first time, quantitative field observations on the lengthscales of deformation of crystal mush layers have been linked to the injection of mafic sheets. We have outlined how the evolution of rejuvenation may proceed and be recorded for a range of geometries and effective viscosity ratios. Finally, we have proposed a conservative condition for the minimum thickness of a silicic mush layer, which must be at least $h_{s_{c r i t}} \approx 5 \mathrm{~m}$ in order for complete overturning to occur. In addition, Figure 2.17 may be used as a field guide to the timescales for overturning, melting and compaction that may have occurred for the observed layer thickness ratio and dominant 
wavelengths.

Further research concerning the conditions under which overturning crystal mush layers can trigger chamber wide convection is needed. Future research directions building on this work might also include the evaluation of whether the timescales over which these processes operate are consistent with the inferred time lapse between mafic injection, as recorded by pre-eruptive seismicity, and eruption. 


\section{Bibliography}

[1] L. Steck, C. Thurber, M. Fehler, W. Lutter, P. Roberts, W. Baldridge, D. Stafford, and R. Sessions, "Crust and upper mantle P wave velocity structure beneath valles caldera, new mexico: Results from the jemez teleseismic tomography experiment," Journal of Geophysical ResearchSolid Earth, vol. 103, no. B10, 1998.

[2] D. Miller and R. Smith, "P and S velocity structure of the yellowstone volcanic field from local earthquake and controlled-source tomography," Journal of Geophysical Research-Solid Earth, vol. 104, no. B7, 1999.

[3] O. Bachmann and M. Dungan, "Temperature-induced Al-zoning in hornblendes of the Fish Canyon magma, Colorado," Am. Mineral., vol. 87, no. 8-9, pp. 1062-1076, 2002.

[4] D. Wark, W. Hildreth, F. Spear, D. Cherniak, and E. Watson, "Preeruption recharge of the Bishop magma system," Geol., vol. 35, no. 3, pp. 235-238, 2007.

[5] G. Mahood, "Second reply to comment of RSJ Sparks, HE Huppert and CJN Wilson on "Evidence for long residence times of rhyolitic magma in the Long Valley magmatic system: the isotopic record in the 
precaldera lavas of Glass Mountain"," Earth Planet. Sci. Lett., vol. 99, pp. 395-399, 1990.

[6] J. Keller, "Origin of rhyolites by anatectic melting of granitic crustal rocks," Bull. Volc., vol. 33, no. 3, pp. 942-959, 1969.

[7] J. Wolff and J. Gardner, "Is the Valles caldera entering a new cycle of activity?," Geology, vol. 23, no. 5, pp. 411-414, 1995.

[8] S. Couch, R. Sparks, and M. Carroll, "Mineral disequilibrium in lavas explained by convective self-mixing in open magma chambers," Nature, vol. 411, no. 6841, pp. 1037-1039, 2001.

[9] M. Murphy, R. Sparks, J. Barclay, M. Carroll, and T. Brewer, "Remobilization of andesite magma by intrusion of mafic magma at the Soufriere Hills volcano, Montserrat, West Indies," J. Petrol., vol. 41, no. 1, pp. 21-42, 2000.

[10] O. Bachmann, M. Dungan, and P. Lipman, "The Fish Canyon magma body, San Juan volcanic field, Colorado: rejuvenation and eruption of an upper-crustal batholith," J. Petrol., vol. 43, no. 8, pp. 1469-1503, 2002.

[11] E. Endo, S. Malone, L. Noson, and C. Weaver, "Locations, magnitudes, and statistics of the March 20-May 18 earthquake sequence," Geological Survey professional paper, p. 93, 1988.

[12] D. Harlow, J. Power, E. Laguerta, G. Ambubuyog, R. White, and R. Hoblitt, "Precursory seismicity and forecasting of the June 15, 1991, 
eruption of Mount Pinatubo," Fire and Mud, Eruptions and Lahars of Mount Pinatubo, Philippines, pp. 285-306, 1996.

[13] C. Gilbert, "Welded tuff in eastern California," Bull. Geol. Soc. Am., vol. 49, no. 9/12, pp. 1829-1861, 1938.

[14] P. Lipman, T. Steven, and H. Mehnert, "Volcanic history of the San Juan mountains, Colorado, as indicated by potassium-argon dating," Bull. Geol. Soc. Am., vol. 81, no. 8, p. 2329, 1970.

[15] A. Anderson, "Hourglass inclusions: Theory and application to the Bishop Rhyolitic Tuff," Am. Mineral., vol. 76, pp. 530-547, 1991.

[16] C. Bacon, "Magmatic inclusions in silicic and intermediate volcanic rocks," J Geophys Res-Solid, vol. 91, no. B6, pp. 6091-6112, 1986.

[17] R. Wiebe, "The Pleasant Bay layered gabbro-diorite, Coastal Maine: Ponding and crystallization of basaltic injections into a silicic magma chamber," J. Petrol., vol. 34, no. 3, pp. 461-489, 1993.

[18] R. Wiebe and W. Collins, "Depositional features and stratigraphic sections in granitic plutons: implications for the emplacement and crystallization of granitic magma," J. Struct. Geol., vol. 20, no. 9-10, pp. 1273$1289,1998$.

[19] R. Wiebe, "Silicic magma chambers as traps for basaltic magmas: the Cadillac Mountain intrusive complex, Mount Desert Island, Maine," J. Geol., vol. 102, pp. 423-437, 1994. 
[20] T. Sisson, T. Grove, and D. Coleman, "Hornblende gabbro sill complex at Onion Valley, California, and a mixing origin for the Sierra Nevada batholith," Contrib. Mineral. Petrol., vol. 126, no. 1, pp. 81-108, 1996.

[21] C. Miller and J. Miller, "Contrasting stratified plutons exposed in tilt blocks, Eldorado Mountains, Colorado River rift, NV, USA," Lithos, vol. 61, no. 3-4, pp. 209-224, 2002.

[22] R. Sparks, H. Sigurdsson, and L. Wilson, "Magma mixing: a mechanism for triggering acid explosive eruptions," Nature, vol. 267, pp. 315-318, 1977.

[23] J. Pallister, R. Hoblitt, and A. Reyes, "A basalt trigger for the 1991 eruptions of Pinatubo volcano?," Nature, vol. 356, no. 6368, pp. 426428, 1992.

[24] J. Eichelberger, "Silicic volcanism: Ascent of viscous magmas from crustal reservoirs," Annual Review of Earth and Planetary Sciences, vol. 23, pp. 41-63, 1995.

[25] O. Bachmann and G. Bergantz, "Rejuvenation of the Fish Canyon magma body: A window into the evolution of large-volume silicic magma systems," Geology, vol. 31, no. 9, pp. 789-792, 2003.

[26] A. Jellinek and R. Kerr, "Mixing and compositional stratification produced by natural convection 2. Applications to the differentiation of basaltic and silicic magma chambers and komatiite lava flows," J. Geophys. Res, vol. 104, pp. 7203-7218, 1999. 
[27] D. Snyder and S. Tait, "Magma mixing by convective entrainment," Nature, vol. 379, pp. 529-531, 1996.

[28] C. Huber, O. Bachmann, and M. Manga, "Two competing effects of volatiles on heat transfer in crystal-rich magmas: Thermal insulation vs defrosting," J.Petrol., 2010.

[29] R. Wiebe, "Basaltic injections into floored silicic magma chambers," Eos Trans. AGU, vol. 1, no. 74, p. 1, 1993.

[30] R. Wiebe, "Late-stage mafic injection and thermal rejuvenation of the Vinalhaven granite, Coastal Maine," J. Petrol., vol. 45, no. 11, pp. 2133-2153, 2004.

[31] D. Hawkins and R. Wiebe, "Discrete stoping events in granite plutons: A signature of eruptions from silicic magma chambers?," Geology, vol. 32, no. 12, pp. 1021-1024, 2004.

[32] S. Seaman, R. Wobus, R. Wiebe, N. Lubick, and S. Bowring, "Volcanic expression of bimodal magmatism: the Cranberry Island-Cadillac Mountain Complex, coastal Maine," J. Geol., vol. 103, pp. 301-311, 1995.

[33] R. Wiebe, "Coexisting intermediate and basic magmas, Ingonish, Cape Breton Island," J. Geol., vol. 82, pp. 74-87, 1974.

[34] C. Falkner, C. Miller, J. Wooden, and M. Heizler, "Petrogenesis and tectonic significance of the calc-alkaline, bimodal Aztec Wash pluton, 
Eldorado Mountains, Colorado River extensional corridor.," J. Geophys. Res., vol. 100, pp. 10,453-10,476, 1995.

[35] C. Bachl, C. Miller, J. Miller, and J. Faulds, "Construction of a pluton: Evidence from an exposed cross section of the Searchlight pluton, Eldorado Mountains, Nevada," Bull. Geol. Soc. Am., vol. 113, no. 9, pp. 1213-1228, 2001.

[36] R. Wiebe, K. Blair, D. Hawkins, and C. Sabine, "Mafic injections, in situ hybridization, and crystal accumulation in the Pyramid Peak granite, California," Bull. Geol. Soc. Am., vol. 114, no. 7, pp. 909-920, 2002.

[37] J. Lindline, W. Crawford, and M. Crawford, "A bimodal volcanicplutonic system: the Zarembo Island extrusive suite and the Burnett Inlet intrusive complex," Can. J. Earth Sci., vol. 41, no. 4, pp. 355-375, 2004.

[38] J. Pons, P. Barbey, H. Nachit, and J. Burg, "Development of igneous layering during growth of pluton: The Tarçouate Laccolith (Morocco)," Tectonophysics, vol. 413, no. 3-4, pp. 271-286, 2006.

[39] W. Collins, R. Wiebe, B. Healy, and S. Richards, "Replenishment, crystal accumulation and floor aggradation in the megacrystic Kameruka Suite, Australia," J. Petrol., vol. 47, no. 11, pp. 2073-2104, 2006.

[40] J. Lister and R. Kerr, "The effect of geometry on the gravitational instability of a buoyant region of viscous fluid," J. Fluid Mech., vol. 202, no. 4, pp. 577-594, 1989. 
[41] R. Kerr, "Melting driven by vigorous compositional convection," $J$. Fluid Mech., vol. 280, pp. 255-285, Jan 2006.

[42] A. Jellinek and R. Kerr, "Magma dynamics, crystallization, and chemical differentiation of the 1959 Kilauea Iki lava lake, Hawaii, revisited," J Volcanol Geoth Res, vol. 110, no. 3-4, pp. 235-263, 2001.

[43] A. Jellinek and D. Depaolo, "A model for the origin of large silicic magma chambers: precursors of caldera-forming eruptions," Bull. Volcanol., vol. 65, no. 5, pp. 363-381, 2003.

[44] D. Martin, R. Griffiths, and I. Campbell, "Compositional and thermal convection in magma chambers," Contrib. Mineral. Petrol., vol. 96, pp. 465-475, Jan 1987.

[45] W. Moore, "Heat transport in a convecting layer heated from within and below," J. geophys. Res, vol. 113, 2008.

[46] J. Niemela, L. Skrbek, K. Sreenivasan, and R. Donnelly, "Turbulent convection at very high rayleigh numbers," Nature, vol. 404, no. 6780, pp. 837-840, 2000.

[47] J. Turner, "Buoyancy effects in fluids," 1980.

[48] F. Busse, "Fundamentals of thermal convection," Mantle convection: plate tectonics and global dynamics, vol. 2395, 1989.

[49] D. McKenzie, "The generation and compaction of partially molten rock," Journal of Petrology, vol. 25, no. 3, p. 713, 1984. 
[50] F. Dullien, "Porous media: fluid transport and pore structure," 1992.

[51] T. Scott and D. Kohlstedt, "The effect of large melt fraction on the deformation behavior of peridotite," Earth and Planetary Science Letters, vol. 246, no. 3-4, pp. 177-187, 2006.

[52] A. Davaille and C. Jaupart, "Onset of thermal convection in fluids with temperature-dependent viscosity: Application to the oceanic mantle," J. of Geophys. Res.-Solid Earth, vol. 99, no. B10, 1994.

[53] H. Huppert and R. Sparks, "The generation of granitic magmas by intrusion of basalt into continental crust," J. Petrol., vol. 29, no. 3, pp. 599-624, 1988.

[54] R. Roscoe, "The viscosity of suspensions of rigid spheres," British Journal of Applied Physics, vol. 3, p. 267, 1952.

[55] P. Welch, "The use of fast Fourier transform for the estimation of power spectra: a method based on time averaging over short, modified periodograms," IEEE Transactions on Audio and Electroacoustics, vol. 15, no. 2, pp. 70-73, 1967.

[56] P. Olson and H. Singer, "Creeping plumes," J. Fluid Mech., vol. 158, pp. 511-531, 1985.

[57] J. Whitehead and D. Luther, "Dynamics of laboratory diapir and plume models," J. Geophys. Res., vol. 80, no. 5, pp. 705-717, 1975.

[58] A. Jellinek and M. Manga, "Links between long-lived hot spots, mantle plumes, D", and plate tectonics," Rev. Geophys, vol. 42, no. 3, 2004. 
[59] V. Thayalan, A. Jellinek, and A. Lenardic, "Recycling the lid: Effects of subduction and stirring on boundary layer dynamics in bottom-heated planetary mantle convection," Geophys. Res. Lett., vol. 33, no. 20, p. L20318, 2006. 


\section{Appendix A}

\section{Field Data}

This appendix contains the 33 photomosaic used in the study, with the accompanying non-differenced and difference power spectra. The maficsilicic interface is indicated in red in each photomosaic. 

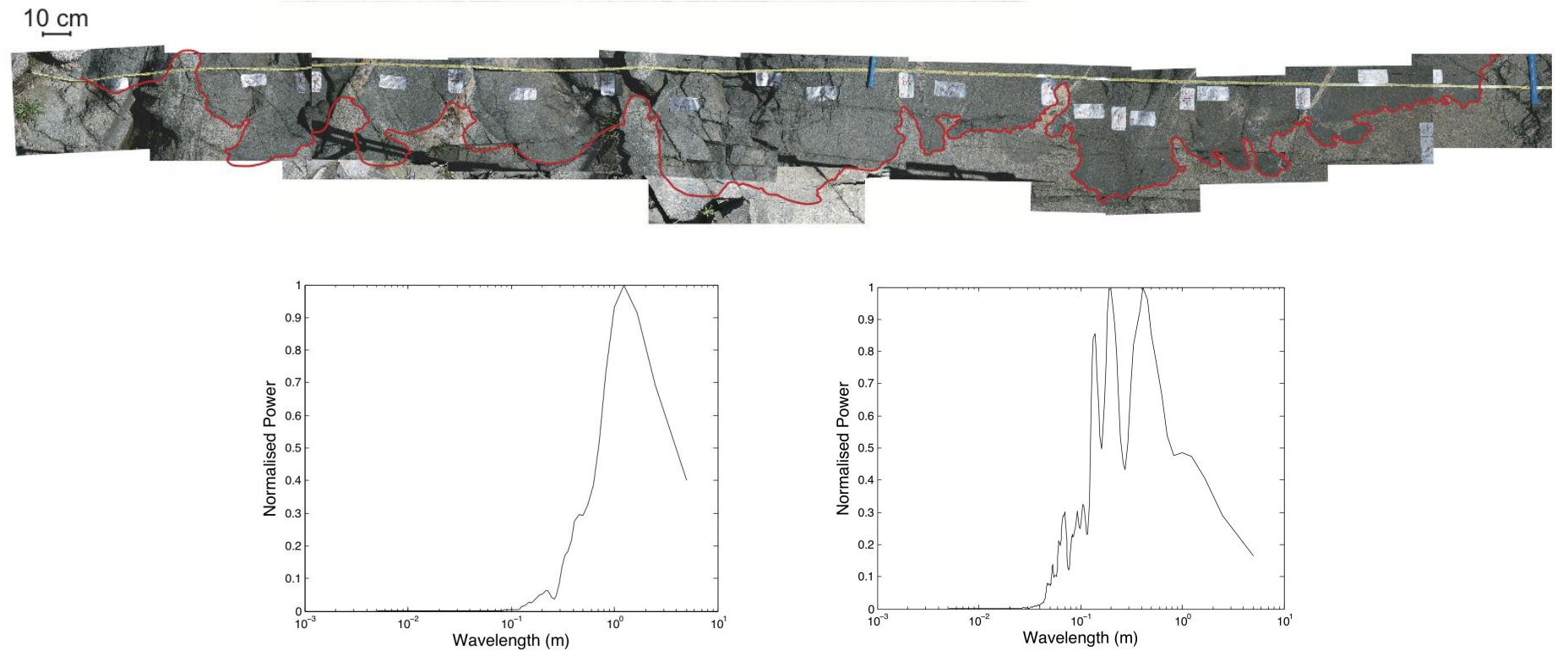

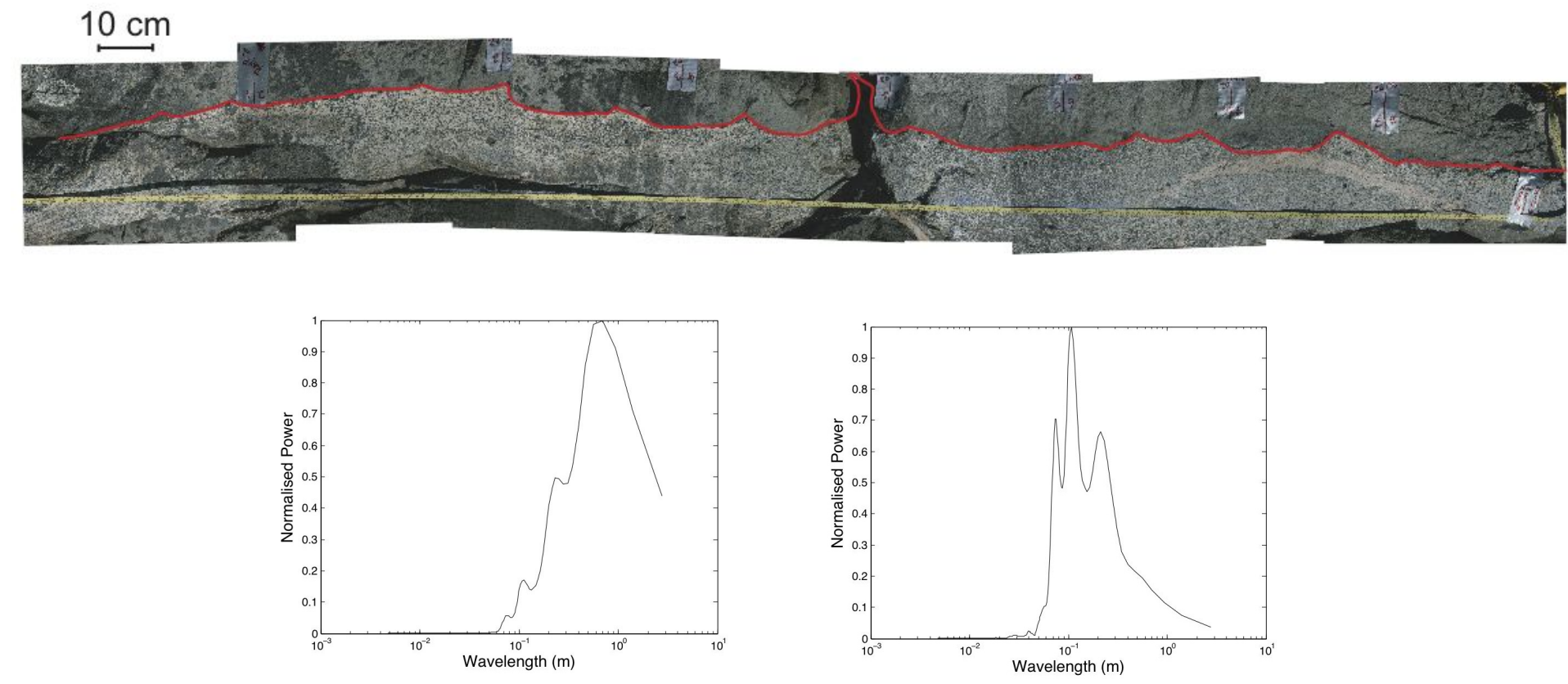

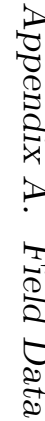



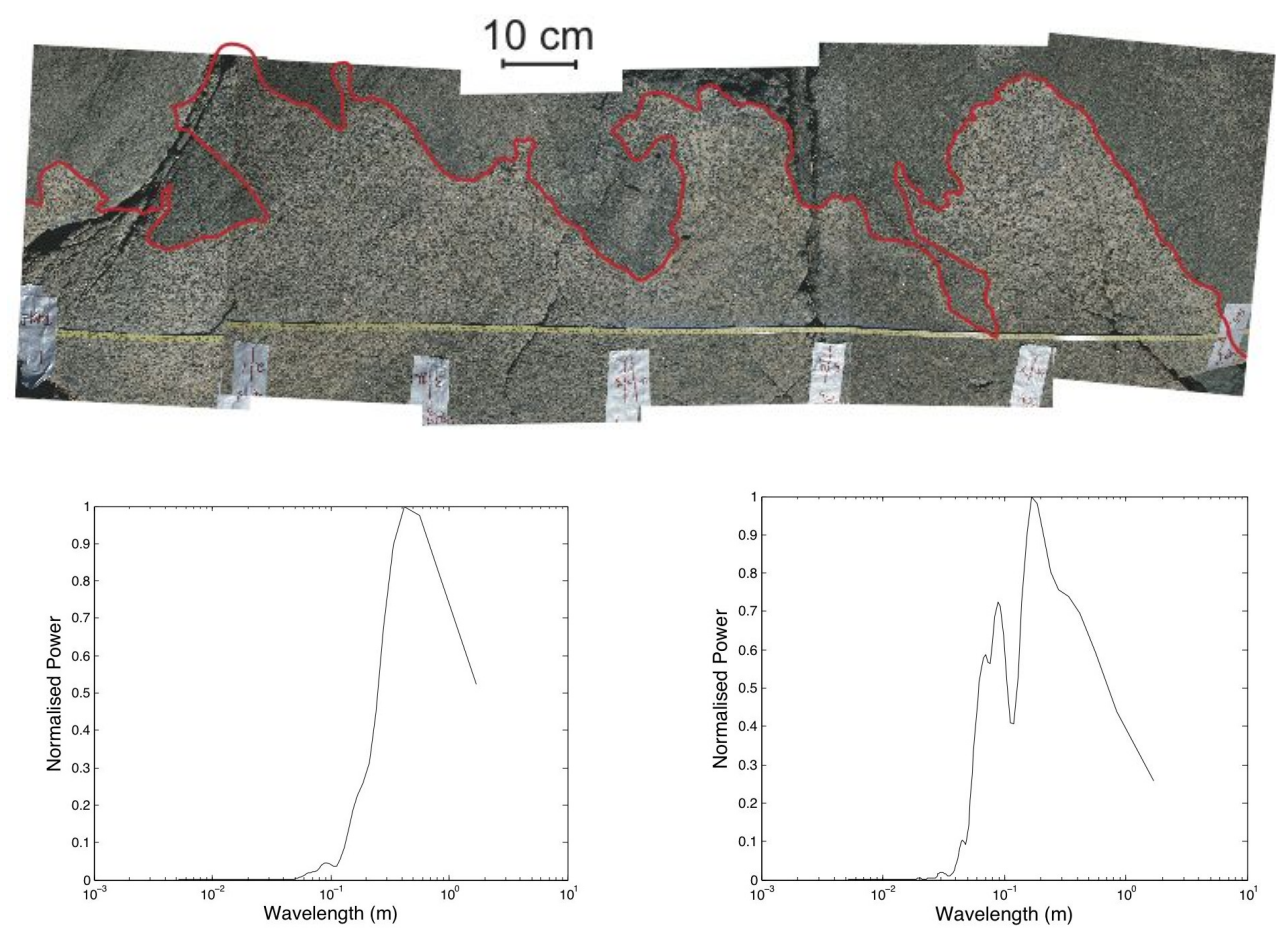

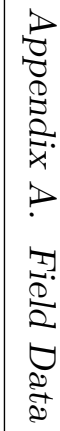

Interface 3: Ray Point, Maine (Pleasant Bay) 

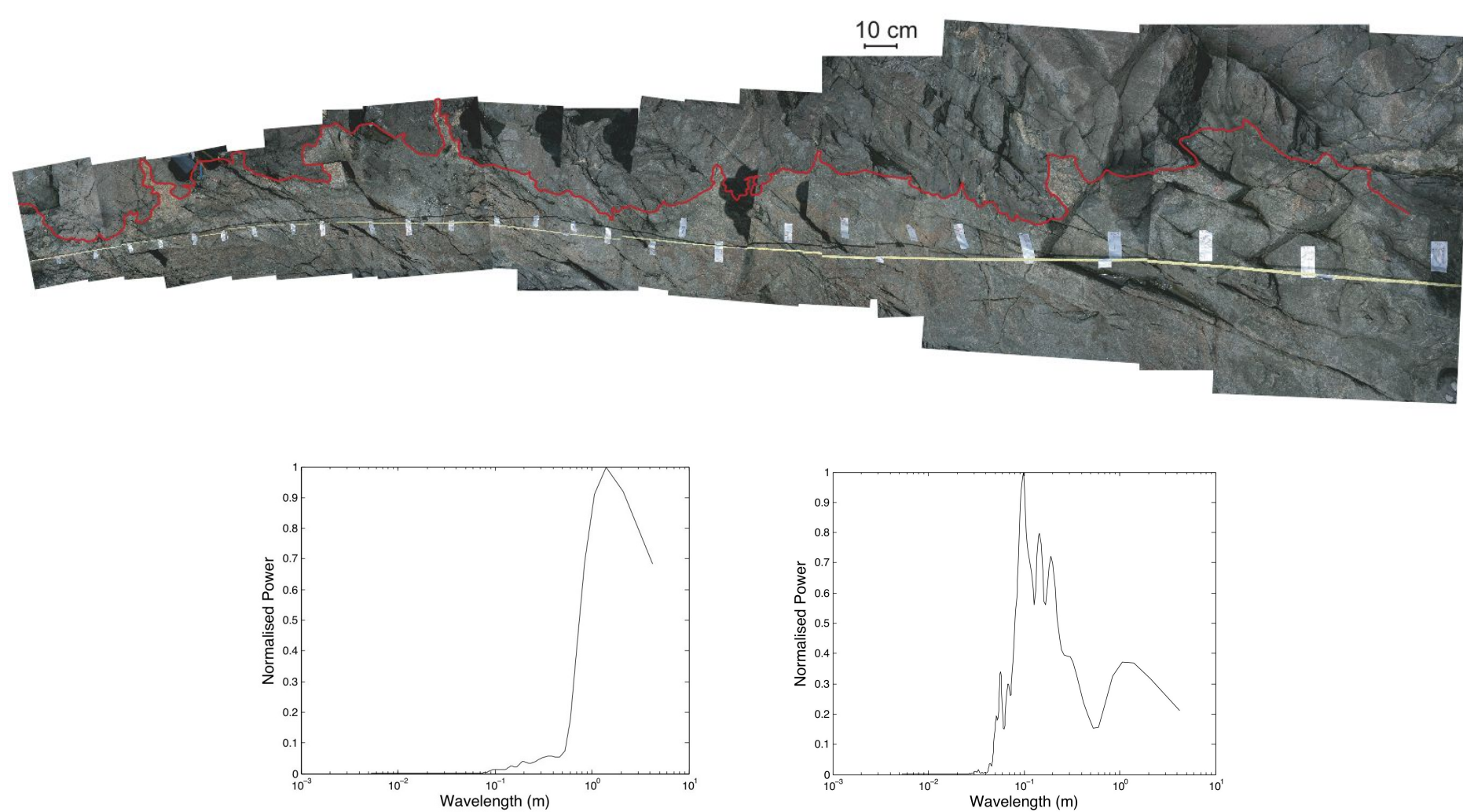

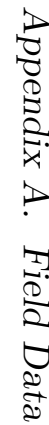




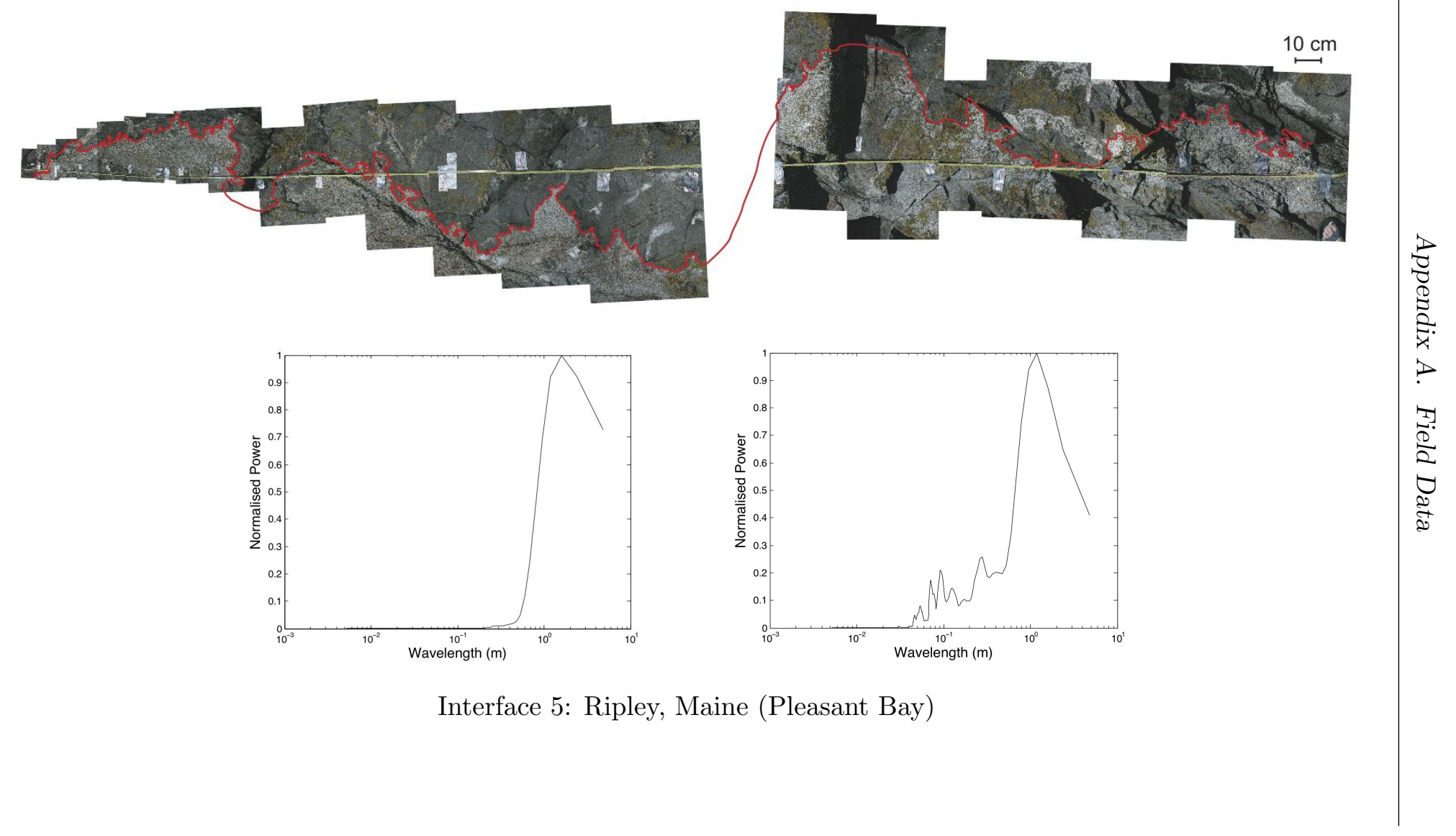



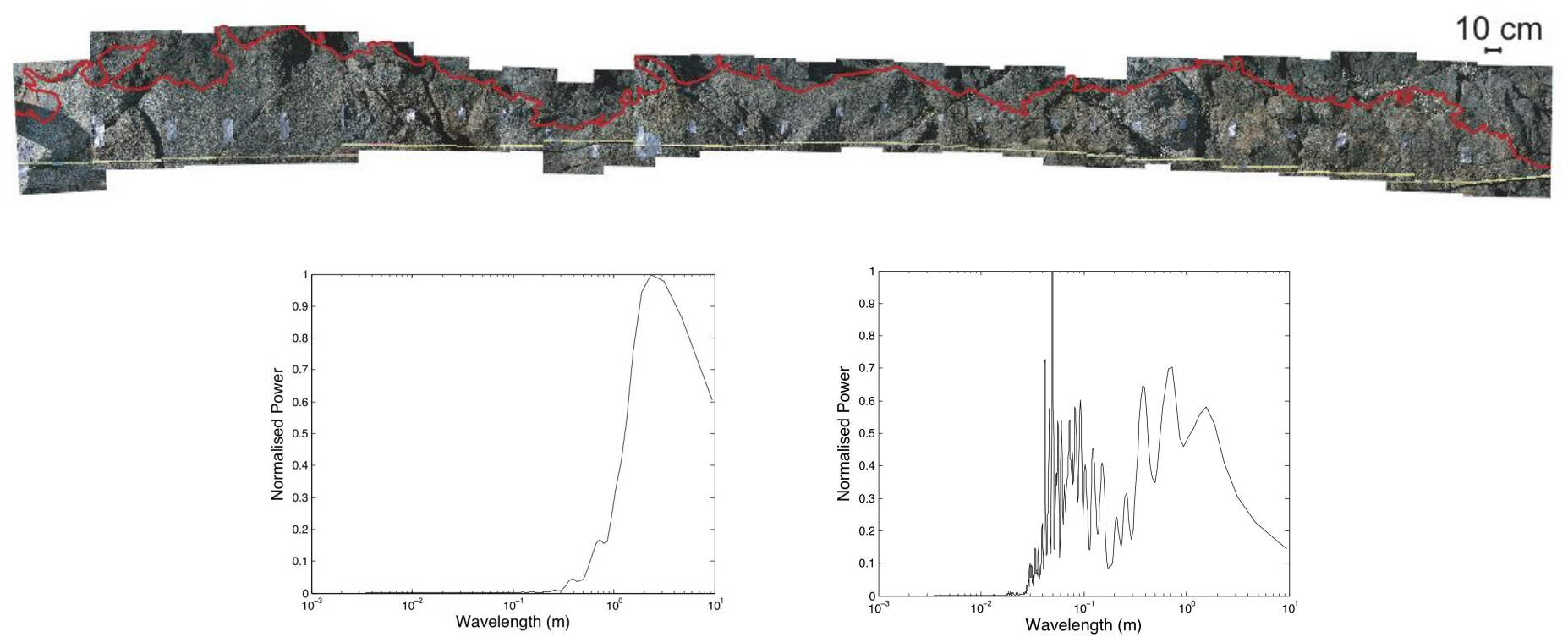

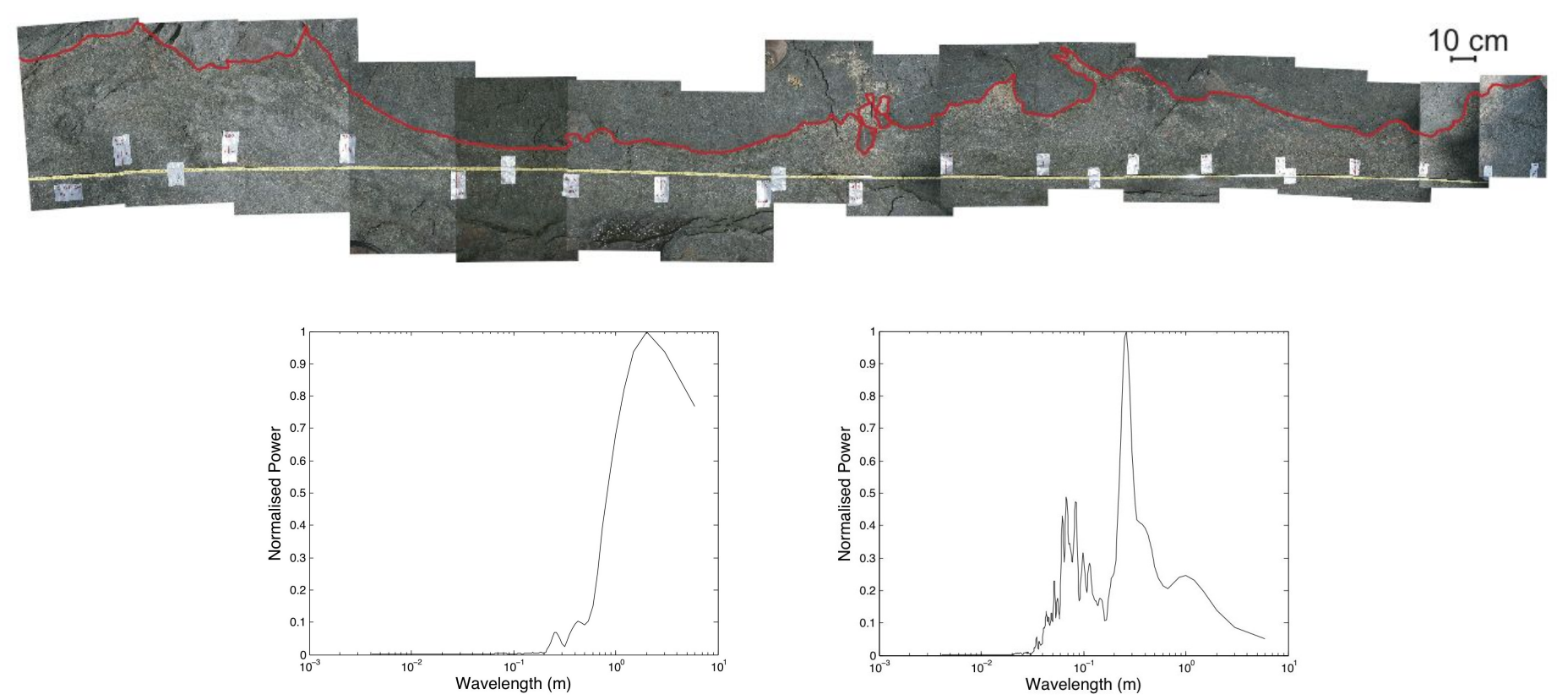


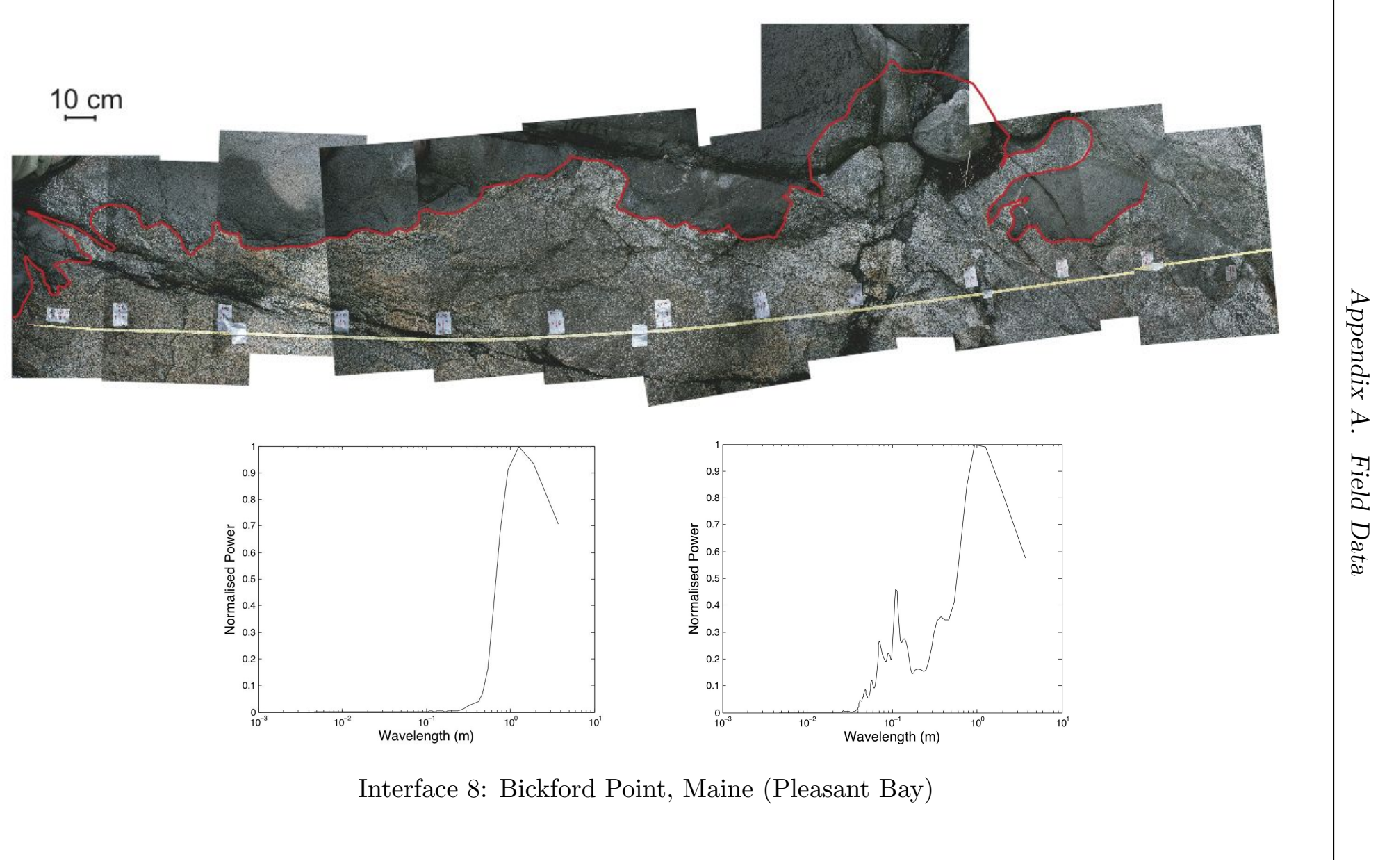



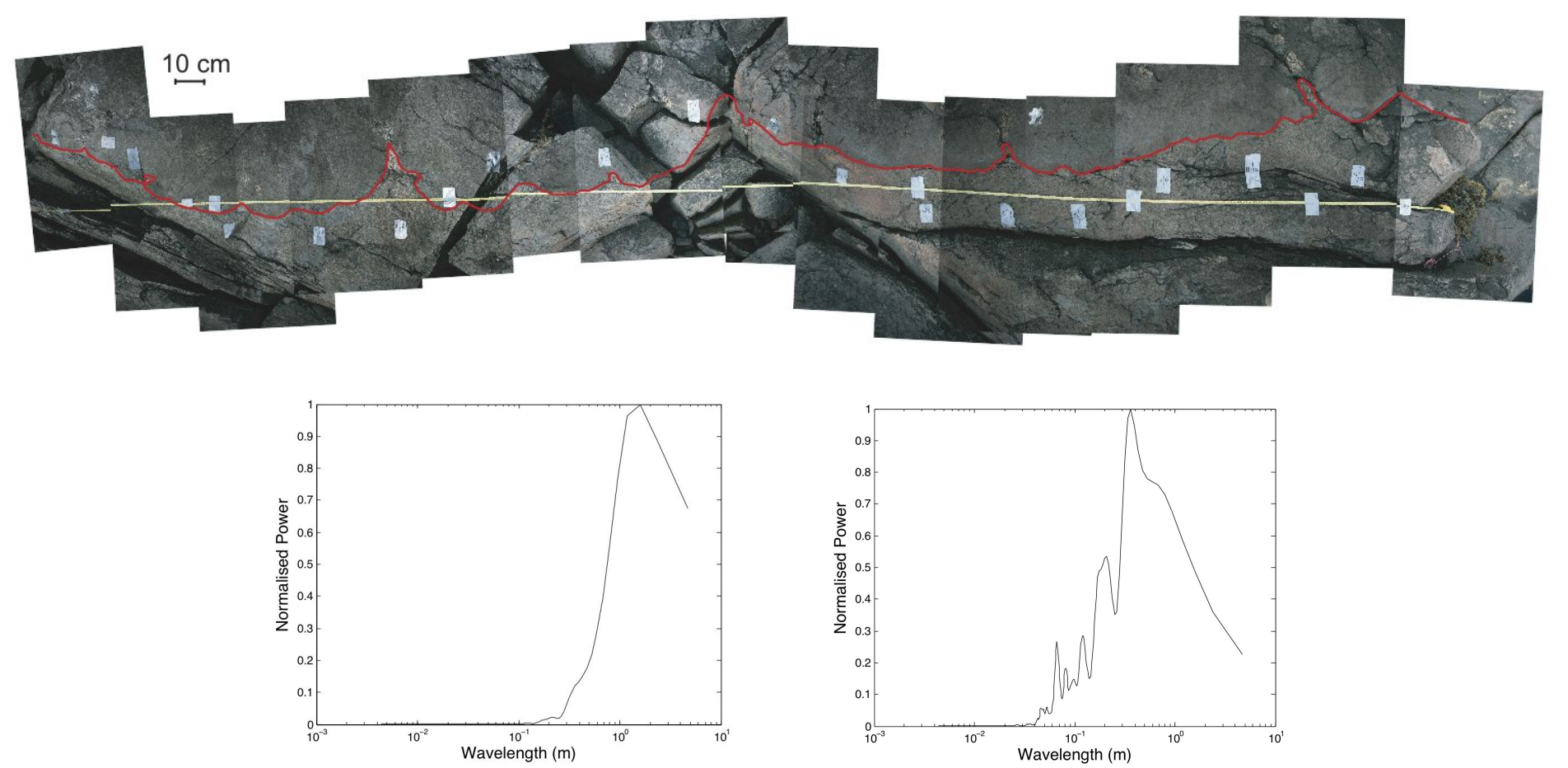

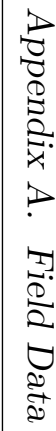




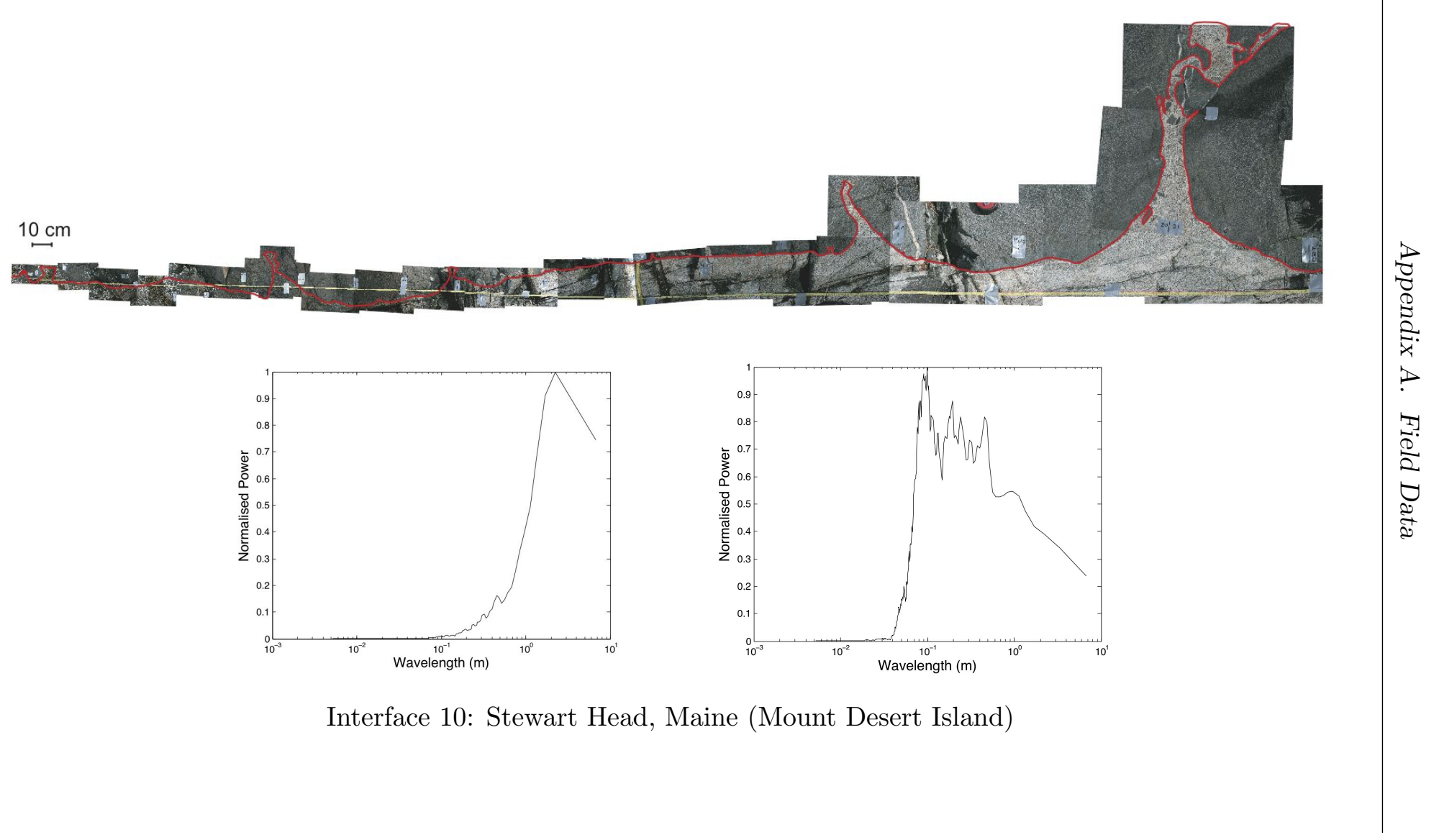



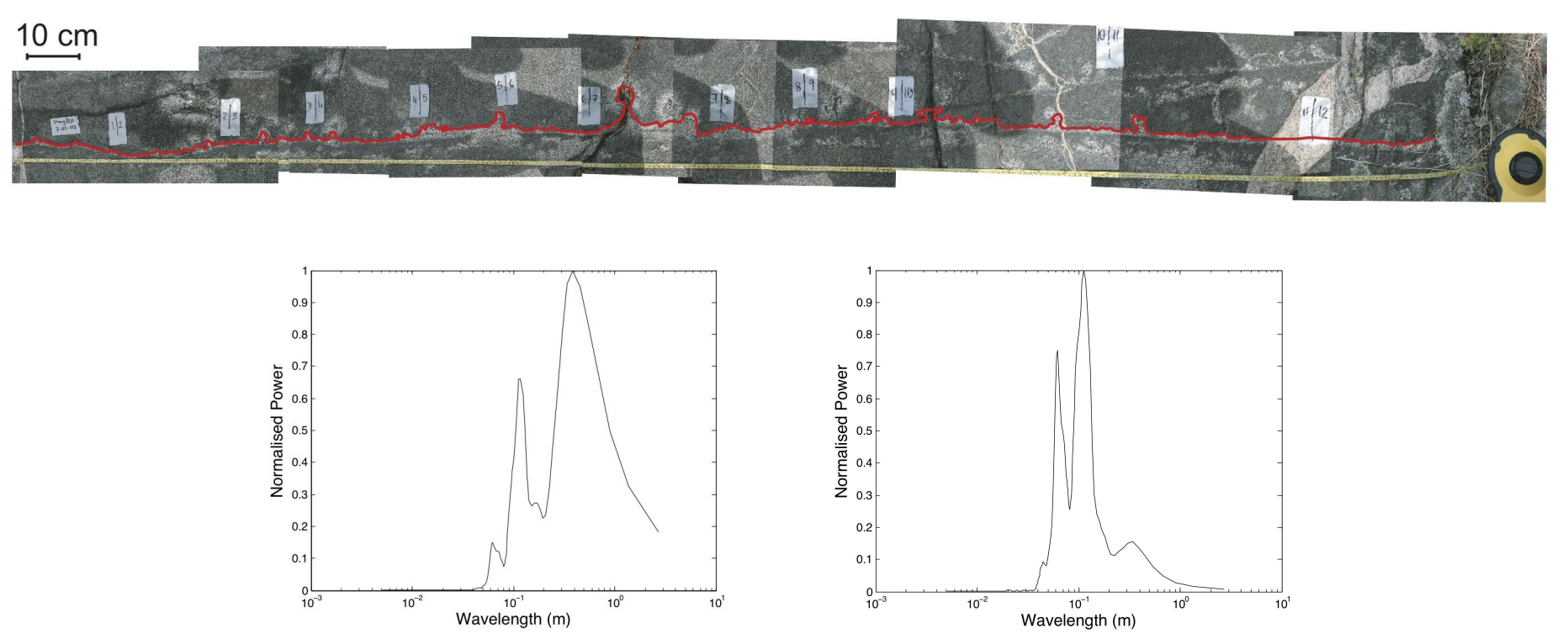

Interface 11: Stewart Head, Maine (Mount Desert Island) 

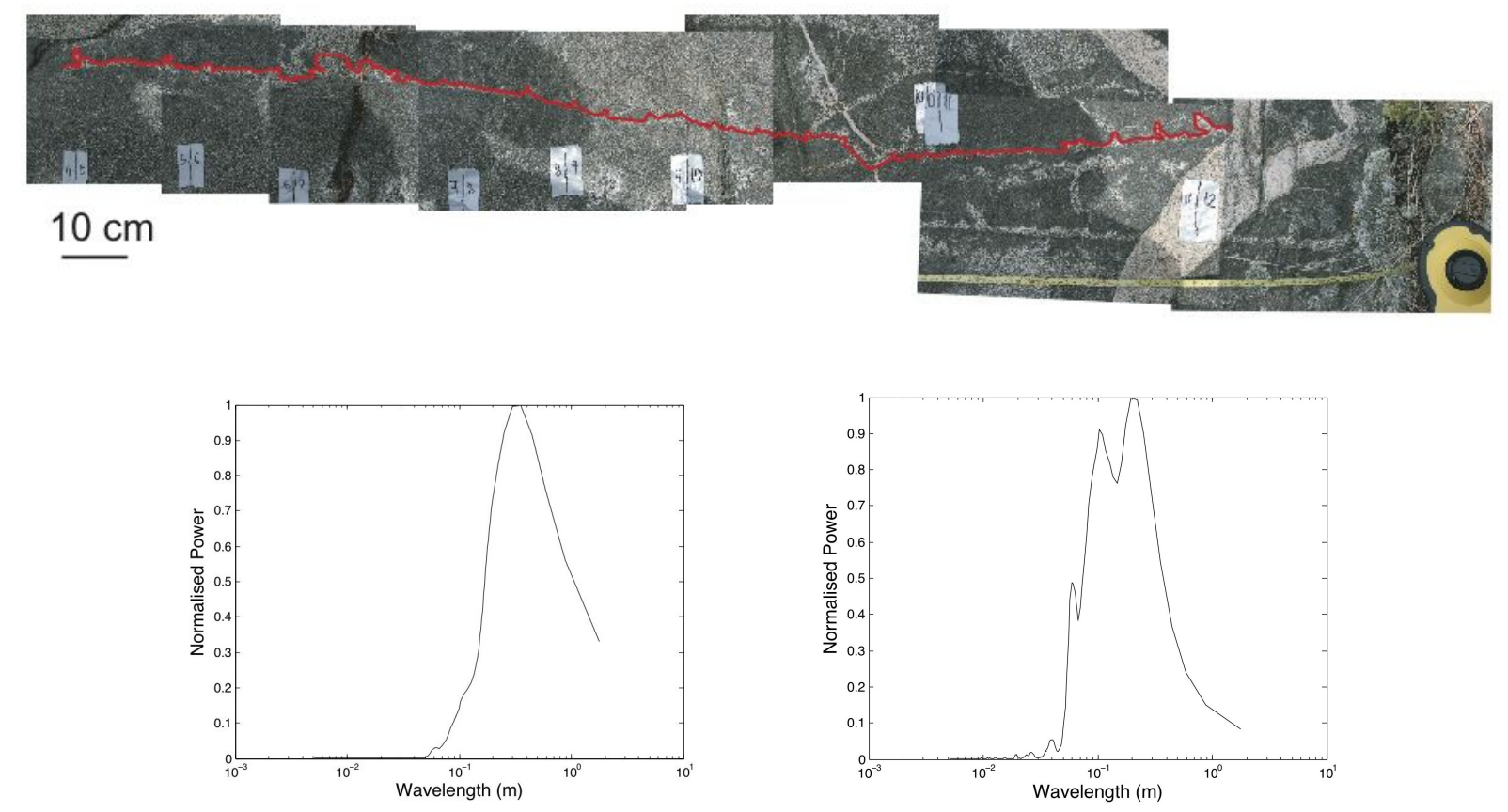

Interface 12: Stewart Head, Maine (Mount Desert Island) 

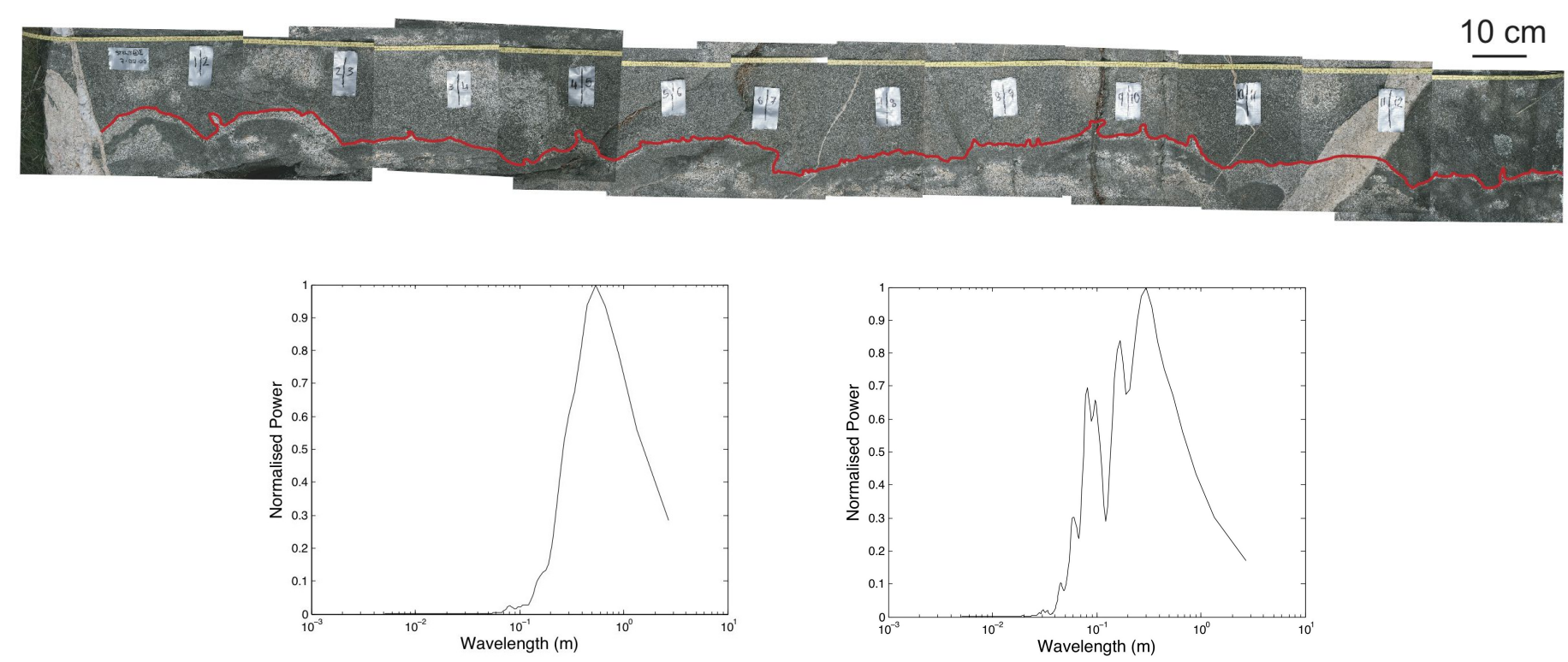

Interface 13: Stewart Head, Maine (Mount Desert Island) 

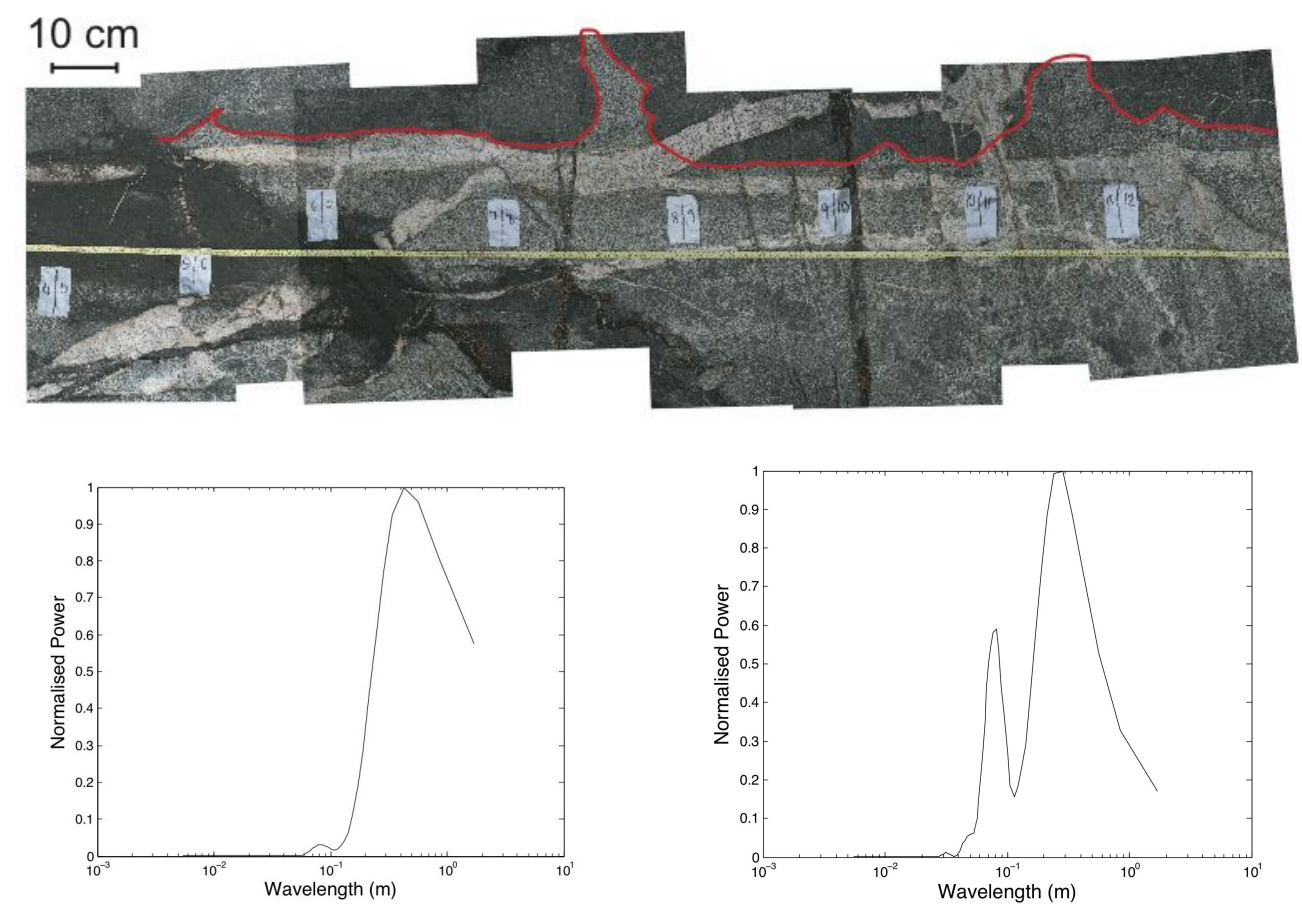

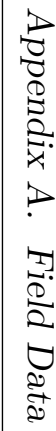

Interface 14: Stewart Head, Maine (Mount Desert Island) 


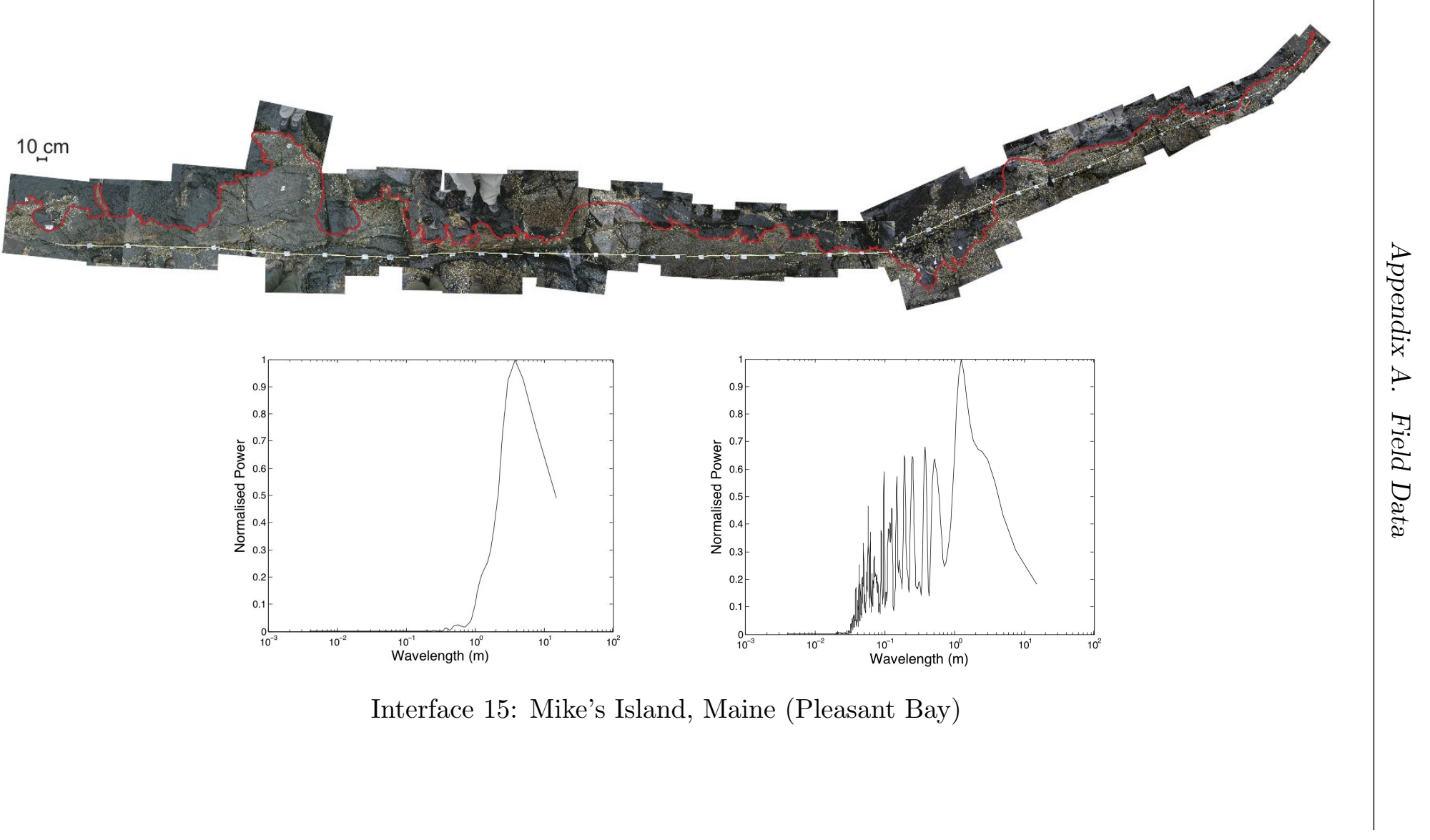



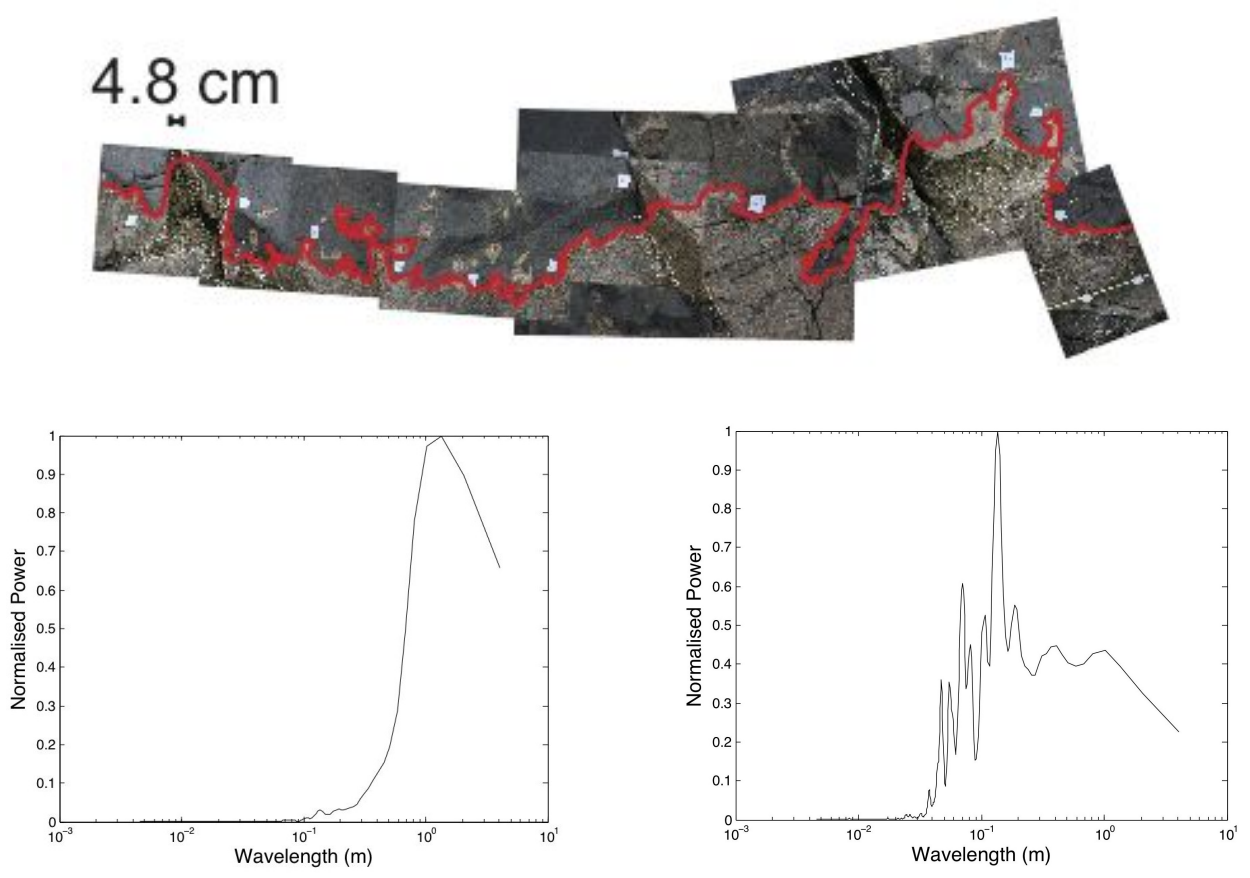

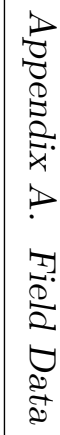




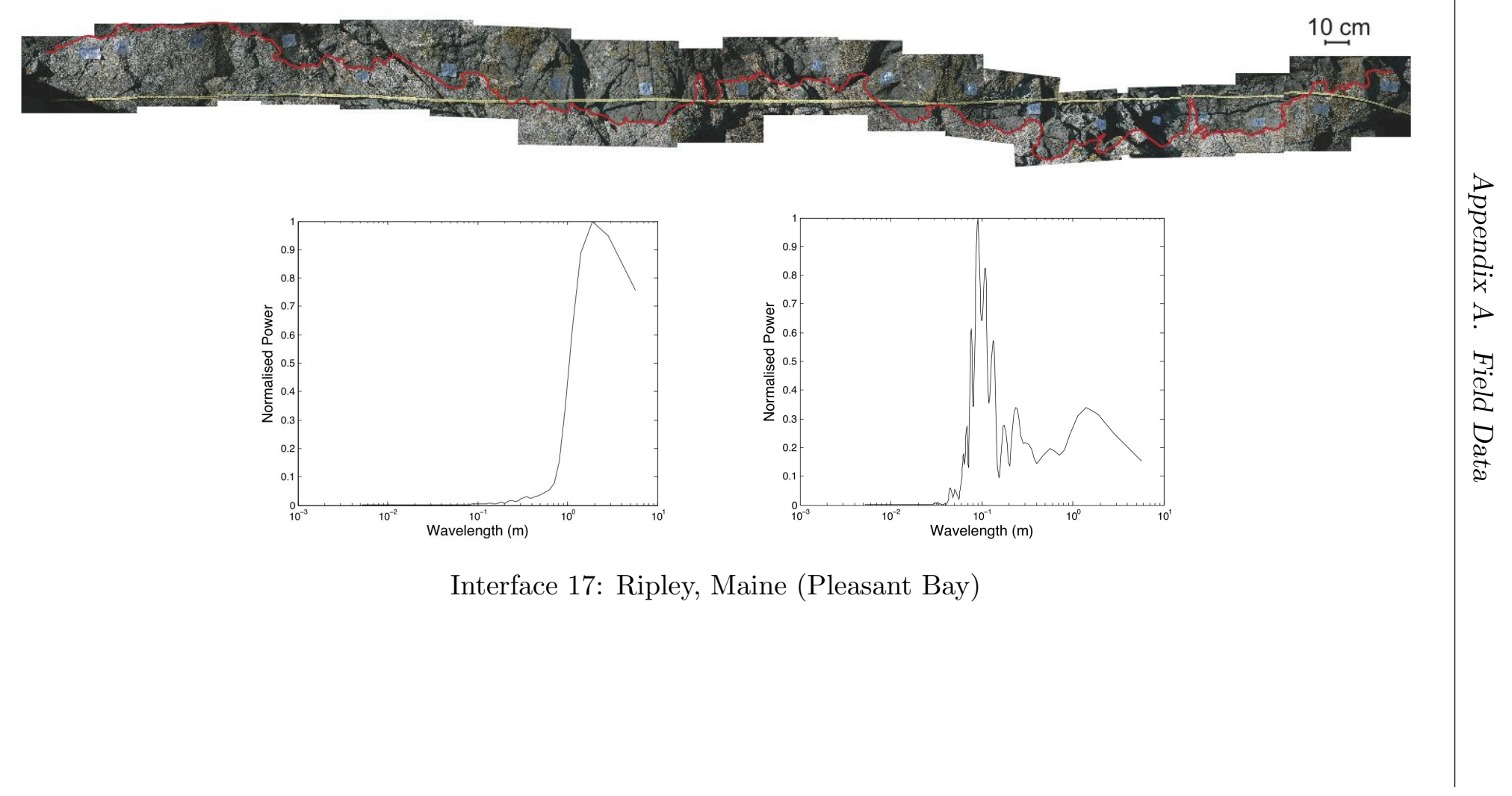



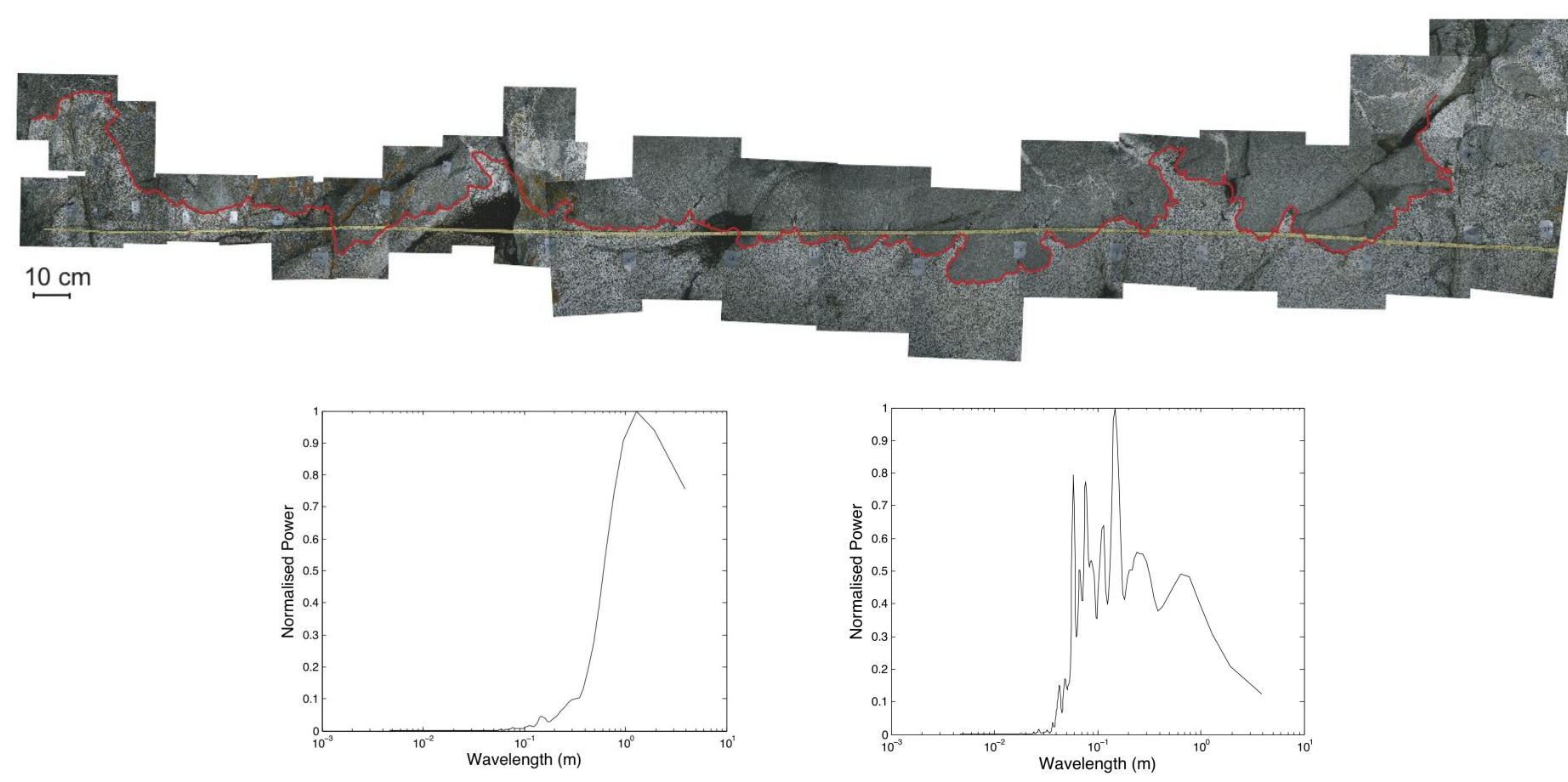


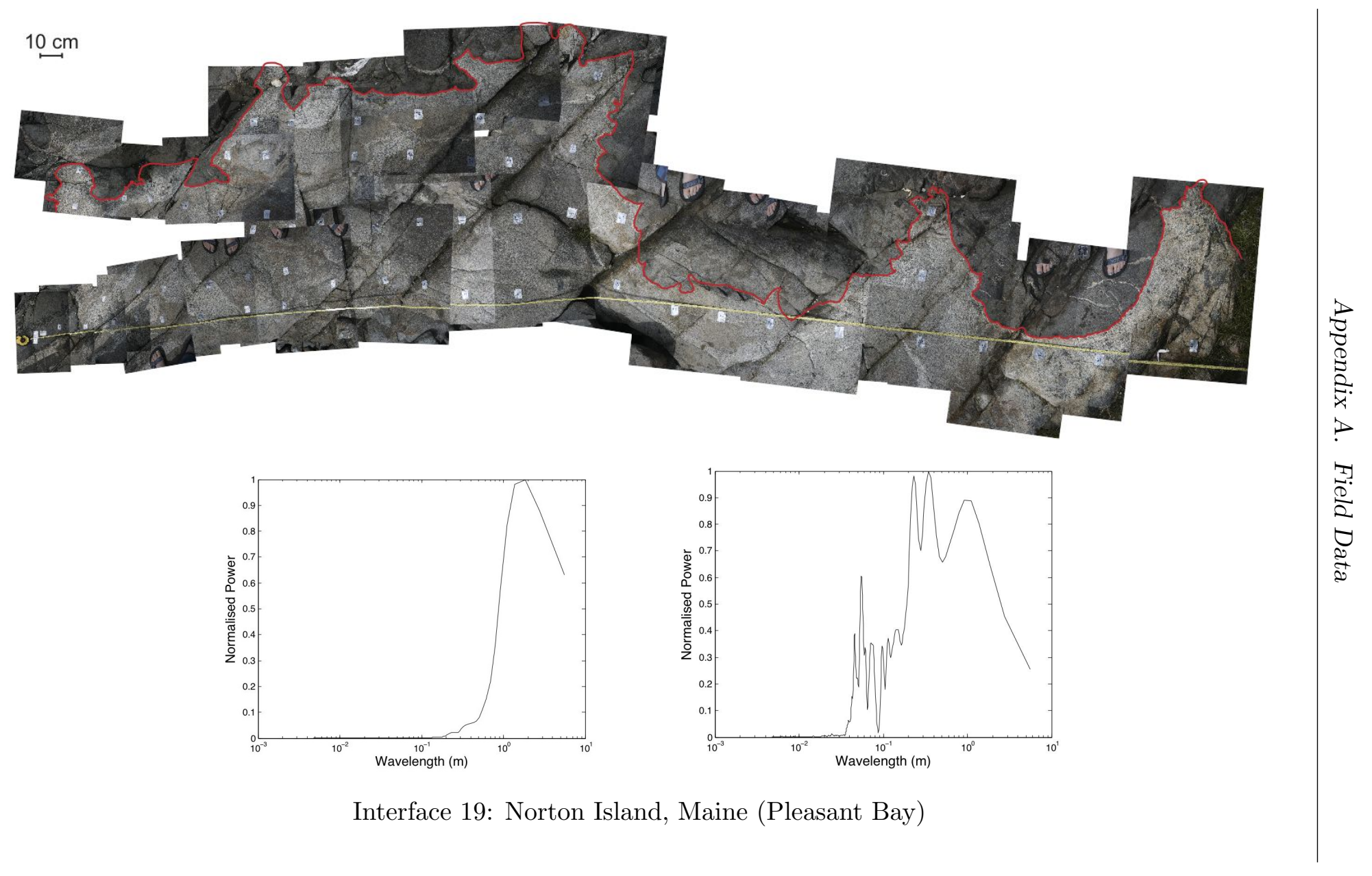



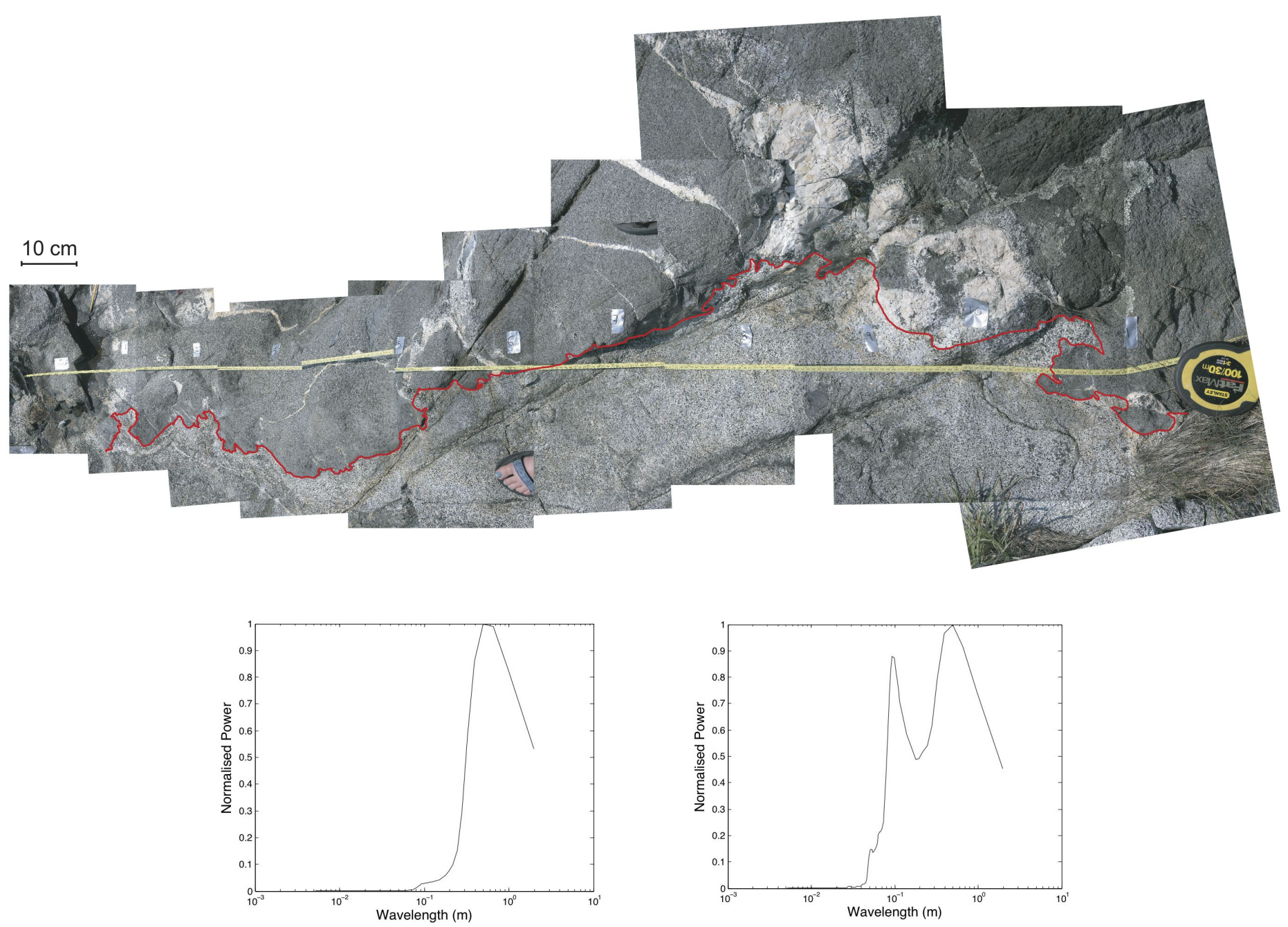

Interface 20: Norton Island, Maine (Pleasant Bay) 

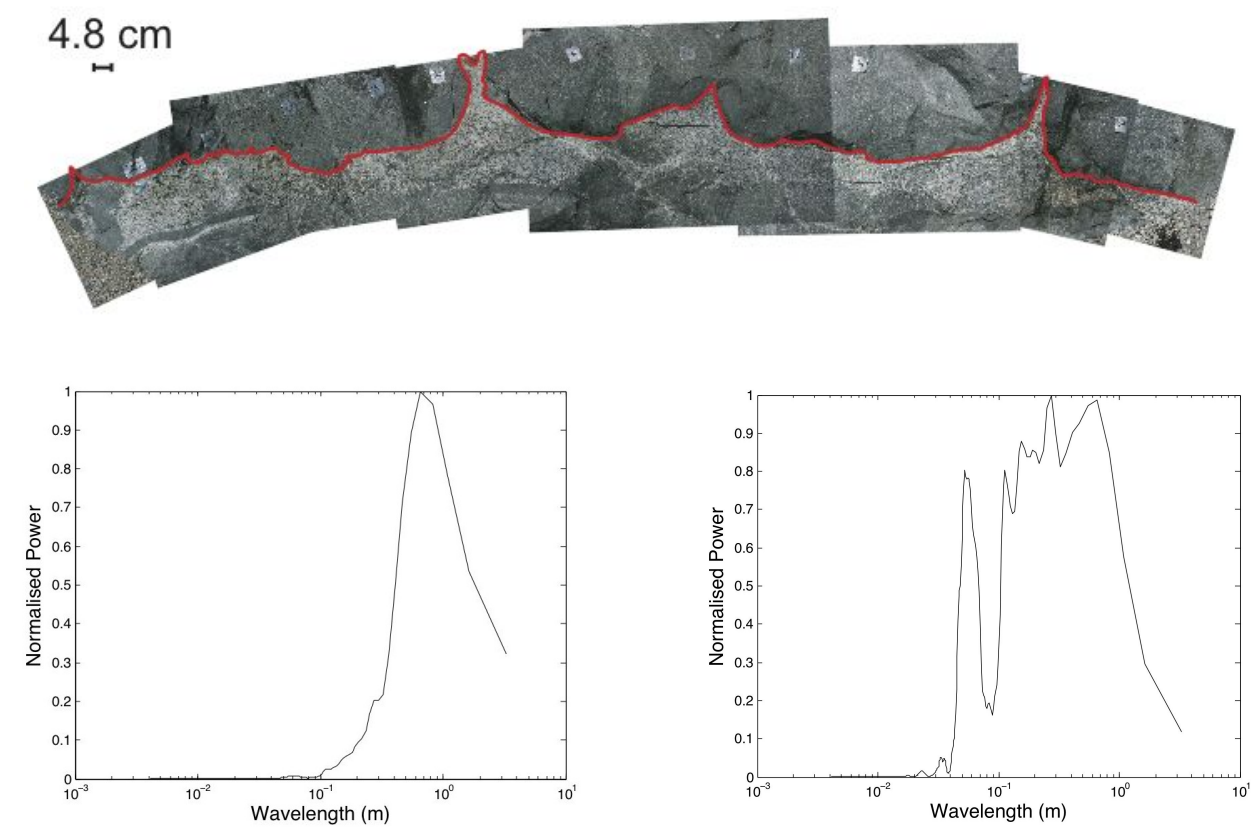

Interface 21: Stewart Head, Maine (Mount Desert Island) 

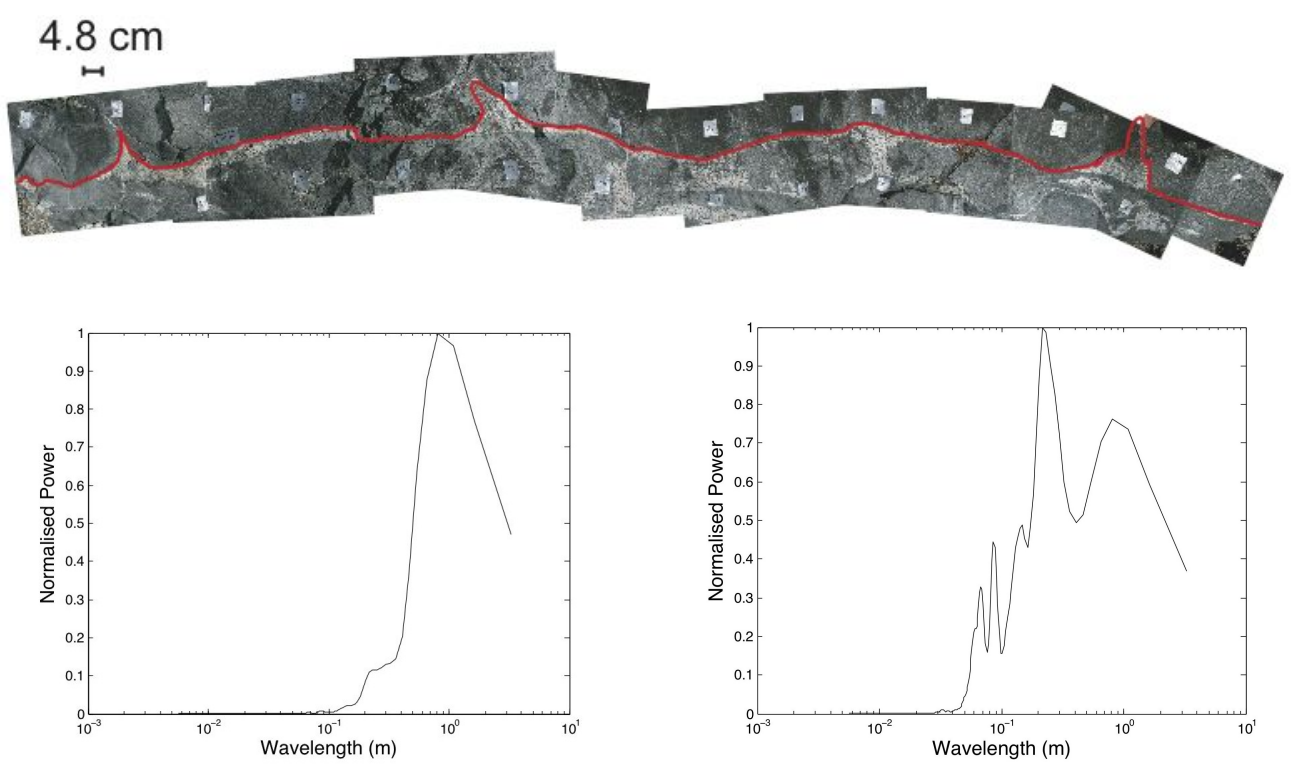

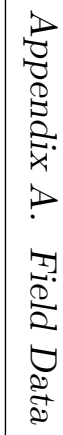

Interface 22: Stewart Head, Maine (Mount Desert Island) 

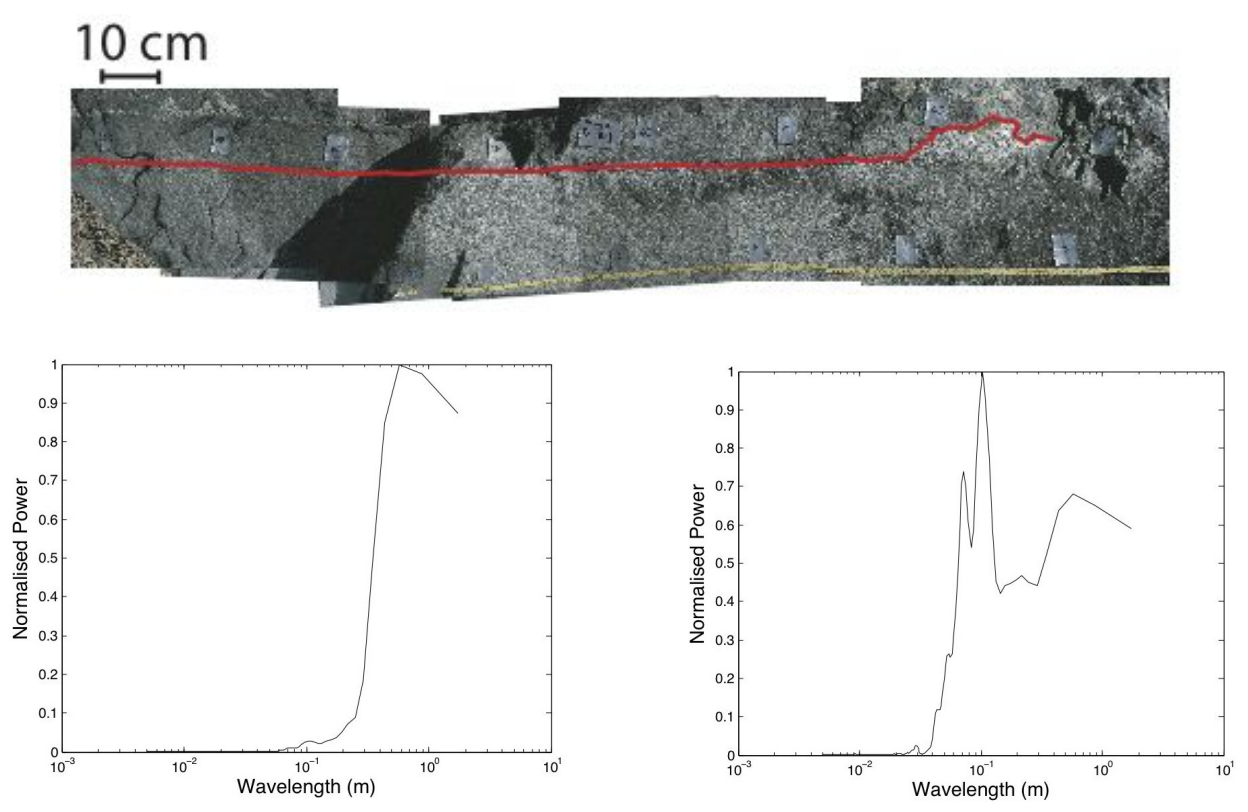

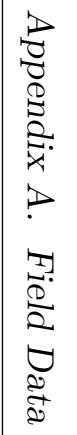

Interface 23: Stewart Head, Maine (Mount Desert Island) 

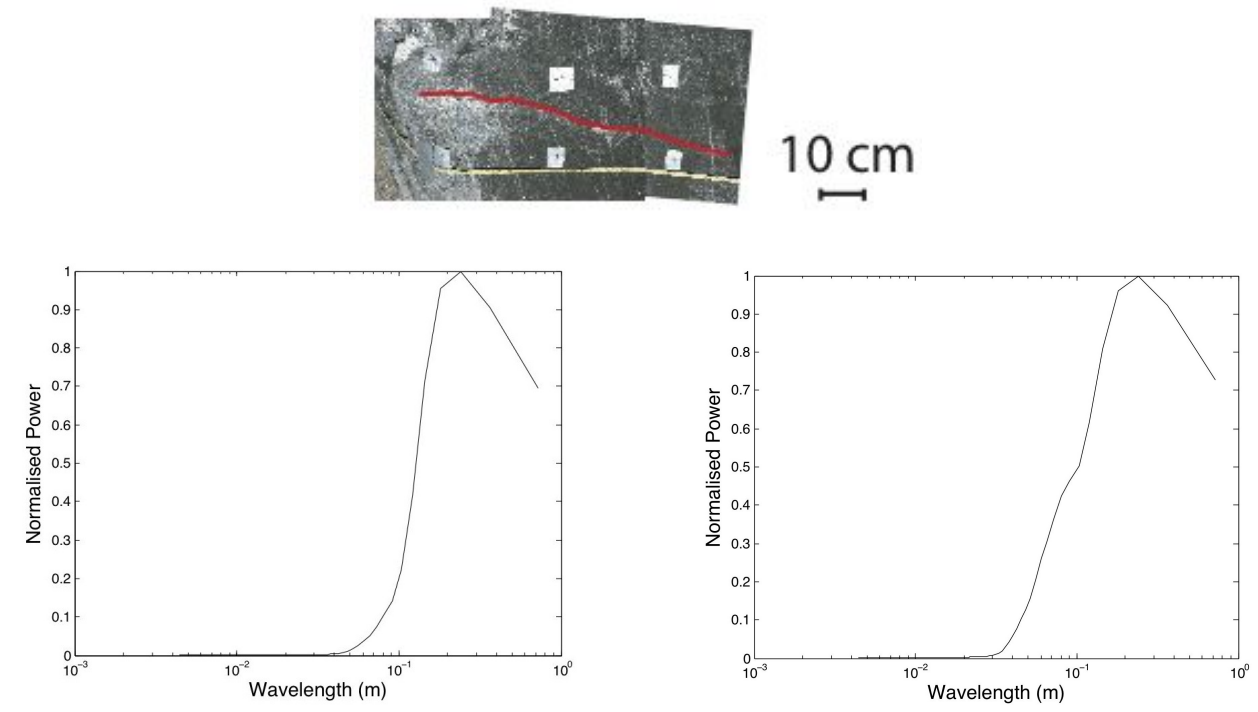

Interface 24: Stewart Head, Maine (Mount Desert Island) 

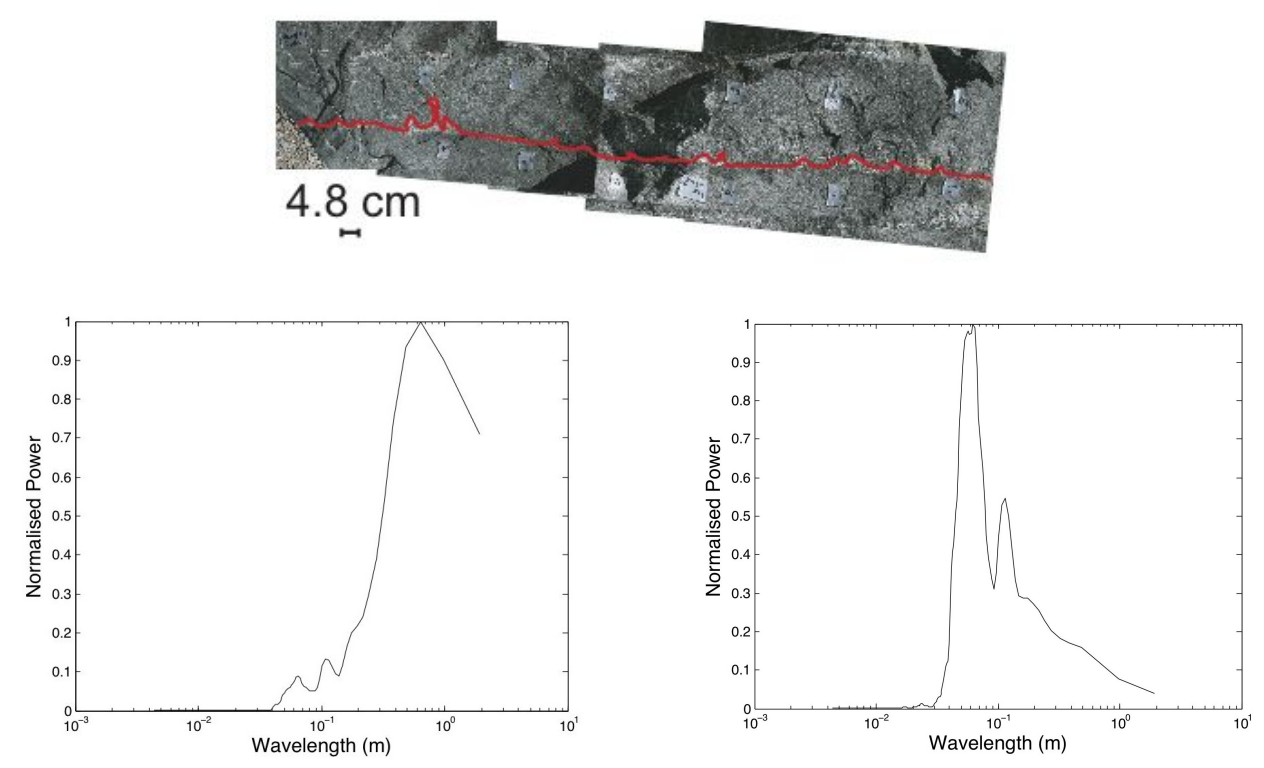

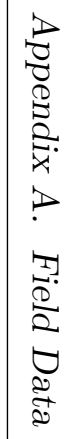

Interface 25: Stewart Head, Maine (Mount Desert Island) 


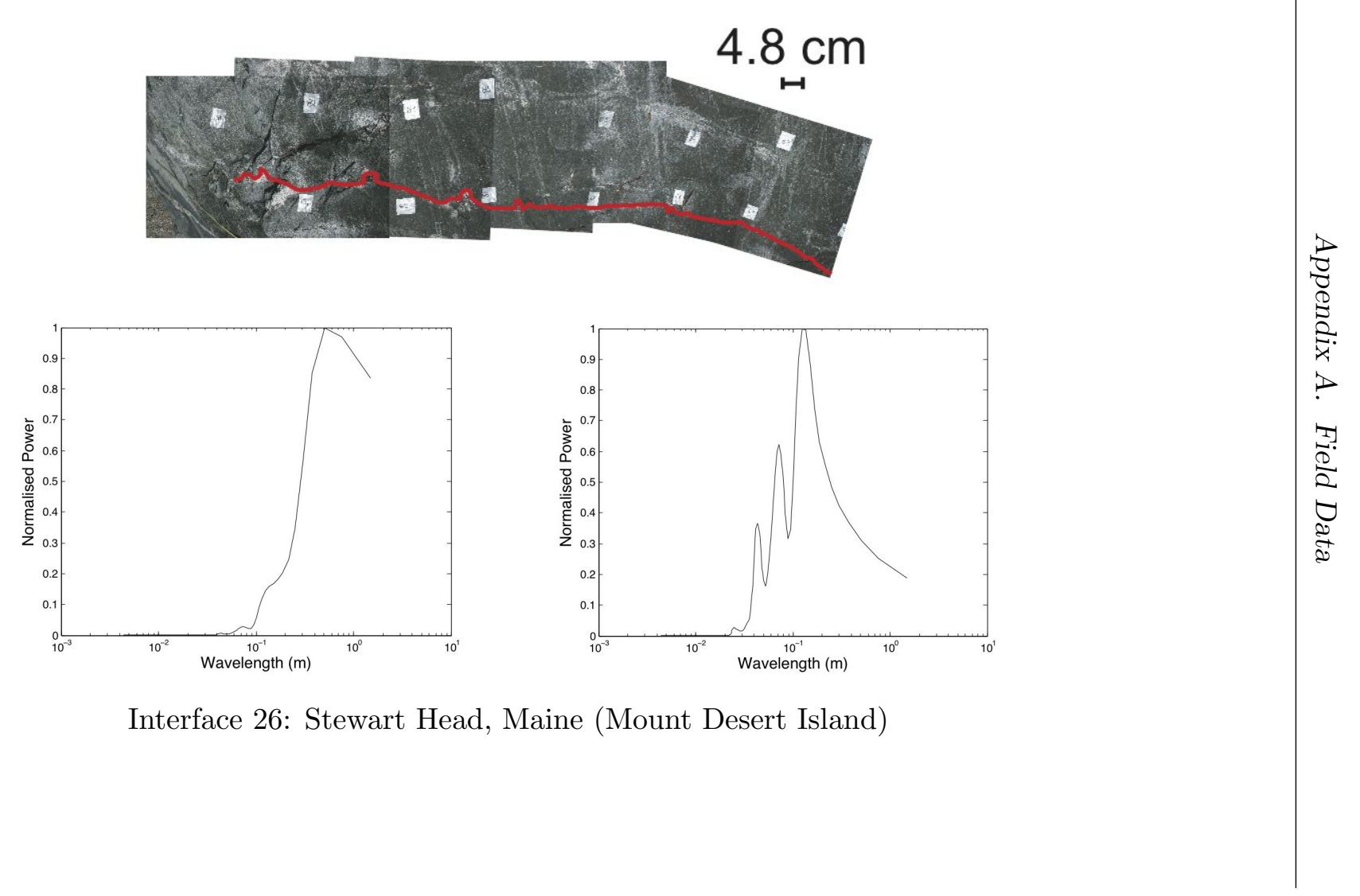



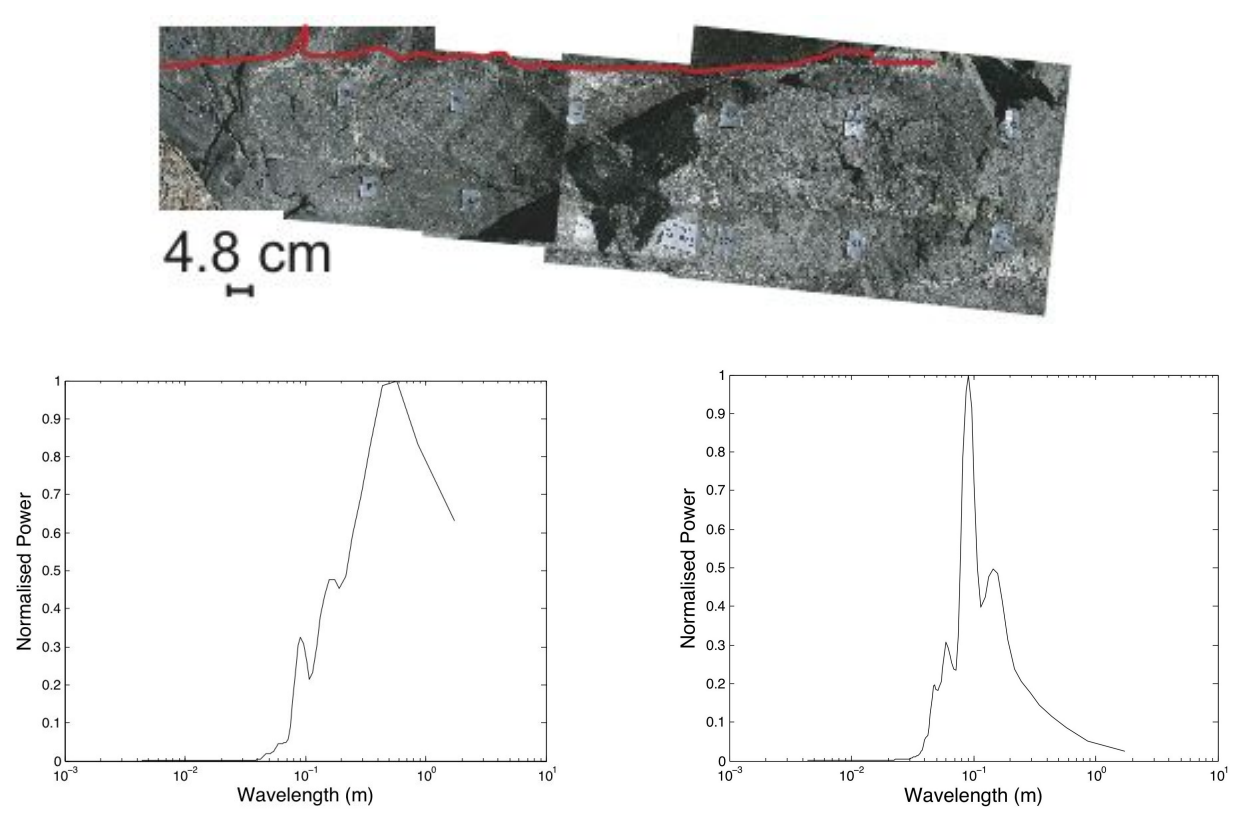

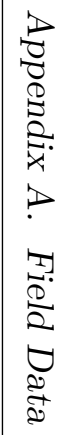

Interface 27: Stewart Head, Maine (Mount Desert Island) 


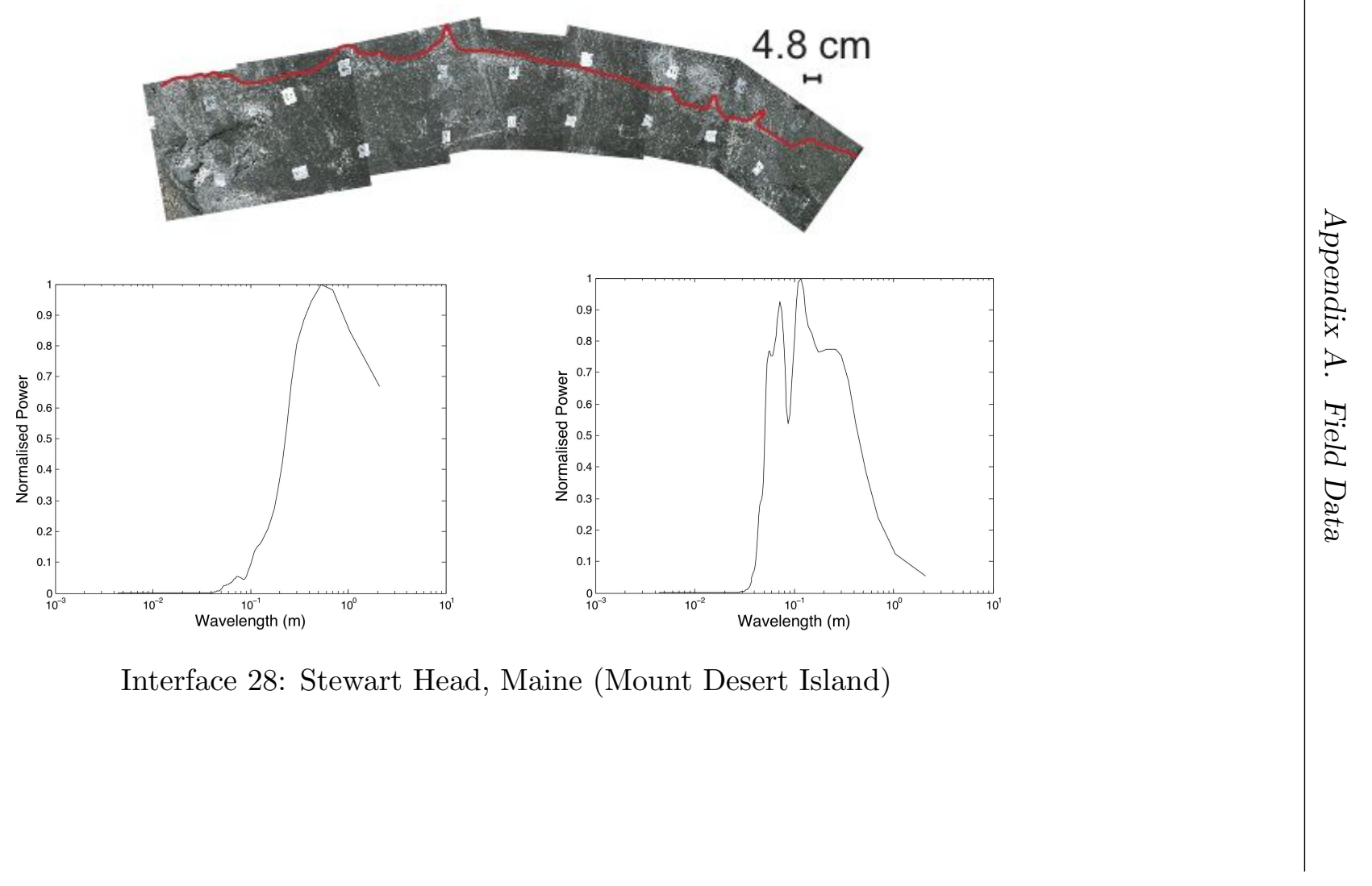


$176 \mathrm{~cm}$

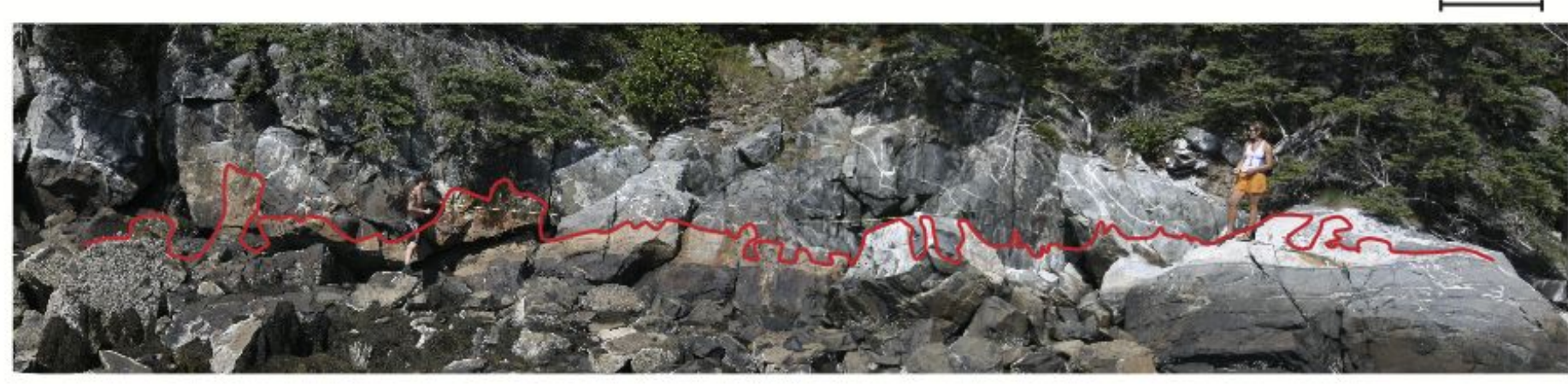

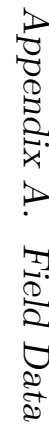

Interface 29: Stewart Head, Maine (Mount Desert Island) 


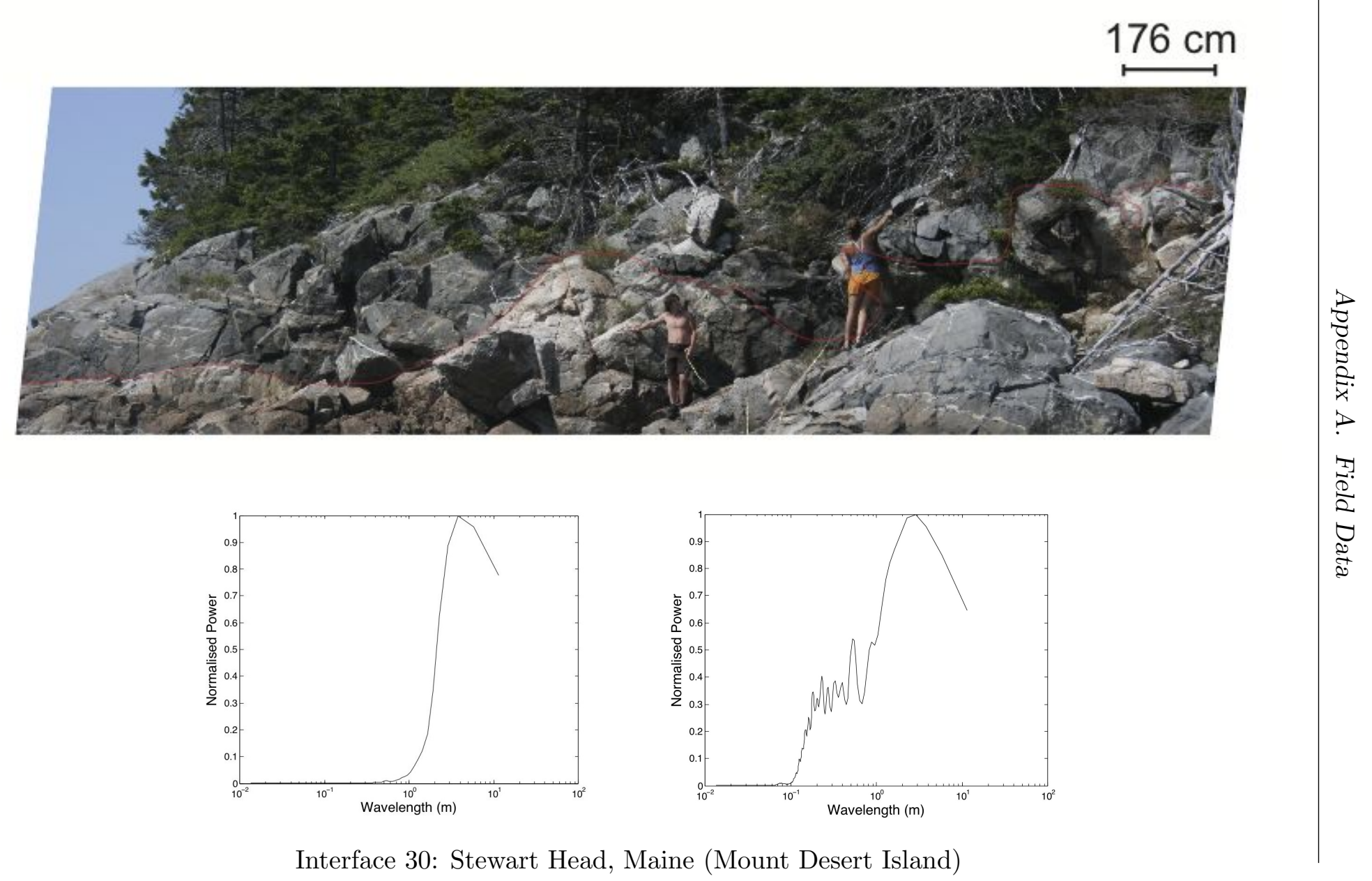



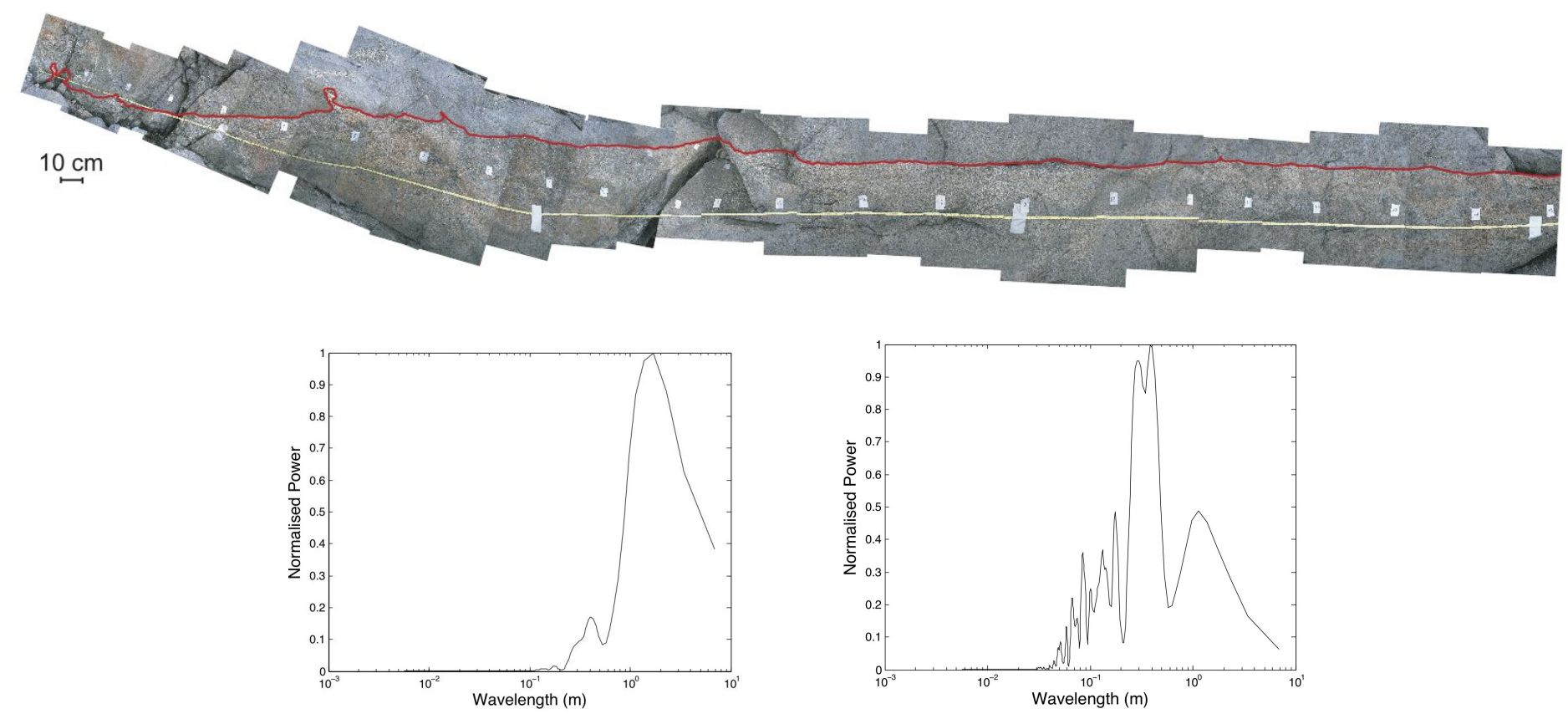

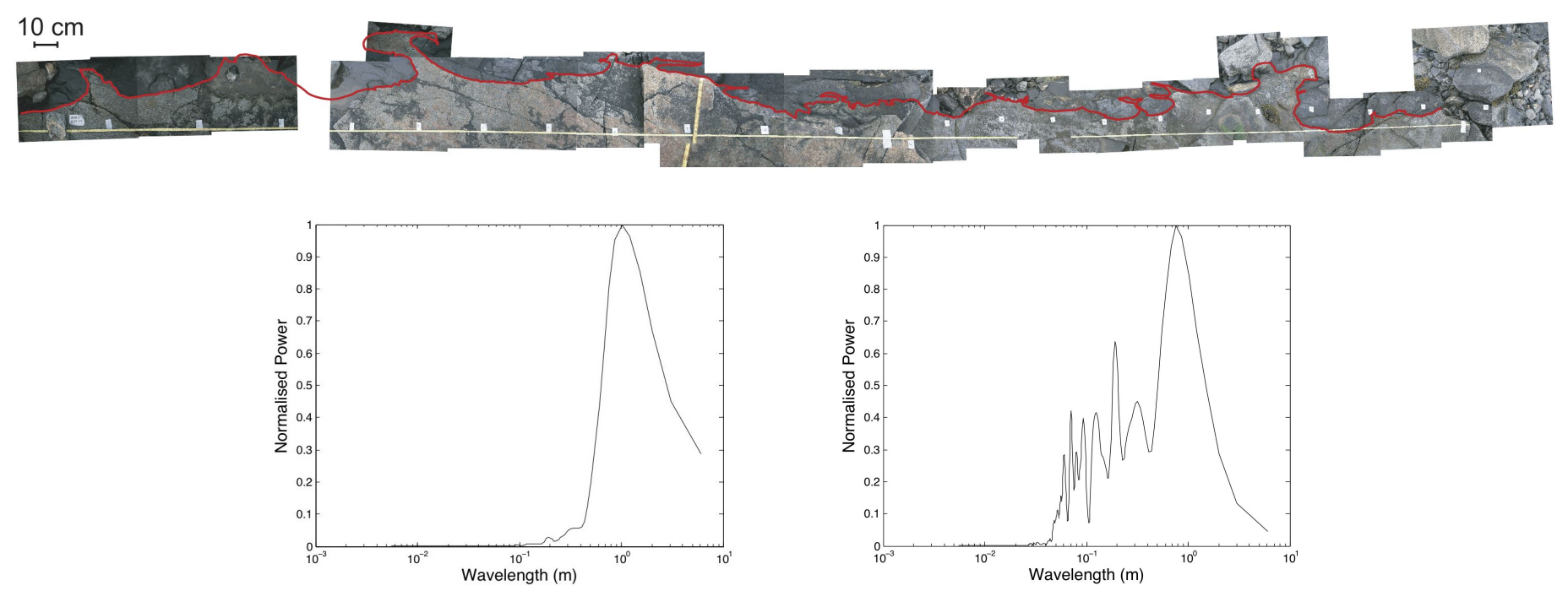

Interface 32: Bar Island, Maine (Pleasant Bay) 


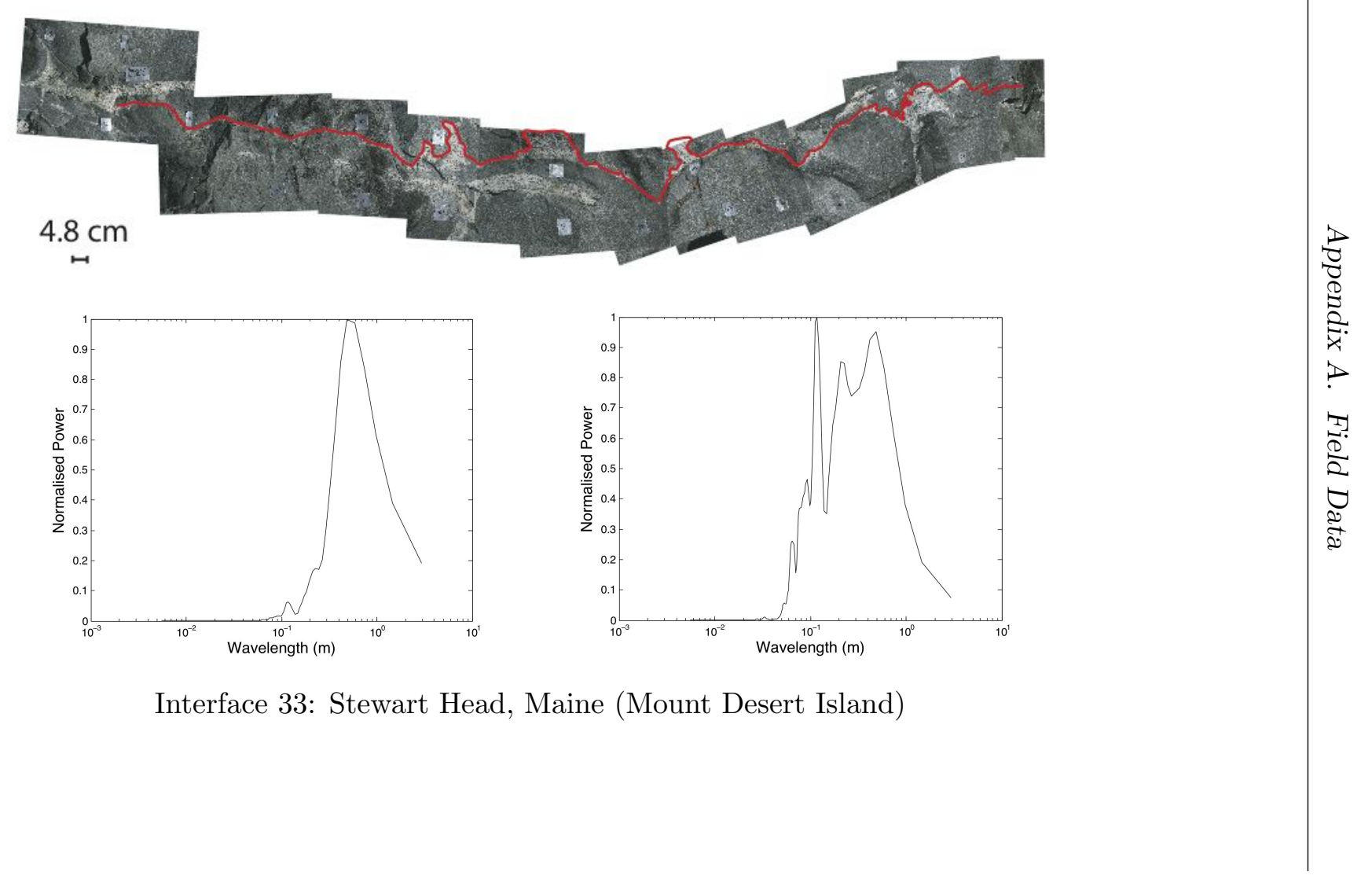




\section{Appendix B}

\section{Codes}

This appendix contains the Matlab codes created to generate all the graphs within this thesis. Electronic versions of these codes and accompanying image files and data files in compatible format are available upon request. 
a. Spectral Analysis

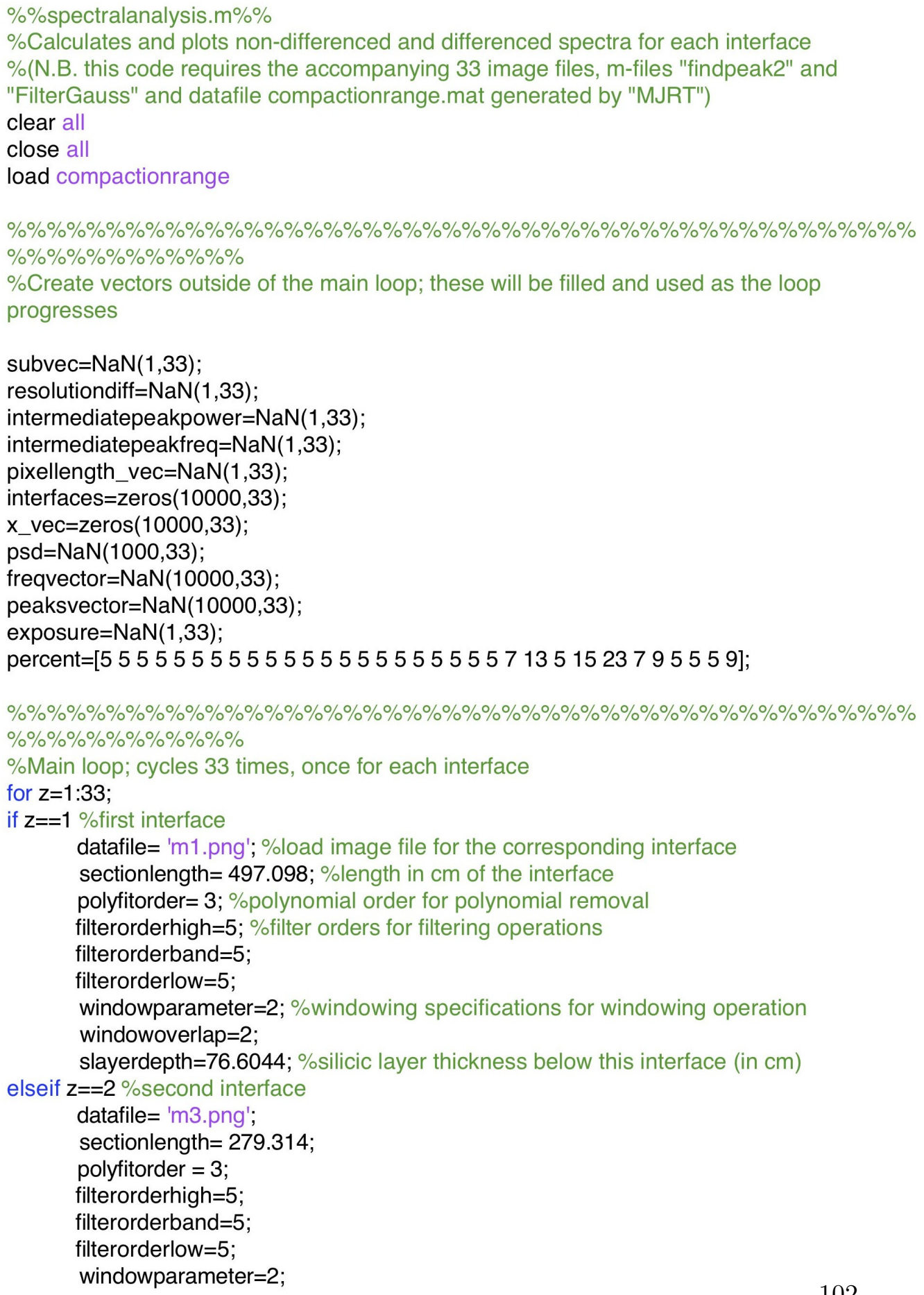


windowoverlap $=2$;

slayerdepth=14.0186;

elseif $z==3 \%$ third interface, etc...

datafile= 'm4.png';

sectionlength $=168.886$;

polyfitorder $=3$;

filterorderhigh $=5$;

filterorderband $=5$;

filterorderlow $=5$;

windowparameter $=2$;

windowoverlap $=2$;

slayerdepth $=27.5776$;

elseif $z==4$

datafile= 'm5.png';

sectionlength $=422.589$;

polyfitorder $=3$;

filterorderhigh $=5$;

filterorderband $=5$;

filterorderlow $=5$;

windowparameter $=2$;

windowoverlap $=2$;

slayerdepth $=69.9127$;

elseif $\mathrm{z}==5$

datafile= 'm6.png';

sectionlength $=477.792$;

polyfitorder $=3$;

filterorderhigh $=5$;

filterorderband $=5$;

filterorderlow $=5$;

windowparameter $=2$;

windowoverlap $=2$;

slayerdepth $=51.1948$;

elseif $z==6$

datafile = 'm7.png';

sectionlength $=941.393$;

polyfitorder $=3$;

filterorderhigh $=5$;

filterorderlow $=5$;

filterorderband $=5$;

filtercutofflow $=0.5$;

windowparameter $=2$;

windowoverlap $=2$;

slayerdepth $=57.6181$;

elseif $\mathrm{z}==7$

datafile= 'm8.png';

sectionlength $=599.861$;

polyfitorder $=3$;

filterorderhigh $=5$; 


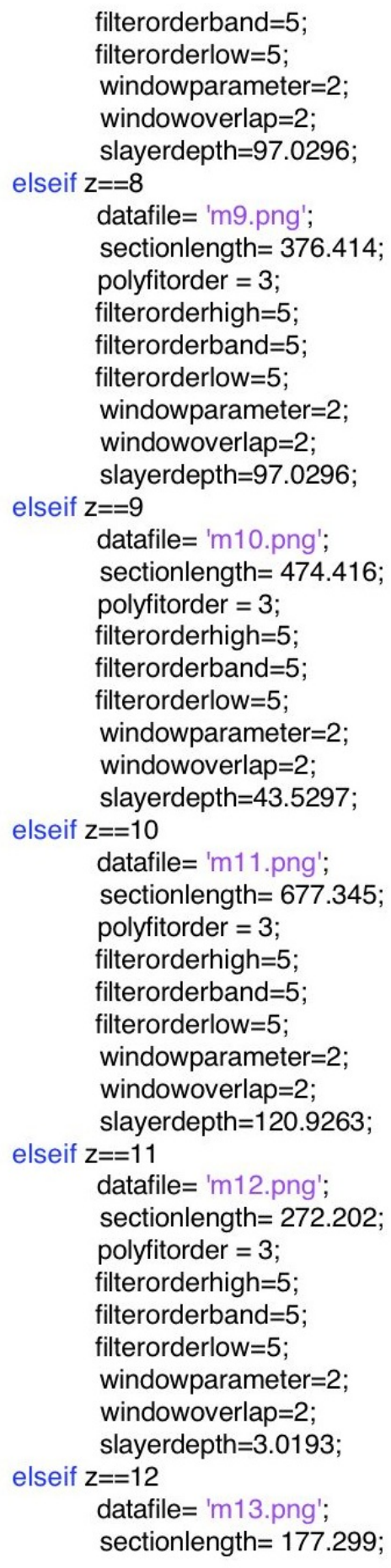


polyfitorder $=3$;

filterorderhigh=5;

filterorderband $=5$;

filterorderlow $=5$;

windowparameter $=2$;

windowoverlap=2;

slayerdepth $=3.1297$;

elseif $z==13$

datafile= 'm14.png';

sectionlength $=269.424$;

polyfitorder $=3$;

filterorderhigh $=5$;

filterorderband $=5$;

filterorderlow $=5$;

windowparameter $=2$;

windowoverlap $=2$;

slayerdepth $=1.3992$;

elseif $z==14$

datafile= 'm15.png';

sectionlength $=170.928$;

polyfitorder $=3$;

filterorderhigh $=5$;

filterorderband $=5$;

filterorderlow $=5$;

windowparameter $=2$;

windowoverlap=2;

slayerdepth=21.2453;

elseif $z==15$

datafile= 'm16.png';

sectionlength $=1495.085$;

polyfitorder $=3$;

filterorderhigh=5;

filterorderband $=5$;

filterorderlow $=5$;

windowparameter $=2$;

windowoverlap $=2$;

slayerdepth $=81.9875$;

elseif $z==16$

datafile= 'm17.png';

sectionlength $=407.687$;

polyfitorder $=3$;

filterorderhigh=5;

filterorderband $=5$;

filterorderlow $=5$;

windowparameter $=2$;

windowoverlap $=2$;

slayerdepth $=91.4061$;

elseif $z==17$ 
datafile= 'm18.png';

sectionlength $=567.617$;

polyfitorder = 3;

filterorderhigh $=5$;

filterorderband $=5$;

filterorderlow $=5$;

windowparameter=2;

windowoverlap $=2$;

slayerdepth $=40.1272$;

elseif $z==18$

datafile $=$ 'm19.png';

sectionlength $=386.829$;

polyfitorder $=3$;

filterorderhigh $=5$;

filterorderband $=5$;

filterorderlow $=5$;

windowparameter $=2$;

windowoverlap $=2$;

slayerdepth $=121.0838$;

elseif $z==19$

datafile = 'm20.png';

sectionlength $=554.467$;

polyfitorder $=3$;

filterorderhigh $=5$;

filterorderband $=5$;

filterorderlow $=5$;

windowparameter=2;

windowoverlap $=2$;

slayerdepth=368.2318;

elseif $z==20$

datafile= 'm21.png';

sectionlength $=196.954$;

polyfitorder $=3$;

filterorderhigh $=5$;

filterorderband $=5$;

filterorderlow $=5$;

windowparameter=2;

windowoverlap $=2$;

slayerdepth=99.0268;

elseif $z==21$

datafile= 'm22.png';

sectionlength $=328.022$;

polyfitorder $=3$;

filterorderhigh $=5$;

filterorderband=5;

filterorderlow $=5$;

windowparameter=2;

windowoverlap=2; 
Appendix B. Codes

slayerdepth=15.5973;

elseif $z==22$

datafile= 'm23.png';

sectionlength $=326.952$;

polyfitorder $=3$;

filterorderhigh $=5$;

filterorderband $=5$;

filterorderlow $=5$;

windowparameter $=2$;

windowoverlap $=2$;

slayerdepth $=2.4465$;

elseif $z==23$

datafile= 'm24a.png';

sectionlength $=174.499$;

polyfitorder $=3$;

filterorderhigh $=5$;

filterorderband $=5$;

filterorderlow $=5$;

windowparameter $=2$;

windowoverlap $=2$;

slayerdepth $=1.273$;

elseif $z==24$

datafile= 'm24b.png';

sectionlength $=72.444$;

polyfitorder $=3$;

filterorderhigh $=5$;

filterorderband $=5$;

filtercutofflow $=0.5$;

filterorderlow $=5$;

windowparameter $=2$;

windowoverlap $=2$;

slayerdepth $=1.273$;

elseif $z==25$

datafile= 'm25a.png';

sectionlength $=194.015$;

polyfitorder $=3$;

filterorderhigh $=5$;

filterorderband $=5$;

filterorderlow $=5$;

windowparameter $=2$;

windowoverlap $=2$;

slayerdepth $=0.8951$;

elseif $z==26$

datafile = 'm25b.png';

sectionlength $=150.758$;

polyfitorder $=3$;

filterorderhigh $=5$;

filterorderband $=5$; 
filterorderlow $=5$;

windowparameter $=2$;

windowoverlap $=2$;

slayerdepth $=0.8951$;

elseif $z==27$

datafile= 'm26a.png';

sectionlength $=173.690$;

polyfitorder $=3$;

filterorderhigh=5;

filterorderband $=5$;

filterorderlow $=5$;

windowparameter $=2$;

windowoverlap $=2$;

slayerdepth $=0.5172$;

elseif $z==28$

datafile = 'm26b.png';

sectionlength $=210.640$;

polyfitorder $=3$;

filterorderhigh $=5$;

filterorderband $=5$;

filterorderlow $=5$;

windowparameter $=2$;

windowoverlap $=2$;

slayerdepth $=0.5172$;

elseif $z==29$

datafile= 'm27.png';

sectionlength $=2445.097$;

polyfitorder $=3$;

filterorderhigh=5;

filterorderband $=5$;

filtercutofflow $=0.5$;

filterorderlow $=5$;

windowparameter $=2$;

windowoverlap $=2$;

slayerdepth $=30.0202$;

elseif $z==30$

datafile= 'm28.png';

sectionlength $=1141.053$;

polyfitorder $=3$;

filterorderhigh $=5$;

filterorderband $=5$;

filterorderlow $=5$;

windowparameter $=2$;

windowoverlap $=2$;

slayerdepth $=278.4386$;

elseif $z==31$

datafile= 'm32.png';

sectionlength $=686.455$; 
polyfitorder $=3$;

filterorderhigh $=5$;

filterorderband $=5$;

filterorderlow $=5$;

windowparameter $=2$;

windowoverlap $=2$;

slayerdepth $=125.1557$;

elseif $z==32$

datafile= 'm33.png';

sectionlength $=609.612$;

polyfitorder $=3$;

filterorderhigh $=5$;

filterorderband $=5$;

filterorderlow $=5$;

windowparameter=2;

windowoverlap $=2$;

slayerdepth $=97.8148$;

elseif $z==33$

datafile= 'm34.png';

sectionlength $=294.514$;

polyfitorder $=3$;

filterorderhigh $=5$;

filterorderband $=5$;

filterorderlow $=5$;

windowparameter=2;

windowoverlap $=2$;

slayerdepth $=0.7422$;

end

$\% \%$ THE FOLLOWING COMMANDS ARE EXECUTED FOR EACH INTERFACE (I.E. FOR

$\mathrm{EACH}$

$\% \%$ VALUE OF z

I = imread(datafile); \%read image

grayl = rgb2gray $(\mathrm{l}) ; \%$ converts true color image to grayscale

maxl=imregionalmax(grayl); \% finds maxima and sets them equal to 1 (returns a binary

image); minima set equal to 0

clear I grayl

\%Pick out interface and make vectors $\mathrm{x}$ and $\mathrm{y}$ corresponding to the interface

$\mathrm{x}=\mathrm{NaN}(1$, length $(\max (1,:)))$;

$\mathrm{y}=\mathrm{NaN}(1$, length $(\max \mid(1,:)))$;

for $\mathrm{i}=1$ :length $(\operatorname{maxl}(1,:))$

$x(i)=i ; \%$ in pixels

$y(i)=$ find $(\operatorname{maxl}(:, i)==0,1) ; \%$ finds the cell number corresponding to first zero entry in column i (in the binary image)

end 
interface $=\mathrm{y}^{\star}(-1) ; \%$ multiplication by -1 makes the line have the same orientation as in the images.

clear maxl

$\%$ Scale the interface to nature

$\mathrm{xa}=\left(\mathrm{x}^{\star}(\right.$ sectionlength/length $\left.(\mathrm{x}))\right) ; \%$ turns pixels to lengths at the scale of the photo

ya $=\left(\right.$ interface $^{\star}($ sectionlength/length $\left.(x))\right) ; \%$ turns cell numbers to lengths

\%Record exposure

exposure $(1, z)=$ sectionlength;

$\%$

\%Sub-sampling operation:

pixellength=sectionlength/length(x); \%evaluates the scale of one pixel from png image pixellength_vec $(z)=$ pixellength;

if pixellength $<0.25 ; \%$ Nyquist frequency to resolve $0.5 \mathrm{~cm}$ crystals

sub=round(0.25/pixellength); \% determine extent to sub-sample

else $\mathrm{sub}=1$;

end

$\operatorname{subvec}(z)=s u b$;

$x z=N a N(1$, floor(length $(x a) /$ sub $)) ;$

$\mathrm{yz}=\mathrm{NaN}(1$, floor(length $(\mathrm{xa}) / \mathrm{sub}))$;

\%sub-sample data

for $c=1$ :(floor(length(xa)/sub));

$x z(c)=x a\left(c^{*}\right.$ sub);

$y z(c)=y a\left(c^{*} s u b\right)$;

end

interfaces $(1$ :length(ya),z)=ya;

$\mathrm{x} \_\operatorname{vec}(1$ :length $(\mathrm{xa}), \mathrm{z})=\mathrm{xa}$;

$\%$

\%De-meaning, polynomial removal and differencing operations:

yd=yz-mean(yz); \%de-mean

$\mathrm{p}=$ polyfit(xz,yd,polyfitorder); \%gives row vector containing the coefficients of a polynomial function that fits the data

$\mathrm{pp}=\operatorname{polyval}(\mathrm{p}, \mathrm{xz})$;

$\% \%$ When wanting non-differenced spectra, use this and comment out below:

\%yaa=yd-pp; \%takes the polynomial away from the data

$\%$ When wanting differenced spectra, use this and comment out above: 
ye=yd-pp; \%takes the polynomial away from the data

yaa=diff(ye); \% difference

$\mathrm{xc}=\mathrm{NaN}(1$, length $(\mathrm{xz})-1) ; \%$ makes $\mathrm{xc}$ the same size as yaa

for $d=1$ : (length $(x z)-1)$;

$x c(d)=x z(d)$;

end

$\%$

\% Remove a moving polynomial from data:

$\mathrm{n}=3$;

width $=30$;

step=3;

$\% \%$ When wanting non-differenced spectra, use this and comment out below:

$\%[$ nondiffy, idx, order] = polyfitp(xz,yaa, n, width,step);

\%When wanting differenced spectra, use this and comment out above:

[nondiffy, idx, order] = polyfitp(xc,yaa,n,width,step);

$$
\%
$$

$\%$ Windowing

$\mathrm{nx}=$ length(nondiffy);

window=hanning(nx); \%type of window

yy=(nondiffy). *window'; \% Applies chosen window

$\%$

$\%$ Butterworth filters

$\% \%$ When wanting non-differenced spectra, use this and comment out below:

$\%$ dist1= xz;

$\%$ When wanting differenced spectra, use this and comment out above:

dist1 = xc;

SI = dist1(2)-dist1(1); \%sampling interval

$\mathrm{Fs}=1 / \mathrm{SI}$ \% $\%$ Sampling frequency $(\mathrm{Hz})$

Nyquist $=0.5$ * Fs; \%Nyquist frequency

resolutiondiff $(1, z)=1 /$ Nyquist;

$\%$ Bandpass = crystal scale-layer depth scale

cutoff $=[(1 /$ sectionlength $) /$ Nyquist 0.9$] ; \%$ frequency cutoff in fractions of Nyquist

order = filterorderband; \%controls steepness of the cutoff

[outyy inyy] = butter(order,cutoff); \%butterworth filter

filtyy = filter(outyy,inyy,yy);

$\% \%$ Highpass = sub-crystal scale 


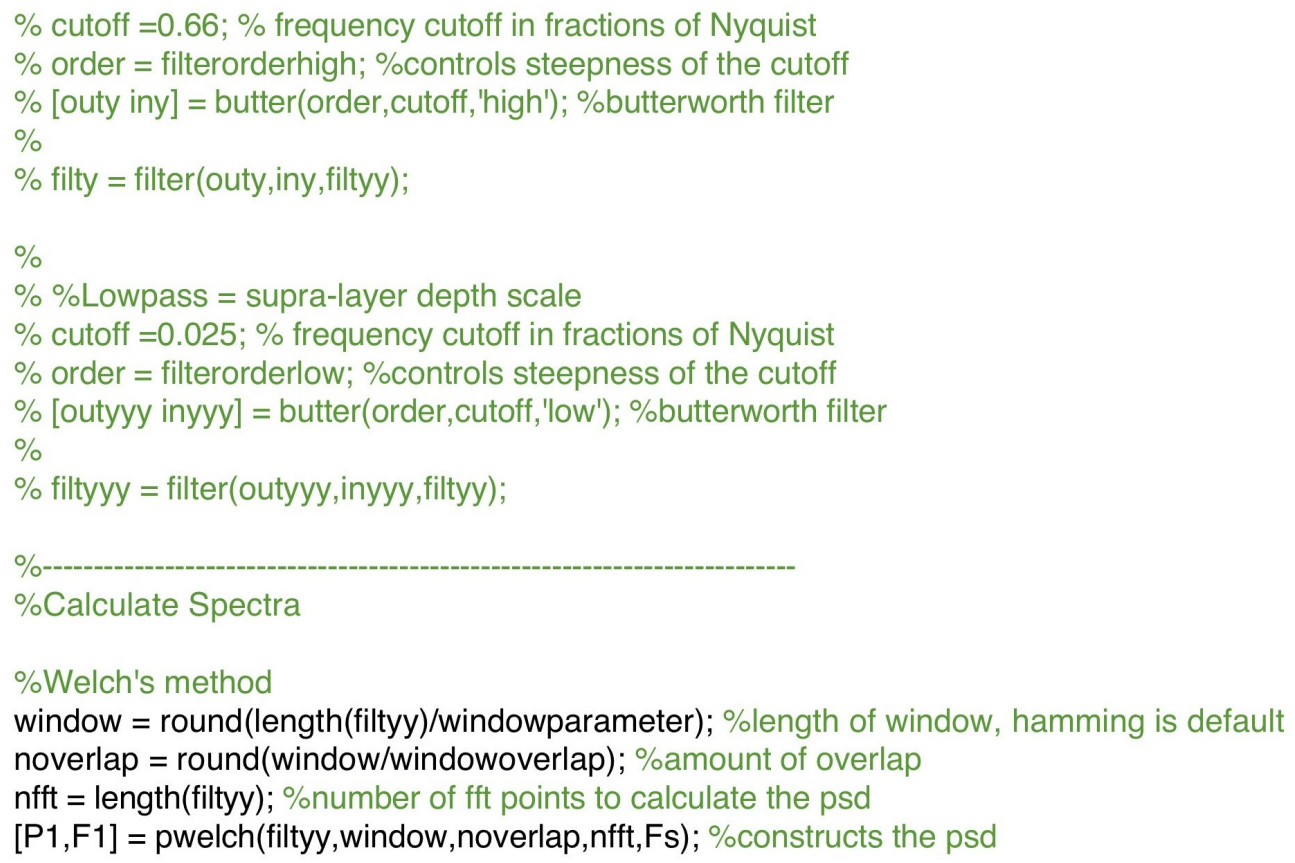

$\%$ Gaussian Smoothing of Power spectrum - convolution of spectrum with a bell curve $\mathrm{p}=10$; \%points of gaussian filter

$W=10 ; \%$ width of bell-curve

smoothP1 = FilterGauss $(\mathrm{P} 1, \mathrm{p}, \mathrm{w}) ; \%$ smoothing the welch-method spectrum powercutoff $=0$;

[peakf, peakp] $=$ findpeak2(smoothP1, F1, powercutoff);

peaks=(1./peakf); \%find wavelength of the peaks in the spectrum $\mathrm{n}=$ find (peaks<sectionlength);

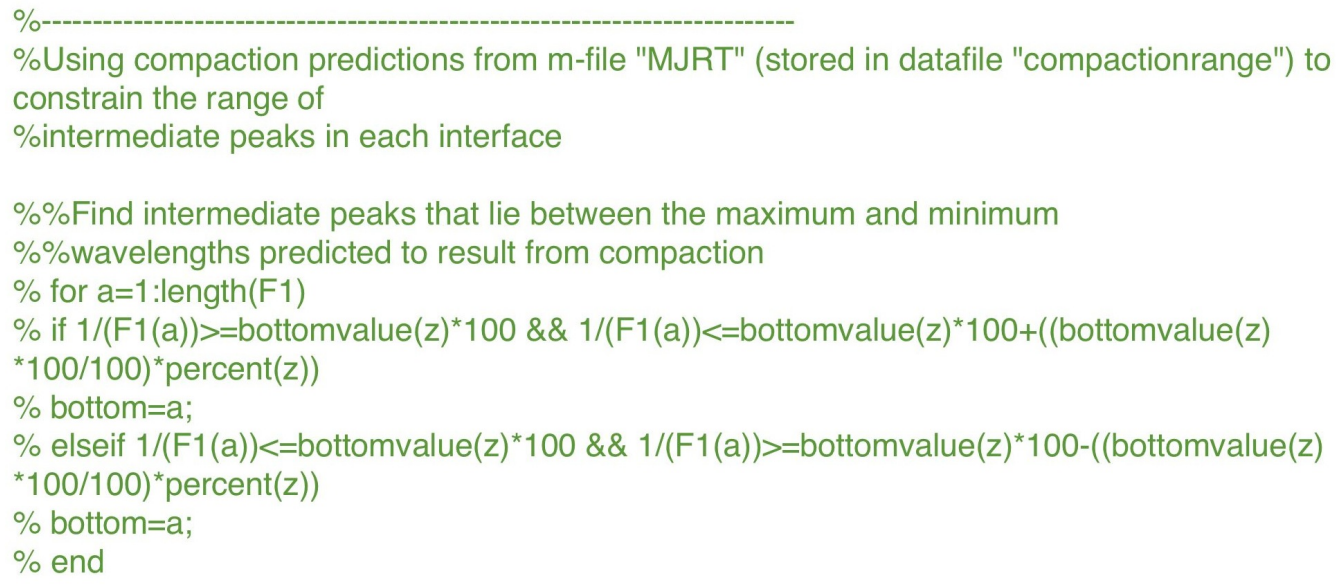


Appendix B. Codes

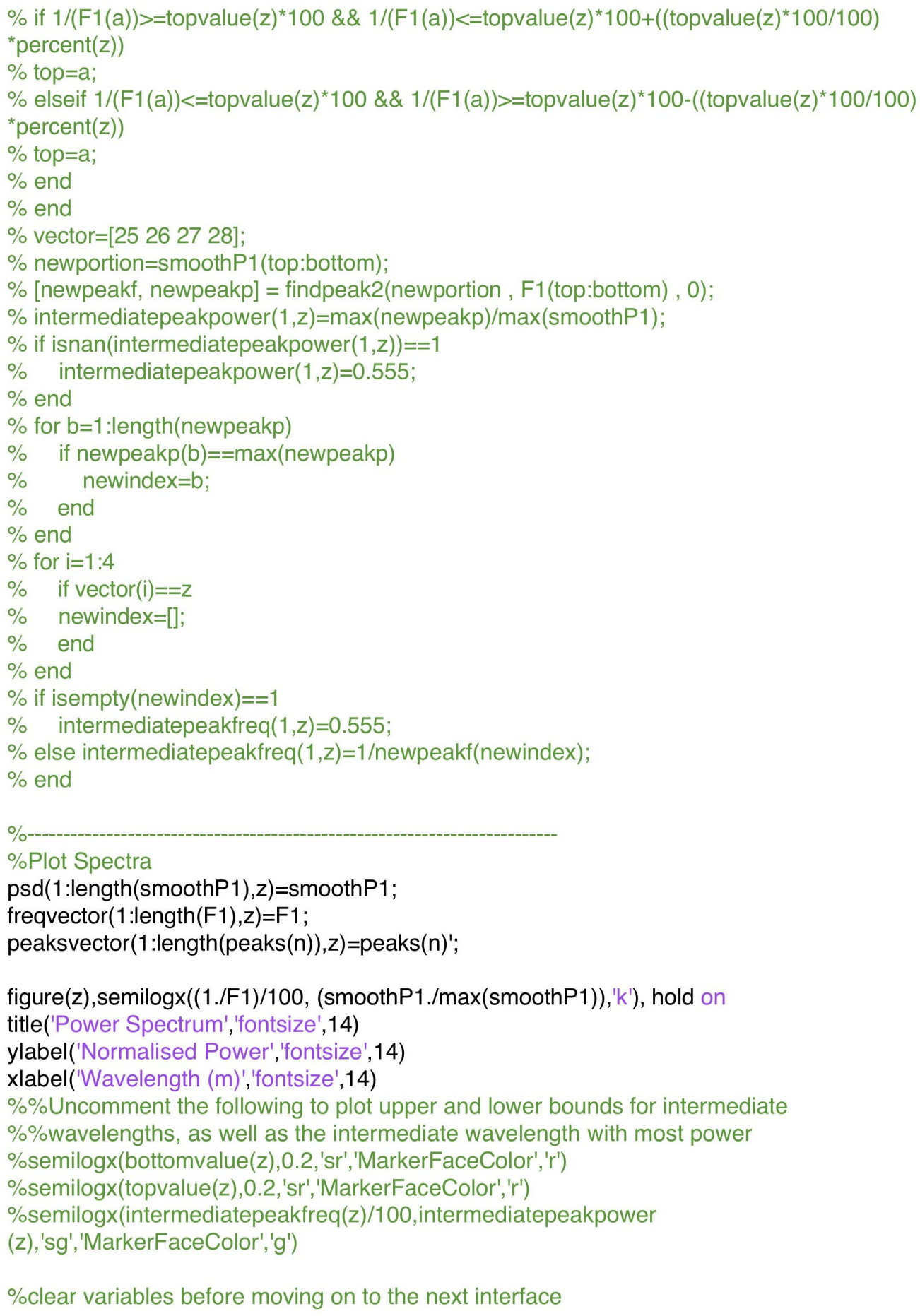


Appendix B. Codes

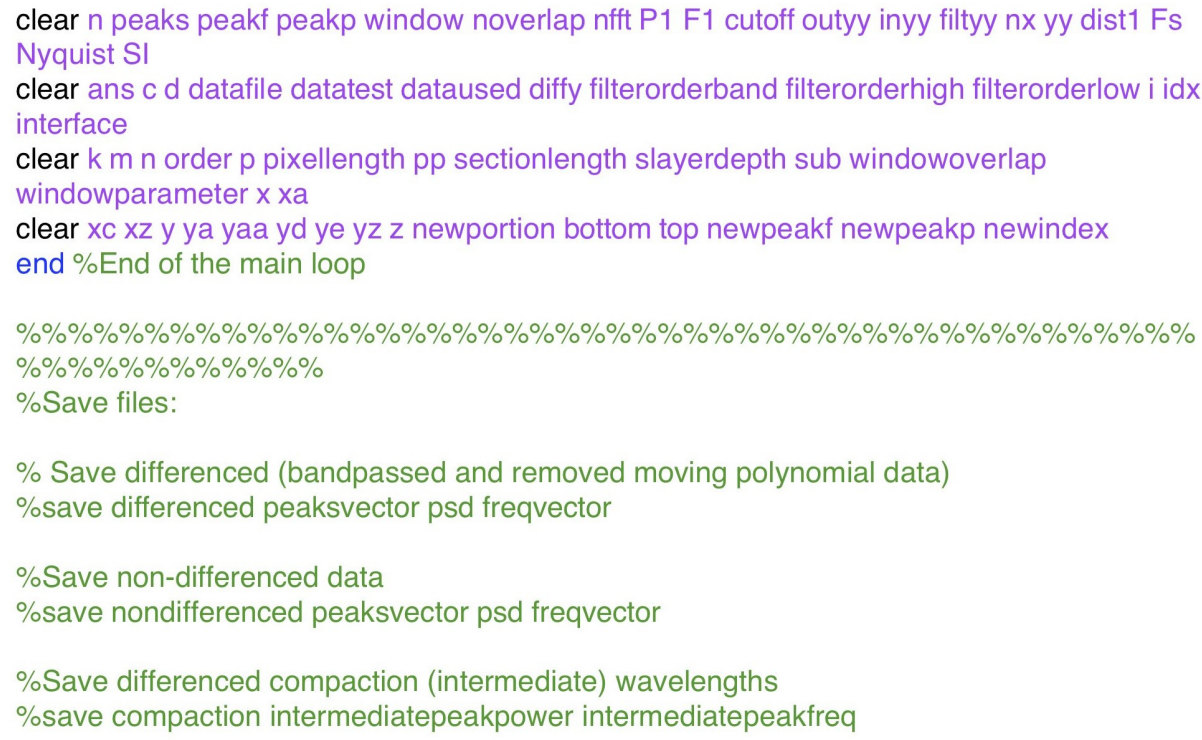

b. Thickness Correct

$\% \%$ thicknesscorrect.m $\% \%$

$\%$ This file calculates the true thickness of the mafic and silicic layers

clear all

close all

alpha=[50 505056475676762588676767678989543626827284848484848484625766 78 55]; \%angle between bedding and section

meash=[100 18.3 36 84.33 70 69.51001001031213.28 3.4 1.52 23.08 82 91.42 49.6 20684010016.4 $2.461 .281 .280 .90 .90 .520 .52343321371000 .906] ; \%$ measured silicic layer height measd=[3000 46 25340300136.82000200036018026 .0811 .2421 .4832 .7821420058188200750 4047.99 .79 .728 .628 .645 .645 .648010002601500 26.44]; \%measured mafic layer height

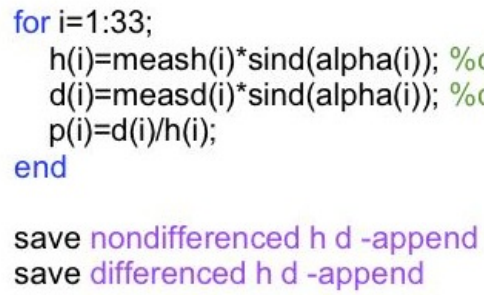




\section{c. MJRT}

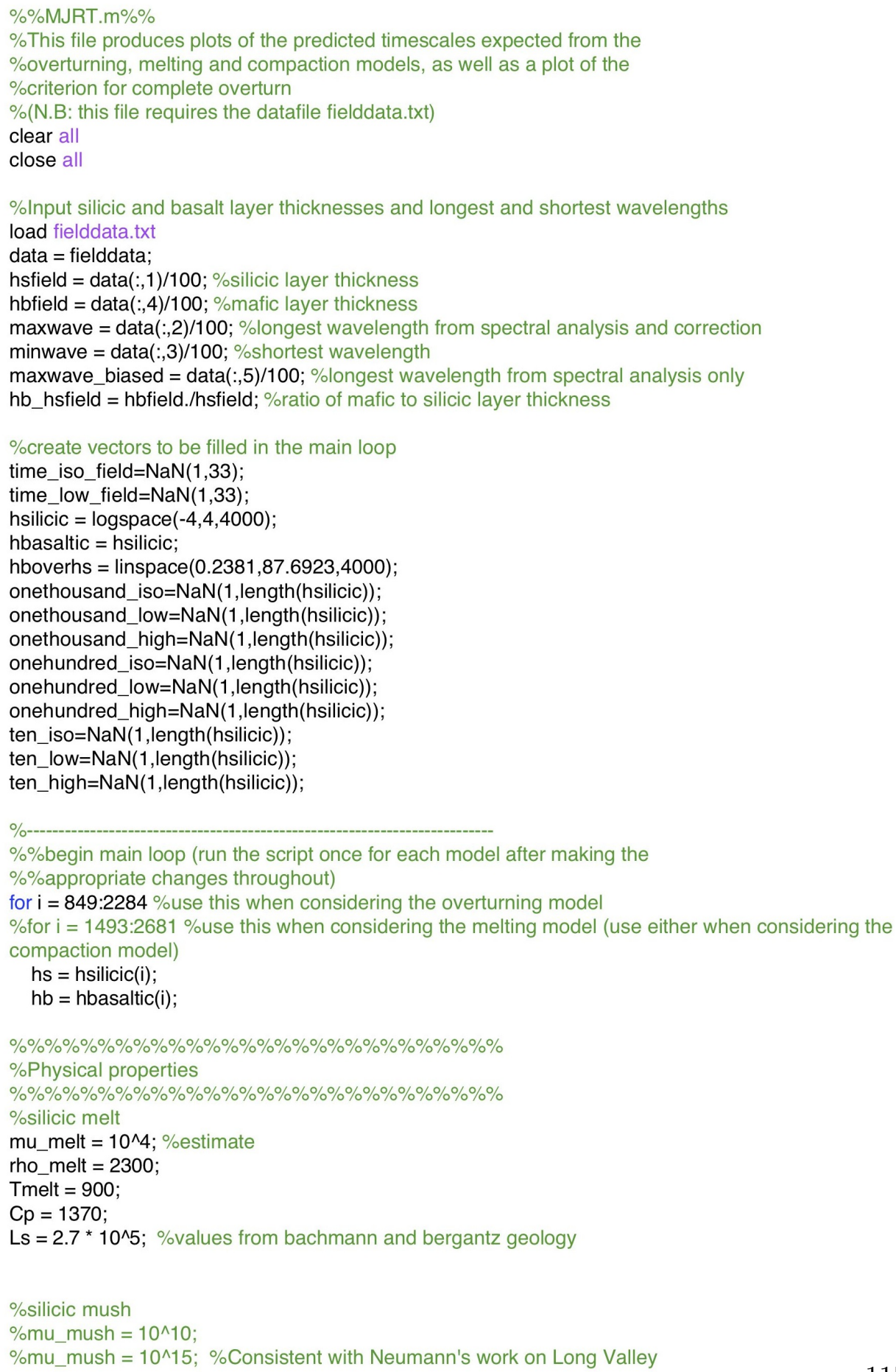




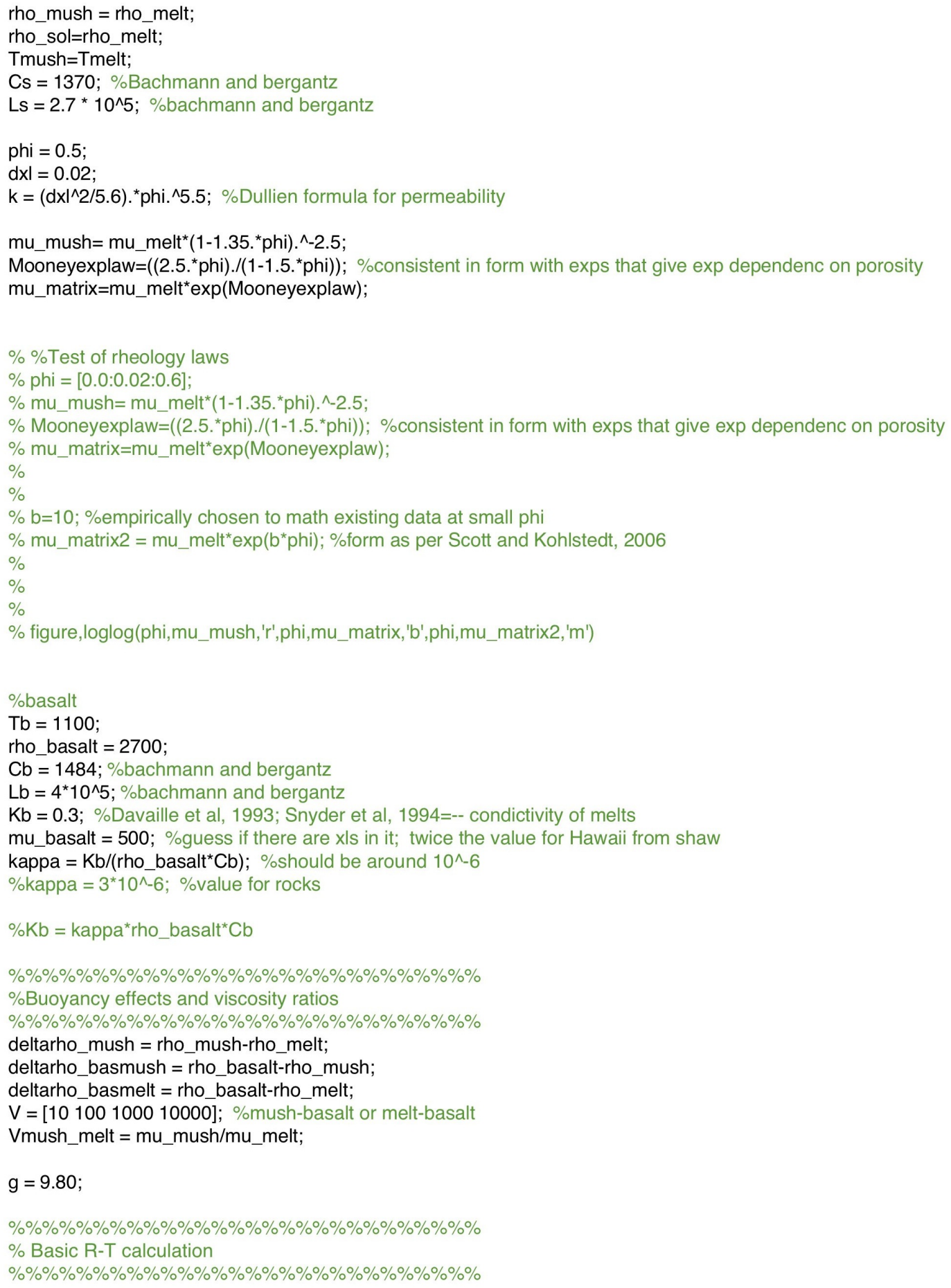




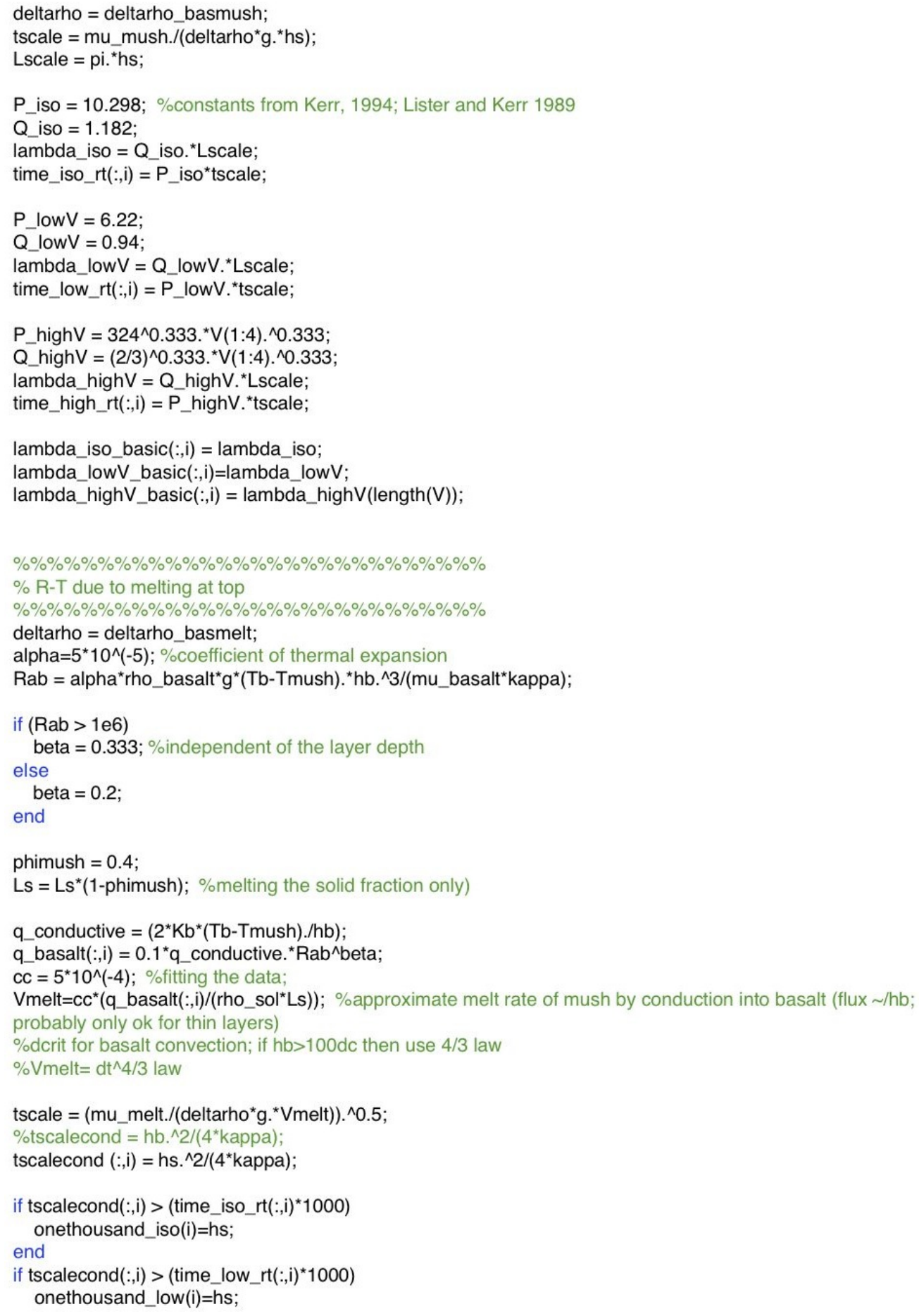




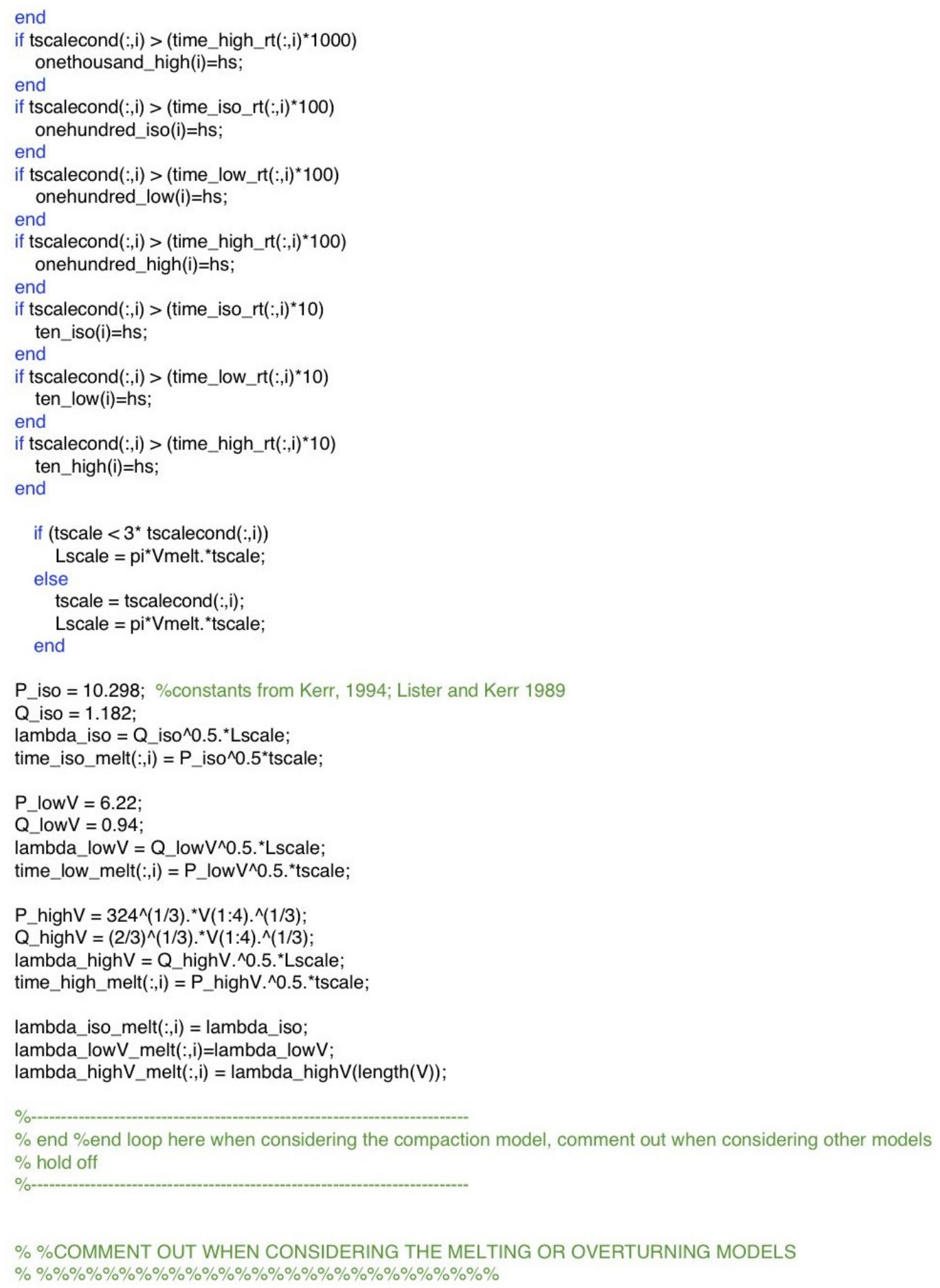




\section{Appendix B. Codes}

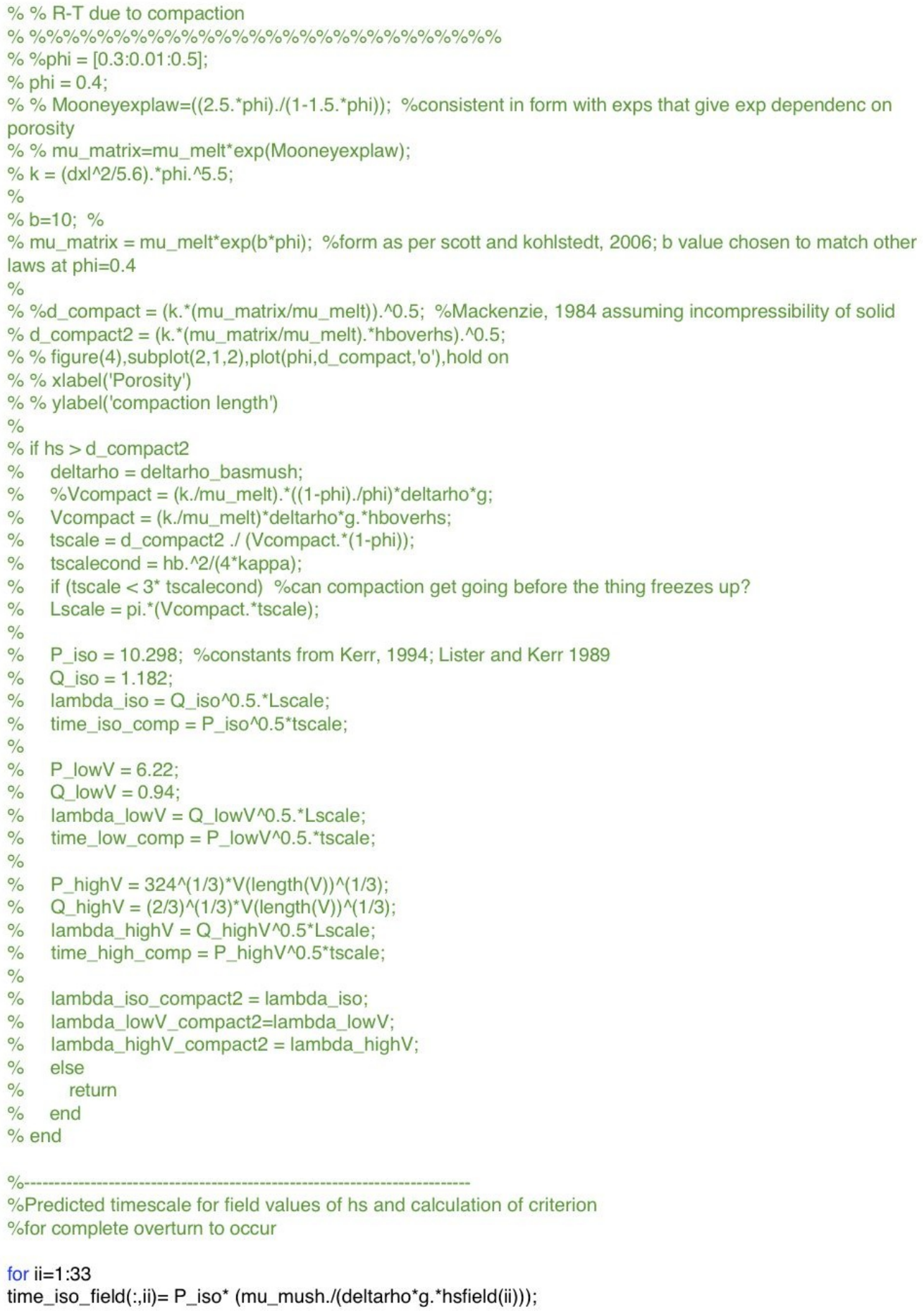




\section{Appendix B. Codes}

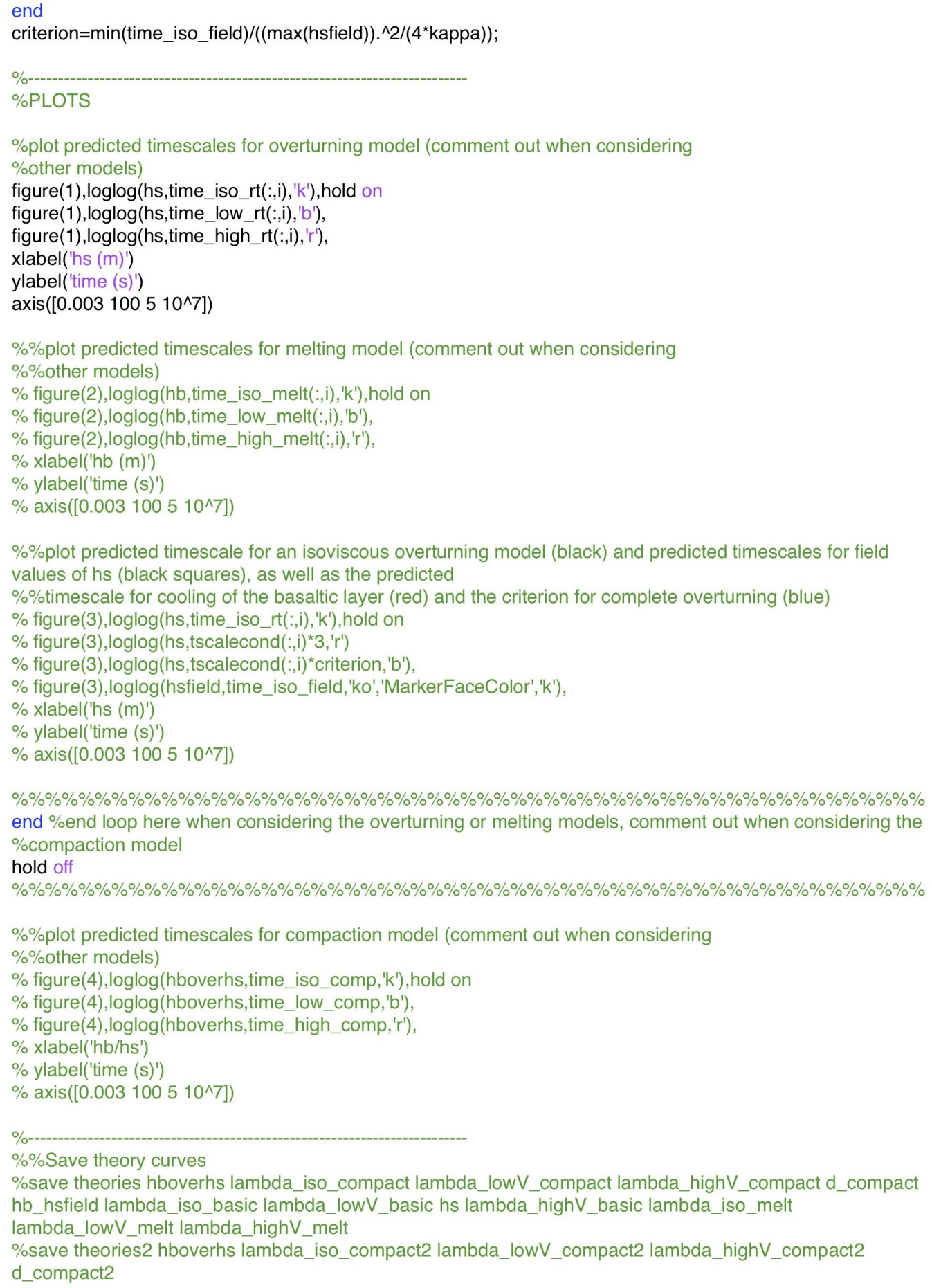




\section{Appendix B. Codes}

\section{d. Plots}

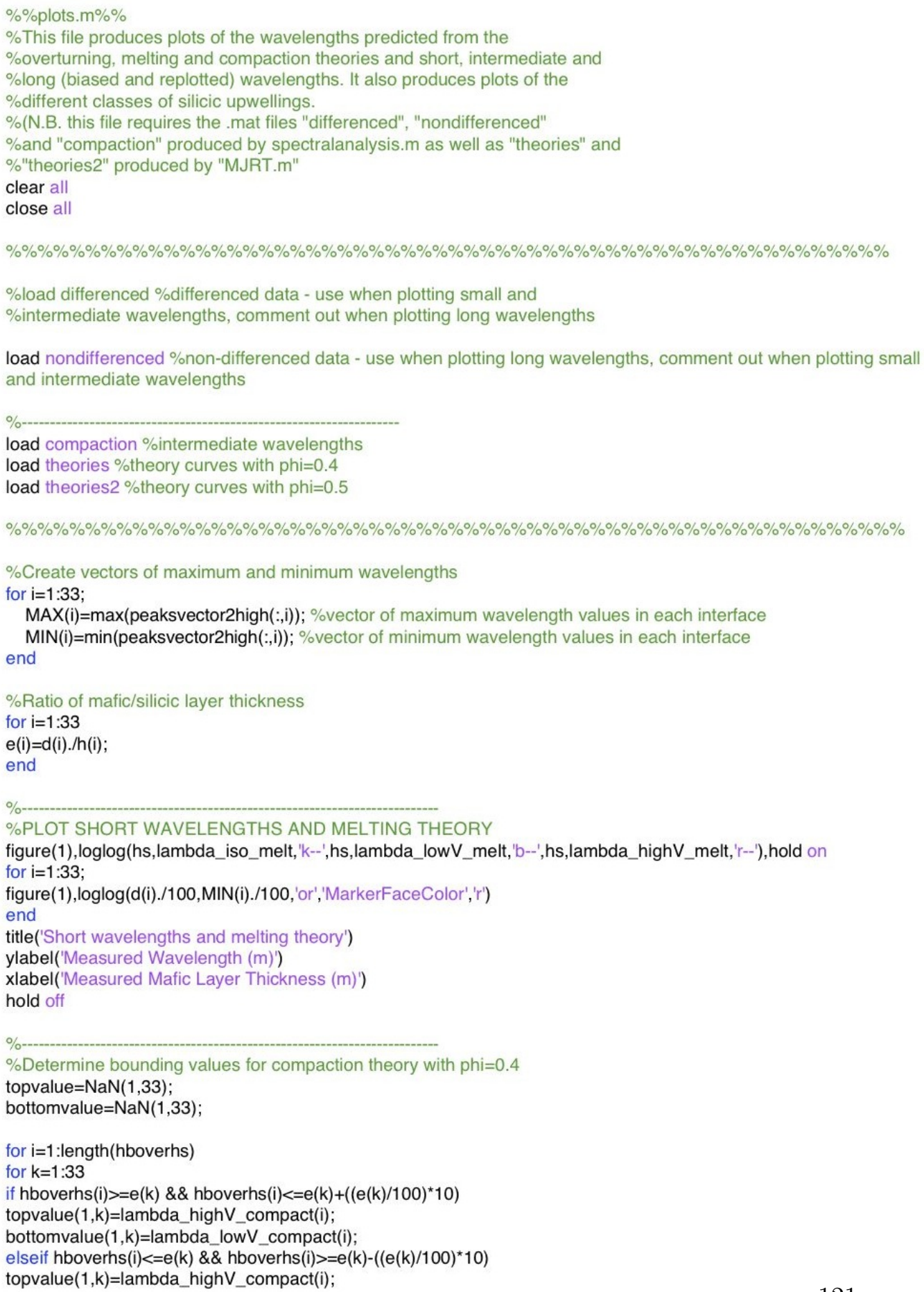




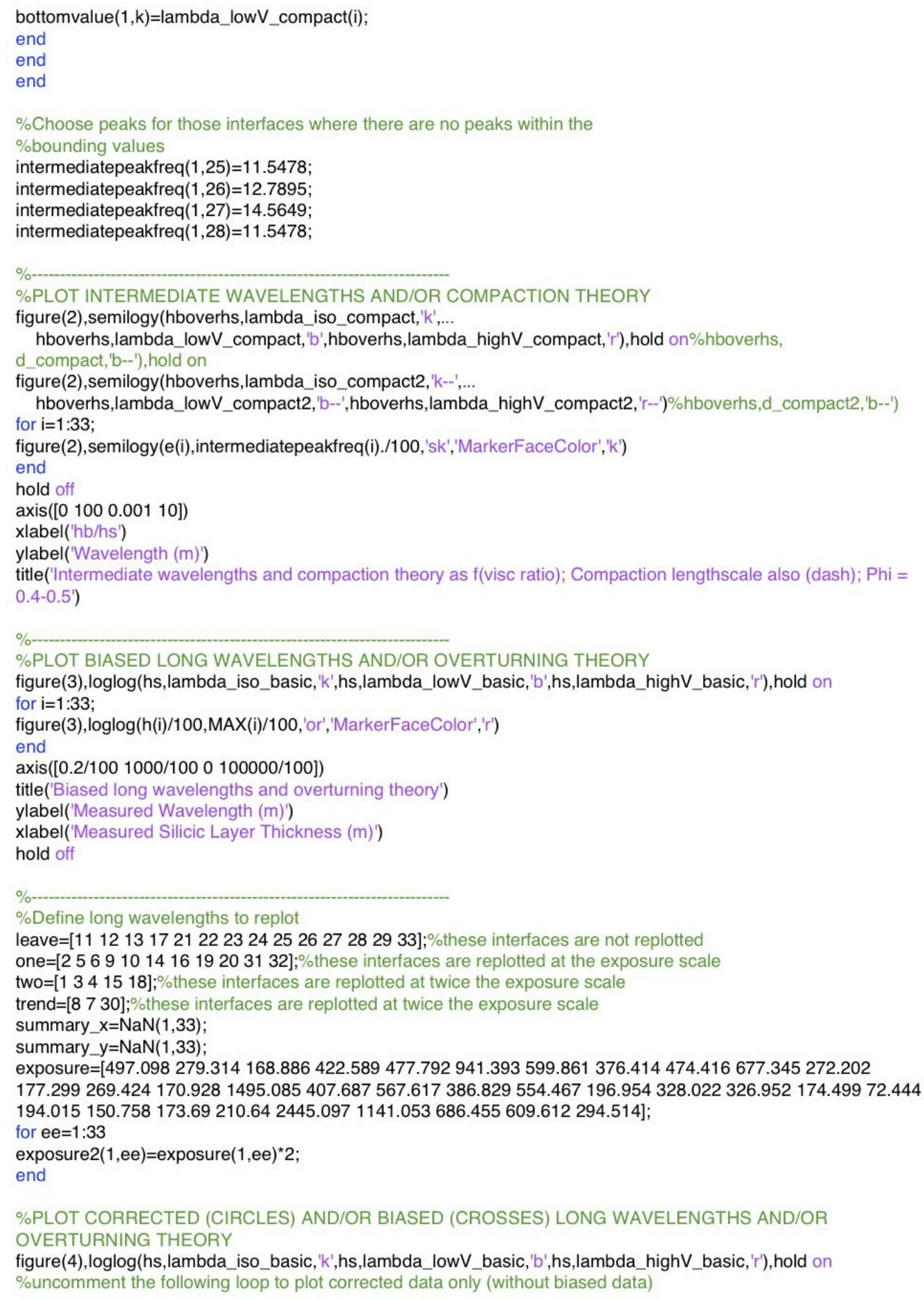




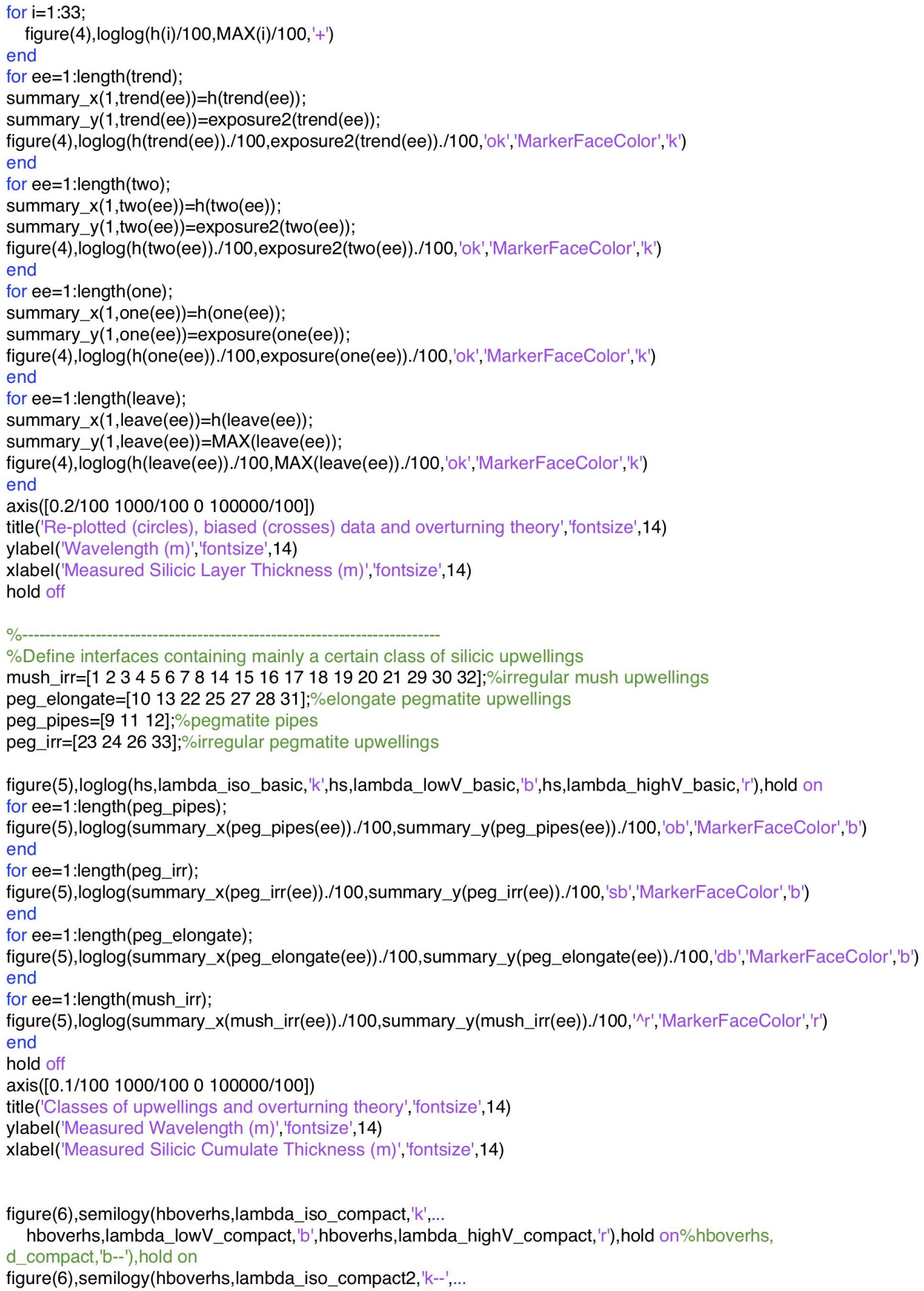




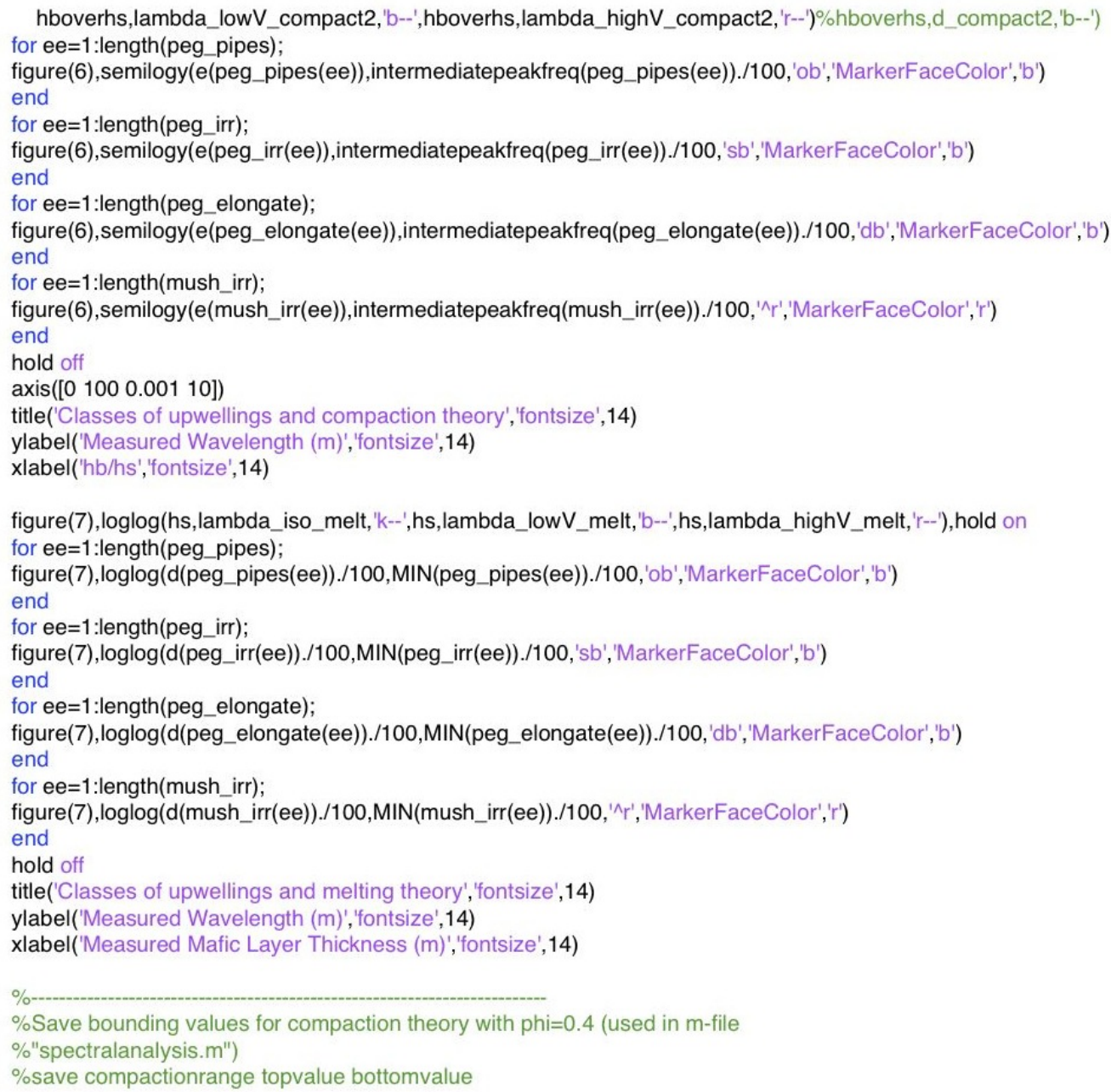




\section{Appendix $\mathrm{C}$}

\section{Experiments}

\section{C.1 Motivation and set-up}

To understand the range of initial conditions that may give rise to the observed deformation of mafic-silicic interfaces, we performed a series of scaled viscous Rayleigh-Taylor experiments where overturn is driven by an unstable density gradient. These experiments build on previous analog investigations of the dynamics of compositional overturn by including two-phase flow as in the natural case.

In these experiments, a dense viscous layer of fluid (corn syrup) is placed upon a more buoyant layer (diluted corn syrup) containing particles as crystal analogues (Figure C.1). We conducted a parallel series of experiments where both layers are particle-free in order to assess the effect of particles on the timescales, length-scales and form of deformation. To explore the full range of parameters warranted by the natural case, we varied the dimensionless ratios of the dense layer thickness to that of the buoyant layer thickness $H=h_{b} / h_{s}$, the density of the dense layer to that of the buoyant layer $D=\rho_{b} / \rho_{s}$ and the effective viscosity ratio $\mu_{b} / \mu_{s}$. The experiments are run in a cubic tank with a sliding plate system separating the lower buoyant layer from the denser upper layer. To begin an experiment, we retract the 


\section{C.2. Results}

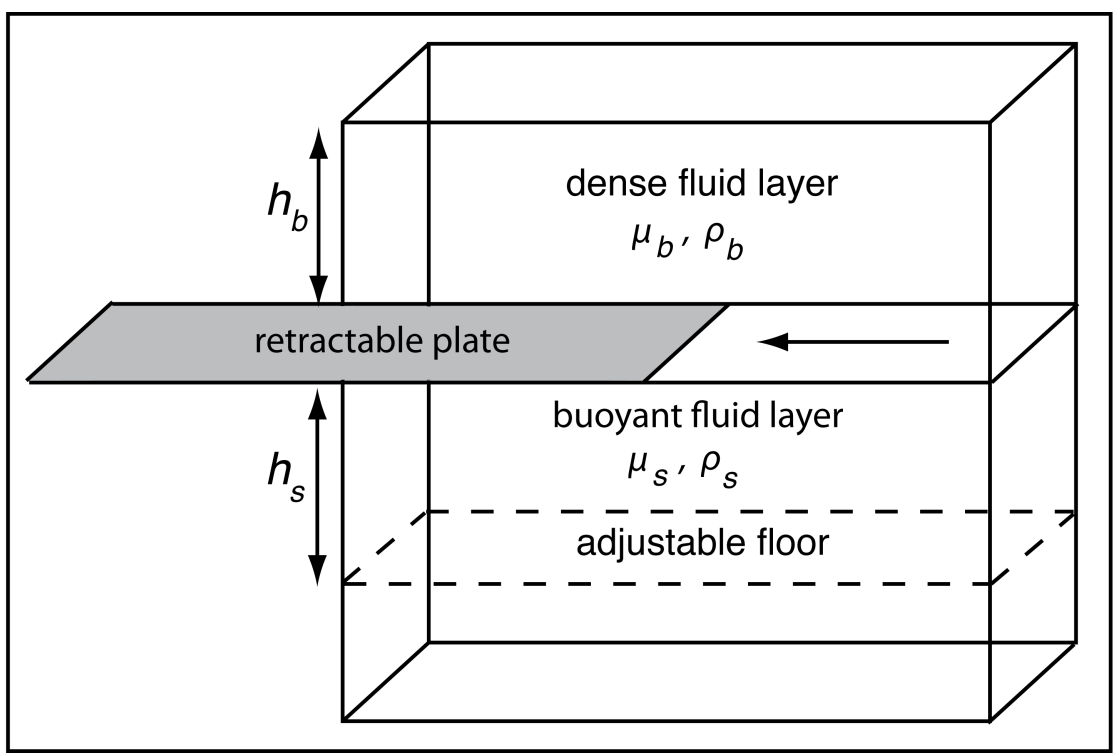

Figure C.1: Experimental apparatus and set-up.

plate system at a constant rate and monitor the spacing, structure and rate of overturn.

\section{C.2 Results}

Large-scale overturn of the lower layer occurs in all our experiments, even for very small density contrasts $\left(\sim 10^{-3}\right.$ g. $\left.\mathrm{cm}^{-3}\right)$ (Figure C.2). The onset of overturning motions, determined from the displacement of the interface, is in the range 5-27 min. This time is generally shorter for experiments where the buoyant layer contains particles. In these experiments, $D$ is larger than the corresponding particle-free experiment for practical reasons, with an equivalent viscosity ratio $\mu_{b} / \mu_{s}$. In one experiment, we measured a shorter onset time than the corresponding particle-free experiment despite a larger 


\section{C.3. Discussion}

$D$, equivalent $\mu_{b} / \mu_{s}$ and the presence of particles. Experiments in which the buoyant layer contains particles show a larger range of interfacial deformation length-scales. Pipes of particle-laden buoyant material and delicate ridges that became organized into axisymmetric plumes formed in two of the experiments involving particles. The smallest length-scale of deformation was set by individual particles, with variably-sized aggregates of particles and interstitial fluid contributing intermediate wavelengths. Experiments in which the buoyant layer does not contain particles undergo successive phases where one dominant deformation wavelength is replaced by a new generation of smaller-scale plumes at a smaller spacing.

\section{C.3 Discussion}

Although these experiments are preliminary and an extensive suite covering the full parameter space is required in order to fully characterise the overturning régimes, they provide some independent confirmation of our analytical findings. Analogous to the deformed interfaces observed in the field, our experiments show that the smallest length-scale of deformation is set by individual particles, whilst intermediate wavelengths of deformation are formed by variably-sized aggregates of particles and interstitial fluid, consistent with the disaggregation of a mush layer. In addition, the largestscale upwellings in our experiments involving particles are mush diapirs. We also observe the formation of irregular/diapiric upwellings as well as axisymmetric pipes within this preliminary range of effective viscosity ratios. 

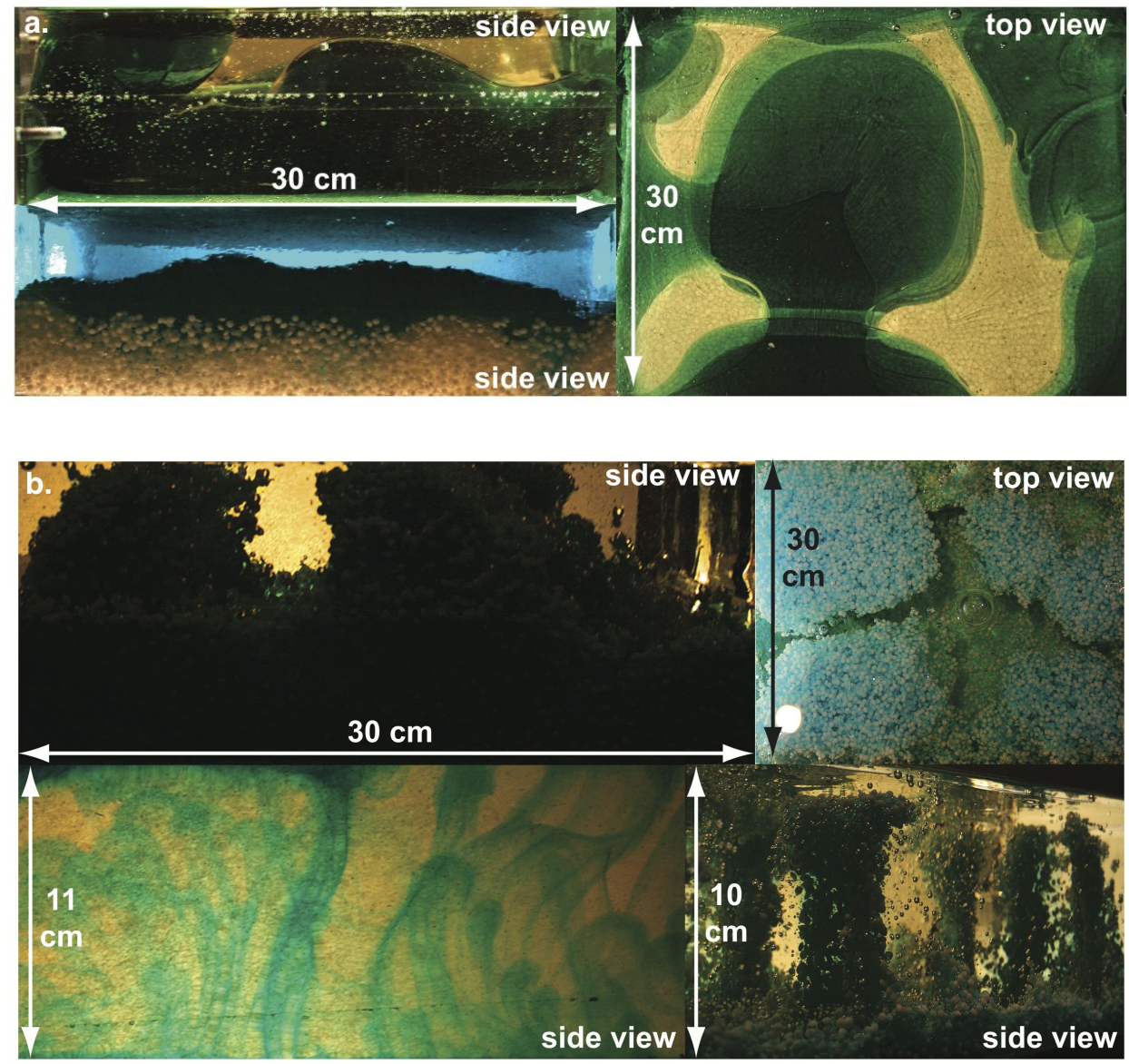

Figure C.2: Diapir (a) and pipe (b) experimental régimes. 
These encouraging results should motivate future experiments expanding the range of parameter space covered here. Developing a more sophisticated set-up would provide an opportunity to investigate the effect of timedependant melting and/or solidification of the layers. Varying the working fluids and particle concentration (i.e. mush layer porosity) would allow us to explore a greater range of mush compaction rates. Finally, image analysis of the evolution of overturn would allow us to compare the changing spectra of deformation wavelengths over the course of an experiment. 